\title{
WestVirginiaUniversity
}

THE RESEARCH REPOSITORY @ WVU

Graduate Theses, Dissertations, and Problem Reports

2001

\section{Theorie und Praxis im dramatischen Werk Rainer Lewandowskis}

Ulrike E. Taylor

West Virginia University

Follow this and additional works at: https://researchrepository.wvu.edu/etd

\section{Recommended Citation}

Taylor, Ulrike E., "Theorie und Praxis im dramatischen Werk Rainer Lewandowskis" (2001). Graduate Theses, Dissertations, and Problem Reports. 768.

https://researchrepository.wvu.edu/etd/768

This Thesis is protected by copyright and/or related rights. It has been brought to you by the The Research Repository @ WVU with permission from the rights-holder(s). You are free to use this Thesis in any way that is permitted by the copyright and related rights legislation that applies to your use. For other uses you must obtain permission from the rights-holder(s) directly, unless additional rights are indicated by a Creative Commons license in the record and/ or on the work itself. This Thesis has been accepted for inclusion in WVU Graduate Theses, Dissertations, and Problem Reports collection by an authorized administrator of The Research Repository @ WVU. For more information, please contact researchrepository@mail.wvu.edu. 
Theorie und Praxis im dramatischen Werk Rainer Lewandowskis

Ulrike E. Taylor

Thesis submitted to the Eberly College of Arts and Sciences

at West Virginia University

in partial fulfillment of the requirements

for the degree of

Master of Arts

in

Foreign Languages

Dr. Jürgen Schlunk, Ph.D., Chair

Dr. Deborah Janson, Ph.D.

Dr. Johann Seynnaeve, Ph.D.

Department of Foreign Languages

Morgantown, West Virginia

2001

Keywords: Rainer Lewandowski, Contemporary German Theatre, German Drama, E.T.A. Hoffmann Theater Bamberg.

Copyright 2001 Ulrike E. Taylor 


\begin{abstract}
Theorie und Praxis im dramatischen Werk Rainer Lewandowskis
\end{abstract}

\title{
Ulrike E. Taylor
}

The purpose of this thesis is to examine selected works of the contemporary German playwright Rainer Lewandowski. This project will introduce Rainer Lewandowski's style and innovative ways of writing and directing plays by first analyzing two significant monographs, one about the German filmmaker Alexander Kluge and the other about the Romantic composer and writer E.T.A. Hoffmann. Second, I will show the importance of Rainer Lewandowski's children's theater, for example his stage adaptation of E.T.A. Hoffmanns children's story The Strange Child. Next, his musicals Me, Marlene, Mambo Mortale and Don't Panik, and his plays Tonight Neither Hamlet and The Birthday or the Same Procedure as Every Year will be discussed. Last, I will talk about two of Rainer Lewandowski's historical plays, one about the assassination of a German king, the other about E.T.A. Hoffmann's life in Bamberg and his fictional characters, and I will introduce two of his most recent, not yet published plays. My interview with Rainer Lewandowski, which was conducted during my stay at the University in Bamberg in August of 2000, concludes this thesis. 


\section{$\underline{\text { Acknowledgments }}$}

I would like to thank my husband Bill and our two sons, Matthew and Ethan, for their patience and support during my time away from them - being at the university or in front of the computer. I would also like to thank my mother-in-law Bea Taylor and my parents, Klaus and Helga Pfannschmidt and Luise Mosl, in Germany for their help and support.

I would like to express my appreciation to Dr. Schlunk, Dr. Janson, Dr. Seynnaeve and Dr. Braidi for the thought provoking and interesting classes I was priviledged to take at West Virginia University.

I want to express my deep gratitude to Dr. Jürgen Schlunk for all his support. I appreciated very much all the help given to me and time spent with helpful suggestions, especially his help with the condensing of the Rainer Lewandowski interview.

Finally, I would like to thank Rainer Lewandowski for his time and willingness to be interviewed and for his understanding and patience with so many more questions that arose later when we continued our exchange over the internet. 


\section{Inhaltsverzeichnis}

Acknowledgments $\quad$ iii

Inhaltsverzeichnis $\quad$ iv

I. Einführung 1

$\begin{array}{ll}\text { II. Ausgewählte Werke } & 10\end{array}$

$\begin{array}{ll}\text { II. 1. Monographien } & 10\end{array}$

a) Die Filme von Alexander Kluge 11

b) Fiktion und Realität. Hoffmann und Bamberg 14

$\begin{array}{ll}\text { II. 2. Hörspiele } & 20\end{array}$

a) 'da wird die Sau geschlacht ...' 20

b) Ohne Motiv 23

c) Hier spricht der automatische Anrufbeantworter 26

d) Ferien im Flöz, oder Städteurlaub einmal anders 28

II. 3. Kinderstücke 32

a) Das fremde Kind 33

b) $\underline{\text { Bambolo }} \quad 35$

c) Junges Gemüse 37

d) Der gestiefelte Kater $\quad 40$

II. 4. Theaterstücke 42

a) Heute weder Hamlet 42

b) Der Geburtstag $\quad 48$

II. 5. Musicals 54 
a) Mambo Mortale $\quad 54$

b) Ich, Marlene $\quad 60$

c) Nur keine Panik! Ein Jahrhundert geht schnell vorbei ... 68

II. 6. Historische Stücke 76

a) Sie sind auch kein Bamberger, wie ich höre? 76

b) Königsmord $\quad 84$

II. 7. Neueste Stücke 92

a) Ich $\quad 92$

b) Nichts hält mich mehr in Kisslingen. $\quad 98$

$\begin{array}{lll}\text { III. Schluß } & 105\end{array}$

IV. Interview mit Rainer Lewandowski, Bamberg, August 2000.

$\begin{array}{lll}\text { V. Zitierte Werke } & 140\end{array}$ 


\section{I. $\quad$ Einführung}

Zweck dieser Arbeit ist es, das Werk des zeitgenössischen Theaterschriftstellers und Intendanten des Bamberger E.T.A. Hoffmann Theaters, Rainer Lewandowski, vorzustellen. Außer Beurteilungen und Kritiken aus Lokal- und Regionalzeitungen gibt es bisher wenig, das über diesen außergewöhnlichen Schriftsteller und Theaterpraktiker geschrieben wurde. Zwar ist Rainer Lewandowski für einige seiner Theaterstücke, vor allem Heute weder Hamlet über den bayerischen Raum hinaus bekannt, aber viele seiner Stücke bleiben unverdientermaßen auf den Bamberger/Münchner Raum beschränkt und sind nicht in anderen Städten nachgespielt worden.

Dabei liegt inzwischen ein erstaunlich umfangreiches Werk dieses vielseitigen Dramatikers vor. Seine schriftstellerischen Anfänge machte er beim Rundfunk, für den er zahlreiche Hörspiele verfaßt hat. Neben theoretischen Aufsätzen über das Theater hat er auch Monographien über deutsche Filmemacher und über den Romantiker E.T.A. Hoffmann verfaßt. Sein Hauptinteresse gilt jedoch dem Theater, für das er Theaterstücke, Musicals, Kindertheaterstücke, regional bedeutsame historische Stücke sowie sozialkritische Komödien geschrieben hat. Weil es bisher noch keinen Überblick über seine Werke und wenige Besprechungen der Stücke im Einzelnen gibt, stellt diese Untersuchung etwas Neues dar. Ein Besprechen aller seiner Stücke würde allerdings den Rahmen einer Magisterarbeit sprengen, weshalb die Zahl der besprochenen Werke hier auf diejenigen beschränkt wurde, die seine Wichtigkeit als deutschen Schriftsteller und seine Bedeutung für das deutsche Theater am klarsten herausstellen. Eine wichtige Quelle der Information über Rainer Lewandowski stammt aus einem Gespräch, das ich im 
August 2000 mit dem Autor führte, und das sich in gekürzter Form am Ende dieser Arbeit befindet.

Rainer Lewandowski wurde 1950 in Hannover geboren. Nach dem Abitur studierte er Deutsche Literaturwissenschaft, Deutsche Sprachwissenschaft, und Wissenschaft der Politik. Im Begleitstudium belegte er sowohl Philosophie, Pädagogik, Psychologie als auch Soziologie bei Oskar Negt, Professor für Soziologie an der Universität Hannover, mit dem Alexander Kluge später zusammengearbeitet hat.

An der Universität beschäftigte sich Lewandowski viel mit Filmen, eine Liebe, die er schon als Heranwachsender mit seinen Eltern teilte. In Seminaren über Film machte er sich vertraut mit der Funktion und Bedeutung von Filmen und lernte, wie man Filme schneidet, was Schnittfolgen bedeuten, und wie man Filme analysiert. Rainer Lewandowski schrieb eine Magisterarbeit über Alexander Kluge mit dem Titel: Alexander Kluge - filmästhetische und gesellschaftstheoretische Voraussetzungen. Überlegungen zu den gesellschaftsverändernden Möglichkeiten ästhetischer Produkte. Es folgten mehrere Sachbücher, die sich hauptsächlich mit dem Film und Filmemachern beschäftigen, wie Die Filme von Alexander Kluge, Die Filme von Volker Schlöndorff und Die Oberhausener Gruppe.

Ab 1975 beschäftigte er sich intensiv mit dem Hörfunk und schrieb viele Hörspiele und Kurzhörspiele für den Norddeutschen Rundfunk, den Südwestfunk, den Hessischen Rundfunk und Radio Bremen, um nur einige der Rundfunkanstalten zu nennen. Neben sachlichen Beiträgen, wie z.B. Bemerkungen zur Dramaturgie Horváths und über das Theater des Nationalsozialismus, hat Lewandowski hier in seinen Hörspielen bereits angefangen, die Grenze zwischen Realität und Fiktion für den Zuhörer 
spielerisch zu verwischen. Viele seiner Stücke sind satirisch, sie kritisieren die Zustände in unserer Gesellschaft und die immer extremer werdende Konsumorientierung der Gesellschaft. Schon bei den Themen der Hörspiele kann man Lewandowskis erstaunliche Vielseitigkeit erkennen: er schrieb Krimis wie Ohne Motiv und Das Sommerhaus, humorvolle Stücke wie Hier spricht der automatische Anrufbeantworter und vor allem sozialkritische und satirische Hörspiele wie Ferien im Flöz, oder Städteurlaub einmal $\underline{\text { anders, }}$ und er montierte Original-Ton-Hörspiele, wie z.B. ,da wird die Sau geschlacht... oder, Solange wir noch da sind“, Eindrücke aus dem Altenheim und viele weitere.

Während seiner Zeit beim Rundfunk begann Rainer Lewandowski sich für das Theater zu interessieren. In meinem Interview mit ihm beschreibt er seine Anfänge am Theater folgendermaßen:

So fing es an: über Hospitanzen, dann eine erste Assistenz, zunächst ohne Bezahlung, dann Dramaturgie ...dann die erste offizielle Regieassistenz, also mit Vertrag... und so hat sich das andere ergeben. Nach zwei Jahren war ich dann in einer ganz merkwürdigen Position, nämlich Regieassistenz und Dramaturg, auf der einen Seite gehörte man zur Theaterleitung, mußte also Entscheidungen treffen, die den Kurs des Hauses mitbestimmten, auf der anderen Seite war man als Regieassistent mit der Ensemble-Basis direkt verquickt. Das ist eine sehr prägende Zeit gewesen ... eine gute Schulung. (I2, 20)

Während seiner Zeit in Hannover schrieb Rainer Lewandowski sein bisher erfolgreichstes Stück: $\underline{\text { Heute weder Hamlet. }}$ 
1989 bewarb er sich für die Stelle des Intendanten am E.T.A. Hoffmann Theater in Bamberg. Hier in Bamberg wirkt Rainer Lewandowski als Theaterleiter und Schriftsteller und hat, wie Jürgen Schlunk in seinem Vortrag „Rainer Lewandowski. Eine zeitgemäße Stimme im deutschen Theater“ beschreibt, durch seine Arbeit „den Ruf des E.T.A. Hoffmann Theaters als eines der kreativsten und erfolgreichsten bayrischen Theater gefördert. Die offizielle Anerkennung dieses Erfolges besteht aus wichtigen künstlerischen Preisen für das Theater, Fernsehaufzeichnungen und zahlreichen Einladungen ...aus dem Ausland“" (Schlunk, 13) und er erreichte wegen der erfolgreichen Leitung des Theaters, daß die lang überfällige Sanierung des Theaters bewilligt wurde.

Das E.T.A. Hoffmann Theater erhielt unter seiner Leitung die folgenden Preise und Auszeichnungen:

Den Preis für Darstellende Kunst 1996 der Bayerischen Akademie der Schönen Künste, zusammen mit der Friedrich-Baur-Stiftung für Das Fremde Kind und für $\underline{\text { Sie sind auch }}$ kein Bamberger, wie ich höre?

Den Preis der Bayerischen Theatertage 1992 für die Inszenierung des Stückes Kalldewey,

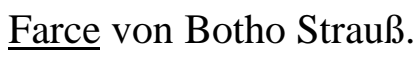

Das Fräulein von Scuderi wurde 1996 vom Freistaat Bayern ausgewählt, an einem Kulturaustausch mit der Ukraine teilzunehmen.

Das Kinderstück Bambolo wurde 1997 vom Freistaat Bayern ausgewählt, am 10jährigen Jubiläum des Kulturaustausches in China teilzunehmen. 
1999 erhielt eine Aufführung des E.T.A. Hoffmann Theaters, Feuergesicht von Marius von Meyenburg, vier Preise und Auszeichnungen bei den Bayerischen Theatertagen in Nürnberg.

Rainer Lewandowski selbst wurde, wie die Zeitung Der Fränkische Tag berichtet, „,vom Bayerischen Staatsminister für Unterricht, Kultur, Wissenschaft und Kunst, Hans Zehetmair in den Gutachterausschuß des Staatlichen Förderpreises für junge Künstler im Bereich darstellende Kunst berufen.“ Die Wahl fiel auf ihn, wegen seiner Erfahrung als Intendant und seines Erfolgs und seiner Leistungen am E.T.A. Hoffmann Theater in Bamberg.

Lewandowski hat also mit seiner Theaterarbeit als Schriftsteller und Theaterleiter die Aufmerksamkeit und Anerkennung der Öffentlichkeit und auch die der Bayerischen Staatsregierung erworben, was dem Theater und damit der Stadt Bamberg wiederum Geld in Form von beträchtlichen Zuschüssen für die geplante Sanierung des Hauses einbrachte.

Jedes Jahr stellt Rainer Lewandowski mit seinen Mitarbeitern ein abwechslungsreiches und anspruchsvolles Theaterprogramm zusammen. Hier als Beispiel die Spielzeit 1999/2000:

Die Saison begann mit der Premiere von Nur keine Panik! Ein Jahrhundert geht $\underline{\text { schnell vorbei..., einem Ensembleprojekt des E.T.A. Hoffmann Theaters, dann Der }}$

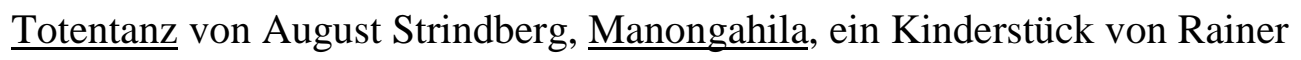

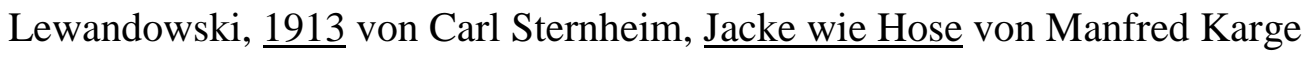
(Studiotheater), EiferSucht von Esther Vilar (Studiotheater), Noch ist Polen nicht

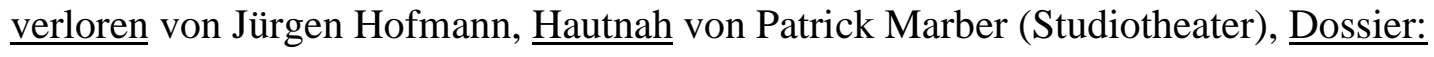




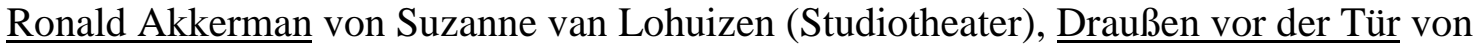
Wolfgang Borchert, Feuergesicht von Marius von Mayenburg (Studiotheater), Eine linke Geschichte von Volker Ludwig und Detlef Michel und zum Abschluß die Calderón Festspiele auf der Freilichtbühne in der Alten Hofhaltung mit Bertolt Brechts Leben des Galilei.

In Selbstporträt Literatur in Franken wurde Lewandowski gefragt, wie er die Anforderungen eines Intendanten mit denen eines Schriftstellers vereine, und ob er zwei Seelen in der Brust habe, worauf er antwortete: „Ich versuche, mich nicht in Seelen zu teilen, denn beide Tätigkeiten fordern den ganzen Menschen mit all seinen kreativen Potentialen, ich versuche die Einteilung eher zeitlich zu gestalten. Sehr früh am Morgen schreibe ich (ab 6 Uhr). Anschließend, ca. 8.30 Uhr, gehe ich ins Theater. Schreiben und Theateralltag zu organisieren, sind teilweise sehr weit entfernte Aufgaben“" (Stoll, 116). In meinem Interview mit ihm betonte er auch, daß beide Tätigkeiten sehr zeitintensiv sind und sich oft „,beißen“ (I2, 17) und deshalb ist es erstaunlich, wie viele Stücke Rainer Lewandowski trotzdem veröffentlicht hat.

Als eine seiner Hauptaufgaben sieht Rainer Lewandowski es, das Theater für das Publikum interessant zu machen, ohne allzu sehr gängigen Unterhaltungstrends nachzugeben. Wie in seinen Spielplänen zu erkennen ist, wechselt er zwischen Musicals, Komödien, Klassikern wie Goethe und Kleist, und vielen modernen Stücken, die oft im Studiotheater gespielt werden, da sie, wie zu allen Zeiten in der Geschichte des Theaters, nur ein zahlenmäßig begrenztes Publikum erreichen. Er betonte auch, daß es wegen der allgemeinen Subventionierung des deutschen Theaters möglich sei, solche ,Risikoproduktionen“, also Aufführungen, die nicht jeden Abend zum Erhalt des Theaters 
ausverkauft sein müssen, zu spielen und daß er sich deswegen verpflichtet fühle, mindestens ein solches Stück pro Jahr auch im Großen Haus aufzuführen. Da Bamberg ein regionales Theater ist, wählt Lewandowski für seine eigenen Stücke - wenn ein Anlaß gegeben ist, z.B. ein Hoffmann-Jubiläumsjahr oder eine große Andechs-MeranierAusstellung von überregionaler Bedeutung im Historischen Museum der Stadt Bamberg - gelegentlich Themen von lokaler Bedeutung, wie z.B. in Königsmord oder jenen Stücken, die mit E.T.A. Hoffmann zu tun haben. Er nimmt auch Texte von lokalen Schriftstellern ins Programm oder arbeitet mit ihnen an Theaterstücken, wie in den Fällen der Kinderstücke Burgfrosch Balthasar, das er zusammen mit Rudi Sopper für die Bühne gestaltete, oder In einem tiefen dunklen Wald von Paul Maar.

Aber Lewandowskis größtes Anliegen ist es, die Entwicklung der Phantasie zu fördern und an sehr hoher Rangstelle rangiert da auch sein jüngstes Publikum. Diese Auffassung teilt er mit dem Schriftsteller, dessen Name das Bamberger Theater trägt, E.T.A. Hoffmann. Beide weisen darauf hin, ,,wie wichtig es für Kinder ist, an die befreiende Wirkung der Phantasie zu glauben, an ihr teilzuhaben und sie lebenslang zu bewahren“ (Schlunk, 9). Aus diesem Grund verfasst Rainer Lewandowski mindestens einmal im Jahr ein Kinderstück mit sehr abwechslungsreichen Themen und ,Spielwelten', in dem sich die Kinder aktiv beteiligen können, in jedem Falle aber ihre Phantasie beflügelt wird.

Aber auch für die Erwachsenen hält er die Bewahrung der Phantasie für äußerst wichtig, vor allem als Gegengewicht zum Alltag, der die Phantasie nur allzu leicht zu ersticken droht. Er sieht die Phantasie der Kinder und Erwachsenen am meisten gefährdet „,von den vorgefertigten Produkten der Massenunterhaltung, die das Widerstand leistende 
Potential eines lebendigen Theaters unterminiert. Deshalb spielt das E.T.A. Hoffmann Theater selten die ohnehin schon bekannten Titel nach, wie es andere Theater ... gerne tun, sondern setzt auf eigene Phantasien, die ... weiterentwickelt werden“ (9 f.).

Zu Amerika hat Rainer Lewandowski eine besondere Beziehung, seit er zusammen mit Jürgen Schlunk einen kulturellen Austausch zwischen dem E.T.A. Hoffmann Theater und der Universität von West Virginia in die Wege leitete. Dies begann 1997 mit Vorträgen, die Rainer Lewandowski an verschiedenen Universitäten hielt, und daraus entwickelte sich dann ein regulärer Austausch zwischen dem Bamberger Theater und der Theaterabteilung der West Virginia Universität. Als erstes wurde Ich, Marlene, (als Video-Großprojektion), gefolgt von Nur keine Panik! Ein

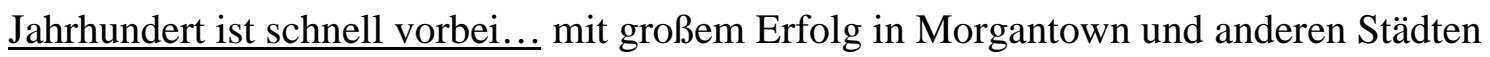
West Virginias aufgeführt und im Gegenzug wurde das Einpersonenstück $\underline{\text { My Chekhov }}$ $\underline{\text { Light des Dramatikers Frank Gagliano (West Virginia Universität) und später Macbeth }}$ von Shakespeare unter der Regie von Jerry McGonigle erfolgreich in Bamberg gezeigt. Dieses Programm besteht weiterhin und beide Städte profitieren von diesem kulturellen Austausch. So hat Jerry McGonigle als Schauspieler in Bamberg zusammen mit einem deutschen Schauspieler des E.T.A. Hoffmann Theaters, Florian Walter, in einem Stück gespielt, $\underline{\text { Robinson \& Crusoe. }}$

Ziel dieser Arbeit ist es, ausgesuchte Werke von Rainer Lewandowski vorzustellen. Lewandowski hat Werke verfasst, die, verbunden mit seiner Funktion als Theaterleiter, mehr regionalen Bezug haben, Werke, die - unverdientermaßen - nicht über den Fränkischen Raum hinaus bekannt sind, aber auch Stücke, die überregionalen, ,allgemeinen' Geltungsanspruch haben und von deutschen Fernsehanstalten 
aufgezeichnet wurden. Es wird in dieser Arbeit versucht, beide Seiten dieses Autors vorzustellen und die jeweiligen Stücke auch inhaltlich zu beschreiben. Außerdem wurden Zitate aus seinen Stücken und Auszüge aus dem in Bamberg im August 2000 entstandenen Interview mit ihm verwendet, um Lewandowskis theoretische Position und seine schriftstellerische Motivation zu erläutern. Das Interview existiert in zwei Versionen: einmal in seiner Orginalfassung (I) und zum anderen in einer von Jürgen Schlunk gekürzten Fassung (I2), die dieser Arbeit beigefügt wurde. Die Werke werden weitgehend in chronologischer Reihenfolge besprochen, um dem Leser seine schriftstellerische Entwicklung vor Augen zu führen: die Vielfältigkeit und Aussagekräftigkeit seiner Werke machen Rainer Lewandowski zu einem ernstzunehmenden, modernen Schriftsteller unserer Zeit. 


\section{Ausgewählte Werke \\ II.1. Monographien:}

Die Filme von Alexander Kluge und

\section{Fiktion und Realität. E.T.A. Hoffmann und Bamberg}

Diese beiden Fachbücher wurden gewählt, da Die Filme von Alexander Kluge die Ursprünge von Lewandowskis Schaffen beleuchten, wogegen Fiktion und Realität.

E.T.A. Hoffmann und Bamberg das wohl wichtigste Motiv für Lewandowskis eigenes Schreiben verdeutlicht: sein leidenschaftliches Interesse an der Rolle der Phantasie im täglichen Leben und, damit verbunden, in der Literatur und im Theater. Es geht mir nicht so sehr um den Inhalt dieser Werke als vielmehr darum, Gemeinsamkeiten und Berührungspunkte zwischen Kluge und Lewandowski und Hoffmann und Lewandowski hervorzuheben. Alle drei Künstler haben sich stark mit der Phantasie beschäftigt und Hoffmanns Aussage, zitiert in Rainer Lewandowskis Buch über den Künstler, trifft bestimmt für alle drei zu:

Es müßte spaßhaft sein, Anekdoten zu erfinden, und ihnen den Anstrich höchster Authentizität, durch Zitate u.s.w. zu geben, die durch die Zusammenstellung von Personen, die Jahrhunderte auseinander lebten, oder ganz heterogener Vorfälle, gleich sich als erlogen ausweisen; - denn mehrere würden übertölpelt werden, und wenigstens einige Augenblicke an die Wahrheit glauben - Gäbe man ihnen einen Stachel, desto besser. (Fiktion, 91)

Lewandowski führt diesen Gedankengang weiter, indem er andeutet, daß Hoffmanns Gedankenspiel nicht nur auf Hoffmann allein zutrifft, sondern auch “die Produktionsweise mancher moderner Autoren ist, z.B. Döblins, oder noch moderner: 
Alexander Kluges. Kluge fand dafür eine andere, vielleicht zeitgemäßere Formulierung seiner Methode: Fiktion in der Ausdrucksform des Dokumentarischen” (91).

\section{II.1.a) Die Filme von Alexander Kluge}

Dieses Buch wurde 1980, drei Jahre nachdem Rainer Lewandowski (zusammen mit Rainer Vasel) seine Magisterarbeit über Alexander Kluge erarbeitet hatte, geschrieben und herausgegeben. Es beschreibt Kluges Entwicklung, seine Bedeutung für den deutschen Film und Kluges Filme. Lewandowski kommt zum Theater über den Film und dieser Aspekt ist wichtig, da man viele von seinen Theaterstïcken unter diesem Gesichtspunkt betrachten sollte. Das filmtechnische Know-how ist in Lewandowskis Werken erstaunlich und er setzt sehr oft Video, Dias usw. in seinen Stücken ein. Um ein Beispiel zu nennen, zeigt er in Nur keine Panik... die Schauspieler im Vordergrund beim Hitlergruß und Marschieren, während im Hintergrund Dokumentar-Filme (als Videos) projiziert werden von Krieg und Konzentrationslagern. In Der Geburtstag zeigt gleichzeitig mit Ablauf des Stückes ein Fernsehschirm die gesamte Aufführung über das, was die Schauspielerin auf der Bühne spielt aus einer anderen Perspektive, eben einer Kameraperspektive.

Zwischen Kluge und Lewandowskis Werken gibt es manche Berührungspunkte.

Kluge ist z. B. sehr politisch und spart in seinen Filmen nicht an sozialer Kritik, man denke hier nur an den Film Die Patriotin, der gezielt die Vergangenheitsaufarbeitung der Deutschen hinterfragt. Lewandowski spart in seinen Theaterstücken auch nicht mit Sozialkritik, wie später in dieser Arbeit gezeigt wird. Beide teilen eine Liebe zur Geschichte, die in vielen Filmen Kluges ersichtlich ist, wie z.B. in Die Patriotin und in 
Artisten in der Zirkuskuppel: ratlos. In Kluges Fall ist es Geschichte, die sich hauptsächlich mit dem Ersten und Zweiten Weltkrieg beschäftigt, in Lewandowskis ist es oft mittelalterliche Geschichte, die sich anfangs aus heutigem regionalen Bamberger Interesse nährt, aber als historisches Faktum deutsche Geschichte allgemein ausmacht, die den Lauf der deutschen Geschichte entscheidend mitbestimmt hat, wie in Königsmord. Lewandowski befaßt sich aber auch mit neuerer Geschichte, die die Hitlerzeit behandelt, wie Ich, Marlene und Der Geburtstag, und auch sehr aktuelle historische und soziale Phänomene und Fakten aufgreift, wie in Mambo Mortale, $\underline{\text { Ich, }}$

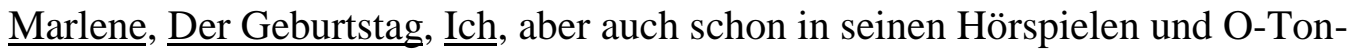
Reportagen.

Beide Künstler setzen Musik bewußt in ihren Werken ein. Lewandowski beschreibt in Die Filme von Alexander Kluge, daß die Musik in Kluges Filmen intensiv genutzt werde, daß er hauptsächlich ,gebrauchte Musik“ (Kluge, 18) verwende. Gebrauchte Musik sei, in Kluges Fall, Musik, die nicht speziell für den Film komponiert wurde, also Opern, Schlager, Tangos, Militärmärsche, usw., die der Zuschauer dann im Zusammenhang des Filmes hört, die Assoziationen in ihm erwecken und zu seinem persönlichen Verständnis des Filmes beitragen. Lewandowski benutzt Musik oft, um den Zeitgeist einer bestimmten Epoche einzufangen, wie z. B. mit Liedern wie „Lili Marlen“ oder „Das kann doch einen Seemann nicht erschüttern“, die zur Kriegszeit berühmt

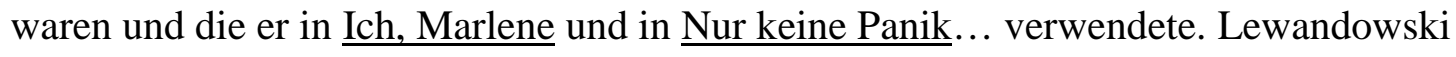
hat auch bewußt Musik von E.T.A. Hoffmann in Theaterstücken über Hoffmann eingesetzt und damit das Interesse an Hoffmanns musikalischen Leistungen neu entfacht. Allerdings gibt es in seinen Stücken nicht nur Musik, die historisch an Personen und Zeit 
gebunden ist, sozusagen als geschichtliches Material, es gibt auch immer wieder Kompositionsaufträge, womit er eine spezielle, für das jeweilige Stück wichtige Musik erstellen läßt. So z.B. im Königsmord von Gerd Bessler, oder in seinen Märchenstücken von Konrad Haas und Wolfgang Stute.

Sowohl Kluges Filme als auch Lewandowskis Theaterstücke sind nicht als bloße Unterhaltung gedacht. Beide verlangen von ihrem Publikum eine kritische Stellungnahme zu den sozialen und historischen Entwicklungen, bis hin zu den Massenmedien Film und Fernsehen. Damit allerdings hört die Gemeinsamkeit auf.

Kluges Filme haben keinen roten Faden, sie wirken zerrissen und chaotisch und der Zuschauer sieht sich „einem Wust von scheinbar ungeordneten Informationspartikeln, thematischen Ansätzen und Abbrüchen, Themen- und Zeitsprüngen“(10) gegenüber. Er „,hört und sieht erzählende Personen, die mit den Handlungsbruchstücken gar nichts zu tun zu haben scheinen, ... wird mit musikalischen Eindrücken verschiedenster Art konfrontiert, muß Zwischentitel lesen... So verwundert es nicht, daß ein Zentralbegriff aus dem Titel eines Films von Kluge immer wieder benutzt wird, um die Situation des Zuschauers zu beschreiben: ratlos“(10).

Das ist natürlich eine bewußte Strategie Kluges, um den konventionellen Sehgewohnheiten der meisten Kinogänger gegenzusteuern. Lewandowski dagegen will keinen Zustand der Ratlosigkeit bei den Zuschauern provozieren, er will sie vielmehr mit klaren, verständlichen, und trotzdem kritischen Theaterstücken dazu bewegen, ihre eigene Wirklichkeit zu hinterfragen. Um nur ein Beispiel zu nennen: in Mambo Mortale ist die Handlung des Musicals einfach, aber es wird kritisch gezeigt, auf welche Weise die Gesellschaft die Jugendlichen und ihre Nöte ignoriert. Einem Publikum, das so 
angesprochen wird, wird es schwer gemacht, zufrieden mit sich selbst und der Welt nach Hause zu gehen.

Unter der Oberfläche der Unterhaltung, teilweise unter dem Zitat der ,Unterhaltung‘, unter dem Zitat dessen, was jedermann für Unterhaltung hält, verbergen sich die wahren Schicksale der Menschen, die umwoben sind mit der historischen Situation, in der sie leben. Die Geschichte ist Bestandteil jedes menschlichen Lebens, ob der Mensch selber sie nun zu ignorieren versucht oder nicht.

\section{II.1.b) Fiktion und Realität - E.T.A. Hoffmann und Bamberg. Über eine Beziehung zwischen Leben und Literatur.}

Rainer Lewandowski schrieb das Buch 1995. 1996 veranstaltete das E.T.A. Hoffmann Theater der Stadt Bamberg ein Hoffmann-Jubiläumsjahr, um dessen 220. Geburtstag zu feiern. Als seinen Beitrag dazu schrieb Rainer Lewandowski ein Theaterstück. Infolge seiner intensiven Hoffmann Forschung interessierte sich Lewandowski immer mehr für Hoffmanns Person und Werk, da er in ihm eine Seelenverwandtschaft entdeckte. So schreibt Schlunk in seinem Vortrag über Rainer Lewandowski: „sobald er (Lewandowski) Hoffmann zu lesen begann, entdeckte er eine persönliche Affinität mit diesem Komponisten und Schriftsteller der Romantik: kein anderer Schriftsteller hatte so prägnant und überzeugend Strategien des Schreibens formuliert, die Lewandowski selbst benutzt und für das eigene Schreiben für relevant erkannt hatte“ (Schlunk, 8). Hoffmann hat, wie Lewandowski, Realität und Illusion so gekonnt miteinander vermischt, daß es oft fast unmöglich für den Leser oder das Publikum ist, zu unterscheiden, was nun wahr und was erfunden ist. 
In Fiktion und Realität. E.T.A. Hoffmann und Bamberg erzählt Lewandowski von Hoffmanns Arbeit am Theater, seinen Freundschaften, seiner großen Liebe zu Julia Mark, von den Enttäuschungen am Theater und beim Publikum, seiner immer schwerer zu ertragenden Armut, seiner Abhängigkeit vom gehobenen Bürgertum mit dessen philisterhaftem Denken und Handeln. Bamberg hatte einen großen Einfluß auf Hoffmann: er hat zwar hier nicht angefangen zu komponieren oder zu schreiben, das geschah schon vor seiner Zeit in Bamberg, ,,aber seine Bamberger Erlebnisse sind für ihn so tiefgreifend, daß er nicht von ihnen loskam und zeitlebens immer auf diese zurückgriff, nicht nur mit Bamberg als Staffage und Lokalkolorit für seine Erzählungen, nicht nur bei der Gestaltung einzelner Figuren nach Bamberger Vorbildern, sondern vor allem auch in seiner psychologischen Entwicklung als Mensch und Autor“ (Fiktion, 11). Hoffmann verlor seine Stelle als Musikdirektor am Bamberger Theater, das zu Hoffmanns Zeiten „Königlich privilegierte Schaubühne“ hieß, schon nach kurzer Zeit, wegen Unstimmigkeiten mit dem Hofviolinisten Georg Anton Dittmayer und wohl auch wegen seiner eigenen Unerfahrenheit im Dirigieren und mit Theaterangelegenheiten. Von da an mußte er sich mit Musikstunden durchschlagen, bekam aber unter Holbein wieder Einfluß am Theater und leitete es wohl während Holbeins häufiger Abwesenheit (Holbein leitete auch das Würzburger Theater). Auch hatte Hoffmann von Anfang an Probleme mit dem Publikum, das leichte Unterhaltung forderte und sich beim Theaterbesuch nicht gern geistig anstrengen wollte. Man wollte Lustspiele sehen und zwar bewährte, hauptsächlich von August von Kotzebue, und die damaligen neuen Stücke: „Die Stücke, die wir heute als ,Klassiker' bezeichnen und von denen man vermuten könnte, sie hätten häufig gespielt werden müssen, führten zu jener Zeit noch ein ausgesprochenes 
Außenseiterdasein. Offenbar ein Schicksal jeweils zeitgenössischer Literatur, denn unsere ,Klassiker`waren ... Hoffmanns Zeitgenossen“ (Fiktion, 36 f.). Dies war aber nicht nur ein Bamberger Phänomen, denn Bamberger Spielpläne unterschieden sich nicht wesentlich von anderen Spielplänen, wie denen in Goethes Weimar, was zeigt, daß „schon damals ein Zwiespalt herrschte, der auch heute noch die Spielpläne dominiert: es geht um die Gewichtung zwischen ,Kunst" und ,Unterhaltung “ und zwischen ,Moderne“ und ,Bewährtem““( (40). Heute gibt es die Massenmedien, die für die leichte Unterhaltung sorgen, das Theater dient einem ausgewählteren Publikum, obwohl es auch hier nicht leicht ist, alle Geschmacksrichtungen zu befriedigen. Hier hat Rainer Lewandowski einen Vorteil, den er sich allerdings von Anfang an ausbedungen und ins Leben gerufen hatte: er hat eine Studiobühne eingerichtet, auf der er moderne und umstrittene Stücke, die im Großen Haus ein zu großes Risiko darstellen würden, einem aufgeschlosseneren, zahlenmäßig begrenzten Publikum vorführen kann.

Die Bedeutung Bambergs für Hoffmanns literarisches Schaffen liegt darin, daß Hoffmann hier begonnen hat, mehr zu schreiben und seine für ihn so typische literarische Methode zu entwickeln, die er für den Rest seines Schaffens beibehielt und „mehr und mehr zur Virtuosität trieb, wohl auch, indem er die Literatur für sich als befreiendes Mittel der Selbstreflektion und Selbsterkenntnis seines Erlebens zu empfinden begann“ (83). Hoffmann hat in Bamberg sehr gelitten, vor allem unter dem Druck der Gesellschaft und unter den philisterhaften Kunstbanausen, von denen er aber lebte, da er deren mehr oder weniger begabten Töchtern Musikunterricht gab. Der Zwiespalt, der sich daraus ergab und auch aus seinem Hin- und Hergerissensein zwischen Künstlertum und Beamtenschaft, spiegelt sich in seiner Literatur und in seinen Figuren, die bekanntesten 
davon wohl der Kapellmeister Johannes Kreisler, sein alter ego, und Anselmus, der junge Künstler aus dem Märchen Der goldene Topf, die beide, wie ihr Schöpfer unter dem Zwiespalt zwischen Wirklichkeit und Phantasie leiden. „Eine Hauptfunktion der Phantasie ist die Überschreitung der Normen, die Störung des status quo, die Übersteigerung. Für Hoffmann war die Phantasie ein wirksames Gegengewicht zu einer ihn erstickenden Wirklichkeit, unter der er oft litt“ (Schlunk, 9). Die Phantasie ermöglicht es ihm also, seine tiefe Armut und das Scheitern des Traumes von seinem Künstlertum zu überwinden. Und so transponiert Hoffmann seine Figuren, seine eigenen Erfahrungen in wirkliche oder erfundene Situationen und erwartet nun vom Leser, daß er sich "aktiv beteiligt am Entscheidungsprozeß über den Wahrheitsgehalt der Texte“ (Fiktion, 92). Hier finden sich Ähnlichkeiten zwischen Hoffmann und Lewandowski: Beide arbeiten mit der Phantasie, halten an der Phantasie fest und verlangen vom Publikum aktive Mitarbeit, aktives Mitdenken und genaues Beobachten, denn beide heben „die Grenze zwischen Fiktionalem, also eindeutig erfundenem, Nicht-Wahrem, und Dokument, Real-Geschehenem, Wahrem, auf und wollen damit den Blick auf beides, auf die Fiktion wie auf das Dokument schärfen“ (Fiktion, 92). Um das Publikum aber übertölpeln zu können, bedarf es genauer Recherchen, denn was als wahr verstanden werden soll, muß ja zumindest den Anschein des Wahren haben: „Je genauer die Arbeit, je detaillierter die Information, um so größer erscheint die Authentizität, um so stärker verwischen sich die Grenzen zwischen Realität und Fiktion“ (93). Beide, Hoffmann und Lewandowski, führen genaue Forschungen über ihr Material durch, z.B. ist in Hoffmanns Der goldene

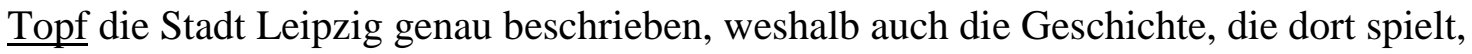
echt zu sein scheint. Die Ereignisse in Lewandowskis Theaterstück $\underline{\text { Ich }}$ sind ebenfalls 
durchaus möglich, wenn auch das Auftreten menschlicher Klone fraglich scheint, aber sicherlich kann man es in absehbarer Zeit nicht mehr als unmöglich abweisen. Ein Stück Prophetie, Hochrechnung gesellschaftlicher Entwicklungen ist oft ein Aspekt seiner Stücke.

Hoffmann war sehr kritisch gegenüber den damaligen Machtverhältnissen und hat sich, wenn er später in Berlin als Richter Entscheidungen als ungerecht empfand, wie bei der Verfolgung des Turnvaters Jahn, gegen die Machtverhältnisse gestellt, was ihm viele Probleme und Unannehmlichkeiten verschaffte. Rainer Lewandowski ist auch sehr kritisch der Gesellschaft gegenüber, was man in vielen seiner Stücke deutlich merkt, wie z. B. in Mambo Mortale, Nichts hält mich mehr in Kisslingen, Ich usw. Lautstarke Kritik hat man auch an manchen seiner Publikationen geübt, die sich mit lokaler Geschichte beschäftigen, wie z.B. Königsmord und das Buch über E.T.A. Hoffmann, da es die jeweilige lokale Legende widerlegt und einige Bamberger sich schwer damit taten, die Geschichte in der von Lewandowski präsentierten Form zu akzeptieren.

Hoffmann als ,phantastischer Realist` oder ,realistischer Phantast" hat, und das wird oft als ,romantisch` verniedlicht, Fluchtwege aus der Realität in die und in der Literatur gefunden. Das war sehr persönlich bestimmt und war weniger gesellschaftskritisch motiviert. Lewandowski hingegen arbeitet gern mit der Idee einer historisch-sozialen Analyse der gesellschaftlichen Situationen der Menschen, die er ,schreibt ${ }^{\star}$, ,erschafft ${ }^{\star}$, die die Produkte seiner Phantasie sind. Aber diese Phantasie ist nicht haltlos, unverankert in einem virtuellen Niemandsland, sondern meistens verwurzelt in real existierenden gesellschaftlichen Verflechtungen, in der - sicher auch von ihm subjektiv empfundenen und interpretierten - ,Realität‘. Diese Denk- und Schreibweise 
hat auch mit den soziologischen Werken Kluges zu tun, z.B. Öffentlichkeit und Erfahrung, die Kluge zusammen mit Oskar Negt geschrieben hat. Das Dokument als einen Teil der Wirklichkeit in eine fiktive ,Realität` ${ }^{`}$ u stellen, diese Realität dann faktisch wirken zu lassen, und auf die Folgen, auch die möglichen sozialen Folgen zu achten, das ist ein wesentlicher Ansatz in Lewandowskis literarischen Werken, aber auch in seinen Hörspielen. Daraus entsteht was er ,Hochrechnung“ nennt, also ein Weiterdenken, Überspitzen von bereits vorhandenen Anlagen und deren sozialen Auswirkungen. Gelegentlich wird aber auch das Faktische, das ,Dokument` als Grundlage für die Hochrechnung genommen, das verwirrt dann die Beziehung zwischen Realität und Fiktion, und sowohl die Realität wie auch die Fiktion wird aufgehoben, und nur noch die genaue Kenntnis (z.B. des geschichtlichen Hintergrundes, einer bestimmten Situation, usw.) kann dem Leser, Zuschauer oder Hörer Klarheit bringen. 


\section{II.2. Die Hörspiele}

Rainer Lewandowski hat zwischen 1975 und dem Beginn seiner Intendanz in Bamberg 1989 viele Hörspiele für den Rundfunk geschrieben. Seit er die Stelle am Bamberger Theater innehat, beschäftigt er sich hauptsächlich mit seinen Aufgaben als Intendant, aber er schreibt weiter, wenn auch seitdem vornehmlich Stücke für das Theater. Es bleibt ihm kaum Zeit für den Rundfunk und das ist schade, denn die Hörspiele sind interessant und vielseitig in ihrer Thematik. Zwei Hörspiele und zwei Kurzhörspiele wurden hier ausgewählt, um Rainer Lewandowskis Spiel mit der Phantasie, der Illusion und der Realität zu erläutern und auch um seine Vielseitigkeit zu illustrieren.

\section{II.2.a) 'da wird die Sau geschlacht...'}

\section{Erleben Sie einen Tag auf einem deutschen Bauernhof.}

'da wird die Sau geschlacht...' wurde 1987 vom Südwestfunk gesendet, 1988 vom Radio Bremen. Es ist ein Orginalton-Hörbild und eine Realreportage. Diese Reportage gibt Eindrücke Rainer Lewandowskis über den Prickingshof - einen Bauernhof im Münsterland - wieder, die er während eines Besuchs dort sammelte. Am Anfang des Hörspiels wird darauf aufmerksam gemacht, daß es alles, was berichtet wird, auch wirklich gibt:

Die Texte, die Sie hören werden, stammen von Schrifttafeln, die auf dem Hof als Teil der Tierschau und des Museums zu lesen sind. Dem Hof gegenüber befindet sich ein Gedenkpark, der, auf Säulen in den Stein eingehauen, Stationen des Leidensweges von Jesus Christus zur 
Besinnung für die Besucher dokumentiert. Auch diese Texte sind Orginaltexte, wie sie in dem Besinnungspark des Prickingshofes zu lesen sind. Außerdem hören Sie Stimmen von Mitreisenden und Auszüge aus einem Gespräch mit Bauer Ewald und seine Begrüßungsansprache. (Sau, Tondokument)

Wenn der Hörer 'da wird die Sau geschlacht...' zum ersten Mal hört, wird er unsicher, ob diese Geschichte nun eine wirkliche Realreportage ist oder ob er hier auf den Arm genommen wird. Zum einen gibt es in dem Hörspiel viele Hinweise, die auf die Echtheit der Reportage deuten, wie z. B. die Ansprache des Bauern, die Interviews der verschiedenen Besucher, die Geräusche usw., aber man denkt doch: das meiste muß übertrieben sein, das wäre ja völlig geschmacklos, wenn das alles so wahr wäre. Lewandowskis Kommentar dazu lautet folgendermaßen:

Diesen Bauernhof gibt es wirklich...er gehört Bauer Pricking, das ist die Person, die singt und ein Interview gibt. Bestandteil dieses angeblich bäuerlichen Besichtigungsparks (reales Bauern-Disneyland) ist ein Stationenweg mit den Leiden Christi. Alles was man hört, gibt es tatsächlich. Alles ist Zitat, Ausdruck der bigotten Haltung dieses Bauern, Ewald mit Vornamen. Deshalb auch Realreportage, alles existiert, ist geschehen und wurde gesagt. ...Das Hörbild zeigt, daß auf dem Prickingshof die Realität aus Geldgiergründen so übersteigert wurde, daß man glauben könnte, es sei Fiktion. (E-mail des Autors, 7.März 2001) 
Im Folgenden werden Beispiele für die Geldgier des Bauern und seine grenzenlose Geschmacklosigkeit gegeben, weshalb es so schwierig ist, diese Realreportage zu glauben:

In seiner Ansprache gibt der Bauer damit an, daß sein Hof bis ins Jahr 1007 zurückgehe und angeblich vom Kaiser Heinrich II. als Lehen gegeben worden sei, daher steht im Besinnungspark eine große Statue vom Kaiser. Im Besinnungspark gibt es auch den größten und schwersten Zuchtbullen Europas (der Kaiser freut sich bestimmt über dessen Gesellschaft!) und einen Stationenweg mit den Leiden Christi. Hier kann man z.B. unter der 9. Station lesen: „Jesus fällt zum dritten Mal unter dem Kreuze. Wir beten Dich an, Herr Jesus Christus. Wir preisen Dich, denn durch Dein heiliges Kreuz hast Du die Welt erlöst“" (Sau, Tondokument). Das Lesen dieser Stationen wird in den Ablauf des Tages eingefügt und macht den Rest des Bauernhoferlebnisses um so geschmackloser. Auch wird immer wieder folgendes Lied vom Bauer Ewald gesungen: „Da wird die Sau geschlacht, da wird die Wurst gemacht, da wird Rabatz gemacht, auf dem schönen, schönen Prickingshof...“ (Sau, Tondokument). Viele der Besucher singen fröhlich und in guter Stimmung mit. Auf dem Weg durch den Bauernhof gibt es mehrere Informationsstationen, bei denen man von einer Mark bis zu sieben Mark einwerfen muß, wenn man informiert werden will. Bauer Pricking macht aus allem Geld, er hat ein riesiges Gasthaus, in dem 2000 Besucher Platz finden, er verlangt Eintrittsgeld und er macht sogar Geld aus dem Mist der Tiere: mit Biogas hat er Millionen gescheffelt. Um den unangenehmen Tiergeruch zu vermeiden, sind Tiere und Besucher durch Glaswände getrennt. 
Trotzdem entsetzen sich viele der Besucher über die Behandlung der Tiere: Tierquälerei wird das enge Zusammenpferchen der Tiere in den Ställen genannt. Auch die Legebatterien der Hühner werden beanstandet und daß die Tiere auf Eisenstäben stehen müssen und nie raus an die frische Luft dürfen. Eine Frau sagte, ihr sei das Fleischessen beim Besuch des Bauernhofes vergangen. Den Bauern aber berührt das alles nicht. Er sagt im Interview, bei dem im Hintergrund das Geld klingelt, daß jedes Jahr mehr Besucher kommen, da sie das köstliche Essen genießen, den Bauern sehen und die Produkte von seinem Hof kaufen wollen.

Daß dieser Bauernhof wirklich existiert und immer wieder besucht wird, ist ein bedenkliches Zeichen für die Verdummung unserer Gesellschaft, die für solche geschmacklose Unterhaltung gutes Geld verschwendet und geldgierigen Menschen wie dem Bauern Ewald noch größeren Verdienst ermöglicht.

\section{II.2.b) Ohne Motiv}

Ein Kriminalhörspiel

Dieses Hörspiel ist besonders interessant, da es ständig zwischen Realität und Fiktion wechselt. Gedanken, gedachtes Handeln wird in die Tat, in die Realität, umgesetzt und dann wieder in eine fiktive Form umgewandelt, nämlich eine Kurzgeschichte. Das Geschehen ist so verzwickt und interessant beschrieben, daß es die volle Aufmerksamkeit des Zuhörers fordert, um der Geschichte folgen zu können.

Ohne Motiv wurde am 4. April 1987 vom Radio Bremen und am 21. September 1989 vom Bayerischen Rundfunk gesendet, danach gab es diverse Wiederholungen des Hörspiels. 


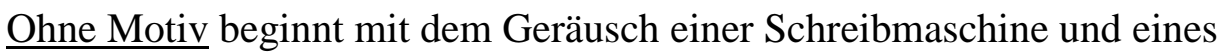
männlichen Sprechers, der Gedanken formuliert und sie dann mit Hilfe der Schreibmaschine aufschreibt. Die Person beschreibt, wie sie am Morgen aufwacht, sich müde fühlt, und die Geräusche von der Straße wahrnimmt. Eine sehr reale Beschreibung für den Leser, aber der Sprecher meint, daß die Situation einen irrealen Unterton gehabt hätte. Jemand steht auf und geht im Wald spazieren, es ist früh und er ist allein. Er fühlt die Schußwaffe in seiner Hand und denkt:

Wenn jetzt ein Passant käme, irgendjemand, eine Radfahrerin vielleicht, die auf dem Wege vorbeiradelte ... ein kleiner Zug mit dem Finger ... und die Realität bräche ein, bräche in sein und ein fremdes Leben ...

Er hätte nichts von ihr gewußt,...gar nichts, einfach so, ein Mord ohne Motiv, eine Realitätserfahrung, ... eine Prüfung der Phantasie mit dem Maßstab der Realität. (Ohne Motiv, 1)

Doch nun führt der Mann diesen Gedanken in Wirklichkeit aus und erschießt eine ihm völlig unbekannte Radfahrerin genauso, wie er es in seiner Phantasie vorher beschrieben hatte. Die Polizei ist ziemlich ratlos, da die Tat ohne erkennbares Motiv begangen worden ist. Aber die Tat hat dann doch ein Motiv: der Täter will sehen, ob seine Tat Aufmerksamkeit erregt, seine „Tat ohne Motiv“ nachvollziehbar und damit entdeckbar ist. Er geht zum Tatort zurück und trifft dort den Polizeiinspektor. Die beiden 
unterhalten sich. Der Hörer weiß, daß der Inspektor, Wertmann mit Namen, den Mörder getroffen hat, aber der Inspektor weiß das nicht. Dann spielt Rainer Lewandowski mit Realität und Illusion, indem der Inspektor eine Frage, die nicht an ihn gerichtet ist, sondern an einen Zeugen: „Sie haben den Mörder gesehen?“ mißversteht und antwortet: „Nein, Werner. Wie kommen Sie darauf ?“(12), obwohl er den Mörder in Wirklichkeit doch gerade gesehen hatte.

Nun schleicht sich die Realität in die Illusion des Täters: weil er Aufmerksamkeit will, schreibt er einen Brief an die Polizei, den Inspektor Wertmann liest:

,Und was, wenn ein Verbrechen kein Motiv

hätte, keines, dem man mit üblicher Methode nachspüren kann?`

Der Täter?

Er fühlt sich sicher. Wir sind auf dem

richtigen Wege, Werner. Es gibt kein Motiv.

Jedenfalls kein Übliches. Und das ist das

Motiv ...

Werner: ein Gedankenspiel ... (17)

Also das Irreale, die Tat ohne Motiv, wird nun real und damit erkennt der Inspektor auch das Motiv des Mörders: dessen Tat ohne Motiv. Mit Hilfe des Briefes findet man einige, wenn auch spärliche Hinweise auf den Mörder, z. B. an Hand der Schreibmaschine, die er benutzte. Aber das hätte wenig genützt, hätte nicht der Mörder selbst begonnen, die Sache weiterzuspielen. Unbefriedigt mit den Gefühlen, die sich nach dem Brief an die Polizei eingeschlichen haben, nämlich Schuldgefühle und „Strafphantasien“ (19), will nun der Mörder noch mehr auf sich aufmerksam machen: er will die Geschichte erzählen 
und zwar in der Lokalzeitung in Form einer Kurzgeschichte. Er beabsichtigt „Literatur und Aktualität eng zu verknüpfen. ... Eine literarische Debatte entfachen - um den Einsatz der eigenen Existenz. Des Gedankenspiels zweiter Teil“ (19).

Nun kommt dem Inspektor der Zufall zu Hilfe: Inspektor Wertmann ist ein Liebhaber der Literatur und liest diese Kurzgeschichte, die genau die Geschichte vom Anfang des Hörspieles ist, in der Literaturbeilage der Zeitung. Wertmann geht zu dem Verfasser der Geschichte, der Stimme, die jetzt einen Namen hat: Michael Marten. Mit Hilfe der Schreibmaschine beweist er, daß Marten die Kurzgeschichte vor der Tat geschrieben hatte und da sie die Tat genau beschreibt, hat Polizeiinspektor Wertmann auch den Mörder gefunden. Und so war Martens Tat und deren Entdeckung mit der Phantasie, der Literatur, der Realität und dem Leben eng verbunden und Marten verlor damit die zweite „Runde des Gedankenspiels“ an Inspektor Wertmann.

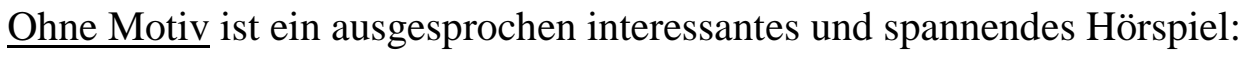
großartige Unterhaltung mit intellektuellem Anspruch!

\section{II.2.c) Hier spricht der automatische Anrufbeantworter}

Dieses Hörspiel wurde 1985 vom Hessischen Rundfunk produziert und gesendet und ist außerdem vom Schulbuchverlag Klett in einem Lehrbuch veröffentlicht worden.

Hier spricht der automatische Anrufbeantworter ist ein äußerst lustiges und amüsantes Hörspiel, das eine tägliche, für viele normale Situation, nämlich wie man mit einem automatischen Anrufbeantworter umgeht, schildert.

Tischlermeister Walter Lohe will seinen Kunden, Herrn Bitterfeld, anrufen um ihm mitzuteilen, daß er seinen Auftrag zwei Tage eher fertiggestellt hat und er möchte 
nun die Fenster liefern. Er ruft an, bekommt aber dauernd den Anrufbeantworter. Um sicher zu sein, daß er die richtige Telefonnummer hat, ruft er die Auskunft an. Auch das klappt für ihn nicht reibungslos: erst ist die Nummer besetzt, dann muß er warten. Er wird so ungeduldig, daß er, als er endlich Verbindung bekommt, anfängt mit der Telefondame zu streiten. Es stellt sich heraus, daß die Nummer die richtige ist und nun entschließt er sich, von seiner Frau Hedwig angespornt, doch eine Nachricht zu hinterlassen. Da er nicht gewohnt ist, mit dieser Art der Verständigung umzugehen, kommt eine völlig wirre Nachricht dabei heraus:

\section{Also Herr Bitterfeld!}

Ich versuche Sie die ganze Zeit zu erreichen, aber Sie sind nicht da. Wenn Sie mich bitte zurückrufen würden, so schnell es geht bitte! Mir wär's sehr drängend, ich warte darauf.

Folgendes: Wir sind nämlich früher fertig als erwartet, da wollte ich Sie nun fragen, ob es mir möglich wäre, daß wir früher kommen als vereinbart, sonst wär's nämlich später und dann könnten wir früher, wei, weil... und das andere ist dann für uns zu spät, wenn Sie mich da umgehend anrufen würden....

- Die Sprechzeit ist zu Ende - (Anrufbeantworter, Tondokument)

Er sagt alles mögliche, nur nicht das Wichtigste: seinen Namen, Telefonnummer und was genau er will. Nach einigen mißglückten Versuchen beschließt Walter, die Nachricht mit seiner Frau einzuüben und zu sehen, ob er es unter 30 Sekunden, die Sprechdauer des Anrufbeantworters, schafft. Nach einigem Hin und Her spricht er den Text in 23 Sekunden und ruft wieder an. Diesmal antwortet Herr Bitterfeld persönlich, aber Walter 
läßt ihn gar nicht zu Wort kommen: „Unterbrechen Sie mich bitte nicht“”, sagt er, rasselt seinen erlernten Text herunter und legt auf. Zufrieden mit sich selbst sagt er: „Na - wie war's?“"

Diese Geschichte ist so echt, weil es viele Menschen gibt, vor allem unter der älteren Generation, die große Probleme mit der Technik haben und lieber vermeiden mit ihr umzugehen, als sich mit ihr auseinanderzusetzen. Rainer Lewandowski hat diese Angst vor der Technik zum Thema genommen und sie so gekonnt überspitzt, daß es ausgesprochenen Spaß macht zuzuhören.

\section{II.2.d) Ferien im Flöz, oder Städteurlaub einmal anders}

Das Kurzhörspiel Ferien im Flöz, oder Städteurlaub einmal anders wurde vom Südwestfunk zwischen 1985 und 1986 gesendet. Man hört von zwei Ehepaaren, die sich an einem Abend treffen, um ihre Ferienerlebnisse auszutauschen. Es geht hier aber nicht um einen normalen Kultur- oder Erholungsurlaub, sondern um einen Abenteuerurlaub. Auch dieses Hörspiel ist ein literarisches Spiel mit Realität und Fiktion, in dem die Fiktion angelegte Entwicklungsmomente in der Gesellschaft hochrechnet, übersteigert. Hier werden z.B. technische Dinge oder Orte genauestens beschrieben, aber der Zusammenhang, in den sie gestellt werden, ist irreal. Rainer Lewandowski erläuterte seine Idee mit fiktionalen Geschichten, die die Möglichkeit des Wahrscheinlichen haben wie Ferien im Flöz - folgendermaßen:

Damals wurden im Ruhrgebiet alle Gruben stillgelegt und diese Flöze ... sind leer. Das wäre ein wunderbarer Ort für Abenteuerurlaub. So können Industrieruinen noch von einer anderen Industrie ausgenutzt werden. Es 
gab auch eine Geschichte über Reisen in Krisengebiete. Reisen mit integrierter Entführung: 500 DM Aufpreis. Heute gibt es das alles wirklich. Amerika fährt nach Vietnam, um in den Stollen von den Vietkong herumzukriechen. Leer stehende Gasometer werden zum Vergnügungspark ausgebaut. Das ist genau der Punkt, die Hochrechnung der gesellschaftlichen Entwicklungstendenzen, wobei man allerdings immer wieder sagen muß: Man kann gar nicht so phantasievoll sein wie die Wirtschaft selbst, um Geld zu verdienen. (I, 42)

Sozialkritik an einer Gesellschaft, die immer mehr Nervenkitzel braucht, um befriedigt zu werden. Rainer Lewandowski ist da fast prophetisch, denn in der September 1998 Ausgabe der amerikanischen Zeitschrift Maxim gab es einen Report, „The Death Dealer“ genannt, in dem beschrieben wurde, wie Abenteuer suchende Reiche in Krisengebiete eingeschleust werden, um für viel Geld tödliche Gefahren erleben zu können.

Sabine und Wolfgang, das eine Ehepaar im Hörspiel, berichten über ihren Abenteuerurlaub im Flöz und zeigen ihren Freunden Dias davon. Sie verbrachten ihren Urlaub in einer stillgelegten Grube und lernten viel Interessantes über den Bergbau. Viele Dinge, wie z. B. der Ausdruck ,wir sind auf den Hund gekommen“ werden hier erklärt: das Ehepaar fuhr in den Wagen, die früher die Kohle transportierten und von den Bergleuten „Hund“ genannt wurden. Wolfgang erklärt das seinen Freunden. Das ist die reale Gegebenheit. Auf der anderen Seite werden reale Möglichkeiten ins Absurde übertrieben, z.B. Wolfgang und Sabine durften ihre Lagerstätte selbst in das Flöz hauen, aber - paradoxerweise -, trotz Mehrarbeit, nur gegen Aufpreis. Auch das Grubenlicht, das von beiden als romantisch angepriesen wird, gibt es nur gegen Aufpreis. Natürlich 
kann man auch anderen Luxus haben, bzw. zum Aufpreis erkaufen: Höhensonne, damit man gebräunt nach Hause kommt. Man kann auch Solarien besuchen, bei Sprengungen mitmachen und man wird von ehemaligen Bergleuten, die in einer Hotelfachschule umgeschult wurden, bedient. Beide begründen ihre Urlaubswahl damit, daß sie bei dem Massentourismus nicht mehr mitmachen wollen und daß sie durch ihre Urlaubswahl der Volkswirtschaft helfen, weil auf diese Weise Arbeitsplätze erhalten bleiben. Sie sehen allerdings nicht, wie konsumorientiert sie sind. Diese Erkenntnis wird dem Hörer überlassen, Lewandowski legt sie zumindest nahe, mit Hilfe der bewußt eingesetzten, aber immerhin doch möglichen Überzeichnungen.

Das andere Ehepaar, Gerd und Lilo, hat sich eine alternative Städtetour ausgesucht: „Städteurlaub einmal anders“(Ferien, Tondokument). Sie wählten Berlin und konnten an einer Demonstration und an einer Hausbesetzung aktiv teilnehmen. Für ihre Teilnahme an der Hausbesetzung wurden sie sogar für drei Tage in Moabit eingesperrt. Alles im Preis inbegriffen! Was nicht inbegriffen war, aber gegen Aufpreis geboten wird, ist die Benutzung eines Polizei-Schlagstockes, das Fahren des Wasserwerfers ${ }^{1}$ oder Zwangsernährung in Moabit. Die beiden beschweren sich, daß zu wenig im Preis inbegriffen war und daß sie gerne alle diese Möglichkeiten genutzt hätten, wenn es nicht so teuer gewesen wäre. Sabine und Gerd hatten die Wahl zwischen Polizeiseite oder Demonstrantenseite und werden von ihren Freunden bewundert, da sie bei solch gefährlichen Unternehmungen mitmachten.

\footnotetext{
${ }^{1}$ Dieses Thema ist jetzt von hoher Aktualität wegen des Unglückes zwischen dem amerikanischen U-Boot USS Greeneville und dem japanischen Fischerboot Ehime Maru. Time Magazine und Associated Press berichten, daß Zivilisten in dem U-Boot waren und durch deren Anwesenheit dessen Maneuver gestört haben sollen. Auch wurde berichtet, daß Zivilisten regelmäßig gestattet wurde, das U-Boot zu steuern. Auch hier wieder ist die Wirklichkeit noch verrückter als das Erfundene.
} 
In diesem Hörspiel wird wieder scharfe Kritik an der Gesellschaft geübt, der es gleichgültig ist, was politisch los ist, wenn nur ein Nervenkitzel dabei ist. Man überlegt sich gar nicht mehr, worum es in der Demonstration eigentlich geht, man will nur dabei sein, um dabeizusein und die Gefahr zu erleben. Das Lustige an dieser Sache ist, daß die Polizei weiß, wer da als „Abenteurer“ mitmacht und sogar für Gerd und Sabine die Videoarbeit übernimmt, damit es „echt“ aussieht.

In Ferien im Flöz, oder Städteurlaub einmal anders erwartet Rainer Lewandowski von seinen Zuhörern, daß sie seine implizierte Sozialkritik erkennen und die Abenteuersucht vieler in unserer Gesellschaft als das sehen, was sie ist: eine zur Mode stilisierte Geschäftemacherei, die sich mit fadenscheinigen Gründen, wie der Besserung der Volkswirtschaft, zu legitimieren sucht. 


\section{II.3. Die Kinderstuicke}

Rainer Lewandowski hat eine Vielzahl von Kinderstücken verfaßt. Jedes Jahr schreibt er mindestens ein neues Theaterstück für sein jüngstes Publikum. Die Kinder liegen ihm am Herzen: das Theatererlebnis soll ihnen zum besonderen Erlebnis werden und vor allem soll es die Entfaltung der kindlichen Phantasie fördern. Inwieweit er damit Erfolg hat, wird die folgende Auswahl an Kinderstücken zeigen.

Seine Kinderstücke kommen aus unterschiedlichen Quellen: manche sind Stücke von den Gebrüdern Grimm, also aus dem deutschen Kulturgut, die Rainer Lewandowski für das Theater bearbeitete, manche Stücke sind in Zusammenarbeit mit Schriftstellern aus der Region entstanden, wie z.B. der Burgfrosch Balthasar, den Rainer Lewandowski zusammen mit Rudi Sopper, dem Autor des Kinderbuches Burgfrosch Balthasar, für die Bühne schrieb. Die meisten der Kinderstücke hat Rainer Lewandowski jedoch selbst geschrieben. Er verfaßt seine Kinderstücke in einer Weise, die es ermöglicht, sogar manchmal notwendig für die Fortsetzung der Geschichte macht, daß die Kinder sich aktiv am Theatergeschehen beteiligen. In meinem Interview erklärte er, warum er die Beteiligung der Kinder für so wichtig hält:

Kinderstücke sind deshalb so wichtig, weil man Kinder ernst nehmen muß, man darf Kinder nicht veräppeln, daß sie einfach nur da sind um ,,ja“ oder „,nein“ zu brüllen oder „Seid ihr alle da“ ..., sondern sie müssen inhaltlich miteinbezogen werden, auch etwas zu tun haben, was zu machen haben. ... Das ging einmal soweit in der Bambolo Geschichte, daß die die 
inhaltlichen Lösungen herstellen mußten. Ohne das Raten von relativ komplizierten Rätseln wäre das nicht weitergegangen. (I, 79 ff.)

Rainer Lewandowski erklärte mir weiter, daß die Kinder ja die Theatergänger der Zukunft wären und hoffentlich, wenn sie als Kinder positive Erlebnisse im Theater hatten, dann als Erwachsene das Theater besuchen und weiter aktiv mitmachen. Oder wenn sie für sich selbst nicht kommen, daß sie dann wenigstens ihre eigenen Kinder ins Theater bringen. Er versucht das Interesse der Kinder durch „,kleine Wunder“ zu beleben, mit der Technik etwas zu tun, damit die Kinder dann beeindruckt fragen, wie das wohl gemacht wurde. Kinder sind ja kein leichtes, unkritisches Publikum, besonders da sie vom Technischen her viel wissen und ihre Sehgewohnheiten ganz anders sind, als die der Eltern. Deshalb, so meint Rainer Lewandowski, muß man sich auch immer etwas Besonderes einfallen lassen, etwas Interessantes für die Kinder machen und einfach gute Geschichten schreiben.

Im Rahmen meiner Arbeit über Rainer Lewandowski möchte ich hier vier Kinderstïcke besprechen: Das fremde Kind, Bambolo, Junges Gemüse und das neueste Kinderstïck, Der gestiefelte Kater.

\section{II.3.a) Das fremde Kind}

Das fremde Kind ist ein Phantasiemärchen, das Rainer Lewandowski nach dem gleichnamigen Kindermärchen von E.T.A. Hoffmann für die Bühne umarbeitete. Auch benutzte er Musik von Hoffmann in dem Kinderstück und es wurde am 17. November 1995 in Bamberg uraufgeführt. 1996 erhielt es den Preis für Darstellende Kunst der Bayerischen Akademie der Schönen Künste, zusammen mit der Friedrich-Baur-Stiftung. 
Lewandowski betont in seinem Interview, für wie wichtig er die Phantasie hält, vor allem bei Kindern, wo sie ja noch vorhanden ist und wo sie ständig von Einflüssen der Erwachsenenwelt bedroht wird. Diese Idee ist in Hoffmanns Märchen enthalten: Das

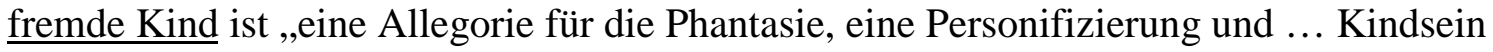
heißt, etwas von dieser Fähigkeit seiner Phantasie zu bewahren” (I2, 11).

Diese Fähigkeit die Phantasie zu bewahren, ist das Hauptthema des Kinderstückes: Die Familie Brakel lebt in der Nähe eines kleinen Dörfchens im Wald. Die Kinder Christlieb und Felix sind glücklich, da sie oft den ganzen Tag im Wald spielen dürfen und dort ihrer Phantasie durch Spielen freien Lauf lassen. Eines Tages besucht sie ihr Onkel mit seiner Tochter Adelgunde, die in der Stadt am Hofe des Königs leben. Vater Brakel ist beeindruckt vom Wissen seiner Nichte und beschließt, daß es höchste Zeit ist, seinen Kindern eine angemessene Erziehung zu ermöglichen. Bei ihrem nächsten Spielen im Wald erscheint ihnen das fremde Kind und warnt sie vor Pepser, dem Gnomenkönig, der alles Spiel und alle Phantasie zerstört. Nun erscheint der Hauslehrer, den der Onkel aus der Stadt schickte. Er heißt Meister Tinte und scheint recht eigenartig zu sein: er ähnelt einer Fliege und sticht die Kinder bei der Begrüßung in die Hand. Die Kinder mögen ihn und seinen Unterricht gar nicht und versuchen in den Wald wegzulaufen. Der Vater befiehlt dem Magister Tinte, die Kinder zur Abwechslung in den Wald zu nehmen und dort beschimpft der Hauslehrer die Phantasie der Kinder als Narrheit und unvernünftiges Zeug. Das fremde Kind erscheint und warnt sie vor dem Magister Tinte, der in Wirklichkeit Pepser ist. Sofort verwandelt sich der Gnomenkönig in eine Fliege und verfolgt die Kinder. Doch mit Hilfe der Eltern verjagen die Kinder ihn. Am Ende gibt der Vater zu, daß auch er als Kind das fremde Kind gesehen habe, aber daß 
er seine Phantasie während des Erwachsenwerdens verloren hätte, daß das doch sehr schade sei und daß er von nun an die Phantasie willkommen heiße.

Hier eine Geschichte, die die Kinder in ihrem Spiel mit der Phantasie unterstützt und anspornt, und die Eltern ermahnt, doch zurück an ihre eigene Kindheit zu denken, damit sie nicht vergessen wie wichtig die Phantasie ist, auch für Erwachsene. Dieses Wichtignehmen und Anspornen der Phantasie zieht sich durch alle Kinderstücke Lewandowskis.

\section{II.3.b) Bambolo - Ein Theatertheater-Mitmach-Theater für Kinder}

Das erfolgreiche Kinderstück Bambolo, Uraufführung in Bamberg 1996, wurde von der Bayerischen Staatskanzlei und vom Bayerischen Staatsministerium für Wissenschaft, Kultur, Unterricht und Kunst eingeladen, am 10jährigen Jubiläum des Kulturaustausches mit der Provinz Schandong in China, im November 1997, teilzunehmen. Es wurde ins Chinesische übersetzt und war dort ein großer Erfolg.

In Bambolo werden die Kinder vor folgendes Problem gestellt: die Fee Maliciosa hat Giuseppe Fantassissimos Marionettentheater so klein gezaubert, daß er es hat schließen müssen. Die Fee Maliciosa möchte nämlich in Giuseppes Marionettentheater mitspielen, aber Giuseppe will das nicht, weil sie keine Marionette ist und weil sie wirklich zaubern kann. Die Fee gibt ihm aber noch eine Chance: er muß mehrere Rätsel in einem Rätselbuch lösen, wenn er sein Theater wieder im Normalzustand zurück haben will. Giuseppe vergißt, das Rätselbuch mitzunehmen und jetzt will die Fee es nicht mehr hergeben. Nun sollen die Kinder helfen und folgende Regieanweisungen sind im Stück gegeben: „Die Fee hält den Kindern das Buch zum Greifen hin, zieht es erst spielerisch zurück, wenn ein Kind danach faßt, läßt es sich dann aber doch nehmen. Falls die Kinder 
aus Respekt sich nicht trauen, ihr das Buch wegzunehmen, läßt sie es während des Spiels ,unabsichtlich“ fallen, sucht es dann selbst, so daß ein Kind es inzwischen aufheben und zu Giuseppe bringen kann“ (Bambolo, 25). Die Kinder werden gefragt, ob sie Giuseppe helfen wollen, die Rätsel zu lösen und sie müssen die richtige Antwort auf die Rätsel finden, bevor die Geschichte weitergehen kann. Also ohne das Mitmachen der Kinder kein Theaterstück! Hier ist eines der Rätsel:

Hast du gefunden dieses Holz,

Dann sei darauf ein bisschen stolz.

Das sind wir. Wir alle zusammen.

Nur dieses Stück,

Das bringt dir Glück.

Zur Freude vieler

Wird daraus ein Spieler.

Bring es zurück

In einem Stück.

Der Stamm, er wird ganz deiner

Schaffst du ihn schnell zum.... (9)

Die Antwort, die die Kinder geben sollen ist natürlich ,Schreiner'. Weiter sollen die Kinder mitmachen, indem sie viele Rätsel lösen, den Schreiner mit einem Vers aufwecken, ein Lied mitsingen, und beim Ankleiden der Holzpuppe Bambolo helfen. Nun kommt der zweite wichtige Teil des Theaterstückes: das Wunder. Als die Darsteller im Keller nach dem nächsten Hinweis suchen, hilft die Fee Maliciosa, die eigentlich gar nicht so schlimm ist, das Rätsel zu lösen. Hier müssen die Kinder eine 3D 
Brille aufsetzen, die ein rotes und ein grünes Glas hat. Die Kinder sehen die Bälle schweben und Guiseppe ruft: „Die Bälle! Sie schweben! Sie schweben und ich kann sie trotzdem nicht greifen...- Ich glaube, ich verstehe: Sie schweben nur in unserer Phantasie. Das ist die Lösung, wir haben es. Das Rätsel ist gelöst“ (22). Rainer Lewandowski beschreibt die Idee mit der Brille und den Bällen als den größten Spaß überhaupt, da es durch optische Täuschung für die Kinder so aussah, als kämen die Bälle direkt von der Bühne auf sie zugeflogen: „Die Kinder sind in Deckung gegangen, weil die Bälle kamen, obwohl gar nichts war“ (I, 34). Die Kinder waren von dem Trick natürlich hell begeistert.

Aber es geht jetzt im Märchen nicht weiter, da die Fee das Rätselbuch gestohlen hat. Wieder stellt sie eine Bedingung für ihre Hilfe: sie will im Theater mitspielen. Die Kinder werden gefragt, ob die Fee mitspielen darf oder nicht und hier haben die Kinder die Macht, das Ende des Theaterstïckes zu beeinflussen: „Antworten die Kinder mit ,Nein`, was kaum zu erwarten ist, dann wäre das Stück hier zu Ende. Dann würde die Fee traurig von dannen ziehen und Bambolo könnte die Kinder nochmals zum Überdenken ihrer Entscheidung aufrufen. Und wenn auch das nichts nützt, gibt es einen traurigen Schluß“ (Bambolo, 62).

Wenn die Kinder sich entscheiden, die Fee mitmachen zu lassen, dann spielen alle Schauspieler das Stück „Prinz Bambolo und Prinzessin Klärchen“ für das junge Publikum und damit endet die Vorstellung.

\section{II.3.c) Junges Gemüse}

Geschichten für Kinder quer durch den Gemüsegarten des Lebens. 
Das Stück Junges Gemüse entstand 1992 und besteht aus Teil I und II. Es wurde vom Fränkischen Tag als „Kindertheater vom Feinsten“ gelobt. Rainer Lewandowski gestaltete dieses Stück im Zusammenhang mit dem Programm Theater und Schule. Dieses Programm arbeitet eng mit Schulen und Lehrern zusammen, um die Theatererfahrung in die Schulen zu bringen. Da Junges Gemüse nur einen Schauspieler oder eine Schauspielerin und mehrere Puppen benötigt und ein kleines, mobiles Stück ist, eignet es sich besonders gut für diesen Zweck. Es kann aber auch im regulären Theater gespielt werden. Es geht hier um den/die Obstverkäufer/in Vitaliano/Vitaliana und sein/ihr Gemüse:

Dem Charakter nach sollte der Obstverkäufer ... italienischer, temperamentvoller Prägung sein und im Kostüm etwas Außergewöhnliches haben, sich vom handelsüblichen Marktverkäufer deutlich unterscheiden. Mit welchen Stimmen, artistischen Einlagen, Sprech- und Spielweisen zu agieren ist, ergibt sich aus den zu spielenden Szenen. Der Virtuosität sind keine Grenzen gesetzt, ebenso den Möglichkeiten, die Kinder aktiv zu beteiligen. (Junges Gemüse, 1) Das Kinderstück ist in einzelne Geschichten unterteilt und diese können, je nach dem Alter der Kinder, geändert oder einige der Geschichten könnten auch ganz weggelassen werden. In diesen Geschichten geht es um Probleme, mit denen sich die Kinder identifizieren können: Probleme mit den Eltern, Fernsehen, Anderssein, Ausländern, usw. Ganz wichtig hier ist wieder, daß das junge Publikum mit ins Geschehen einbezogen wird, z.B. werden Fragen gestellt: Weiß hier jemand, was Krieg ist? Diese Fragen sind Fragen und Probleme, die Kinder beschäftigen: 
Pommodore: So geht das? Einfach (die Pistolen) wegwerfen?

Vitaliano: Naja, eigentlich schon. Hör mal: Wenn man wirklich

Frieden spielen will, braucht man keine Waffen. Keine

Pistolen, keine Gewehre, Knarren, Panzer, Raketen, und

Kanonen. Wenn man wirklich Frieden spielen will, fängt

man erst einmal an, das ganze Zeug wegzuwerfen, zu ver-

schrotten und so. Erst dann wird's wirklich friedlich. (5)

Wieder werden die Kinder gefragt, womit man denn friedlich spielen kann und die Antworten der Kinder werden ernst genommen. Auch hier können die Kinder entscheiden, indem sie für oder gegen eine Figur aus dem Stück wählen, und den Verlauf der Geschichte beeinflussen, auch können sie mitmachen (den Kopf bedächtig hin und her wiegen wie Knabi Kohlrabi oder gähnen wie Schmuse Pampelmuse) und mitsingen. Ein anderes aktuelles Problem, das aufgegriffen wird, ist Umweltschutz und Müll. Die Kinder werden dazu angehalten zu helfen, zu Hause, beim Einkaufen und mit ihrem eigenen Verhalten, z.B. das Bonbonpapier in den Müll und nicht auf die Straße zu werfen:

Alle Menschen haben nur die eine ein'zge Welt,

Die allen da, da wo sie leben, meistens gut gefällt....

Wir alle haben's in der Hand.

Wir retten unser krankes Land.

Wir müssen Gift und Müll vermeiden,

Dann muß die Natur nicht länger leiden. (37) 
Ein weiteres gesellschaftliches Problem, das hier behandelt wird, ist Fremdenfeindlichkeit und Rassismus. Lümmel Kümmel, ein Fremder, wird von Fieschen Radieschen beschuldigt, ihr Gummiband gestohlen zu haben. Verallgemeinerungen werden benützt, um zu zeigen, wie schnell Vorurteile entstehen können, wie z.B. ,„hhr Kümmel klaut doch alle,“ „Alle Ausländer klauen,“ „Du kannst nicht einmal richtig sprechen,“ (39-42) usw. Vitaliano spricht für die Gefühle der Fremden, wenn er sagt: „Es ist schon schlimm, wie manche von uns mit Menschen umgehen, bloß weil sie aus einem anderen Land kommen. Ich könnte auch ein Lied davon singen“ (44). Kinder sind oft sehr sensibel gegenüber den Gefühlen anderer, vor allem wenn man sie darauf aufmerksam macht, wie weh man jemandem tun kann, insbesondere wenn jemand ungerecht behandelt wird. Am Schluß des Theaterstïckes werden die Kinder aufgefordert, die Figuren und deren Probleme zu wiederholen, damit Vitaliano

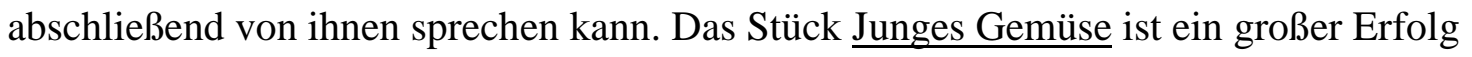
bei den Kindern, da es ihre Probleme behandelt und die Kinder persönlich, auf ihrer intellektuellen Entwicklungsstufe und Ebene anspricht.

\section{II.3.d) Der gestiefelte Kater}

Der gestiefelte Kater ist bekanntlich ein Grimmsches Märchen und es wurde hier von Rainer Lewandowski nach der Vorlage von Charles Perrault in ein Märchen-Musical für die Bühne umgestaltet. Da es sich hier um Lewandowskis neuestes Kinderstück handelt, möchte ich kurz auf dessen Publikumsnähe und technische Seite aufmerksam machen. Die Kinder werden hier wieder zum Mitmachen aufgefordert und zwar sollen sie die Rolle der Bauern übernehmen, die der König immer wieder befragt, wem dieses 
Schloß oder dieses Feld gehöre. Auch müssen sie dazu ein Lied lernen, damit es echt wirkt und der Kater übt mit ihnen, bis sie es ohne ihn singen können. Also auch hier geht es ohne die Mitwirkung des Publikums nicht.

Als technische Neuerung benutzt Lewandowski Videoclips aus der Bamberger Umgebung für die Burgen und die Umgebung. Man machte Aufnahmen von der Altenburg, der Giechburg, usw., die den Kindern aus ihrem eigenen Umfeld bekannt sind, aber die dann doch, da sie im Märchen auftauchen, in die Phantasiewelt miteinbezogen werden.

Beim Lesen der Kinderstücke fällt auf, daß Rainer Lewandowski viel Phantasie verwendet und die Kinder auch am Geschehen teilnehmen lässt. Sie sind nicht nur unbeteiligte Konsumenten, sondern sind aktiv und werden gebraucht, um dem Stück Richtung zu geben. Die Kinder können entscheiden, welches Ende ein Stück bekommt, sie lernen neue Lieder und haben Spaß an technischen Neuigkeiten, wie z.B. Bambolos Bällen, die die Phantasie der Kinder entfesselt.

Ein weiterer Aspekt der Attraktivität hier ist, daß Lewandowski eine Verbindung zwischen seinen einzelnen Kinderstücken herstellt: „Ich stelle in meinen Stücken gern einen Anknüpfungspunkt der Kontinuität her, etwas über den einzelnen Moment Hinausgehendes. ... Am ausgeprägtesten ist das in den Kinderstücken. Da ist immer eine Verbindung: da taucht mal ein Name auf, mal ein Kostüm, ... mal ein Liedteil, der zitiert wird“ (I2, 29). Die Kinder sollen diese Verbindungen unter den Stücken herausfinden, es soll ihnen gewahr werden, daß sich der Leitfaden der Phantasie durch alle diese Stücke zieht. 


\section{II.4. Theaterstücke}

\section{II.4.a) Heute weder Hamlet}

Das Stück Heute weder Hamlet hat Rainer Lewandowski während seiner Jahre am Niedersächsischen Theater in Hannover geschrieben. Das Theaterstück wurde 1986 an den Städischen Bühnen Osnabrück uraufgeführt. Inzwischen gibt es über 50 Inzenierungen von Heute weder Hamlet, darunter einige mit bekannten deutschen Schauspielern. Hans Clarins Aufführung an der Komödie im Bayerischen Hof in München wurde 1994 vom Bayerischen Fernsehen aufgezeichnet und im deutschen Fernsehen wiederholt gesendet. Andere bekannte Schauspieler waren Volker Lechtenbrink, Ernst-Deutsch-Theater, Hamburg; Raimund Gensel, Köln; Heinz Meier, Freiburg; Wolfgang Hübsch, Wien; Walter Plathe, Berlin.

Heute weder Hamlet existiert auch in mehreren Übersetzungen: englisch, französisch, russisch. Die englische Erstaufführung fand am 12. Mai 1997 in Windhoek statt. Dort wurde Heute weder Hamlet am National Theater Namibia aufgeführt mit dem Schauspieler Mees Xsteen. Das Stück Heute weder Hamlet war Lewandowskis erster großer Erfolg.

Das Stück beginnt damit, daß ein fiktiver Ansager vor den Vorhang tritt, das Shakespeare-Stück Hamlet absagt und das Publikum nach Hause schickt. Danach öffnet sich der Vorhang und Sassmann, der etwa 50-jährige Vorhangzieher, tritt auf. Lewandowski verunsichert hier das Publikum bewußt und sehr geschickt: der „Wechsel zwischen Realität und Fiktion, die Darstellung des Wirklichen mit dem Ziel, die Phantasie zu befreien, oder Fiktives darzustellen, um das Verständnis der Wirklichkeit zu erhöhen, das ist auch ein Merkmal mancher Stücke von Lewandowski, insbesondere von 


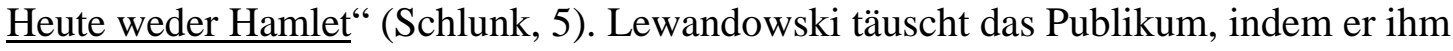

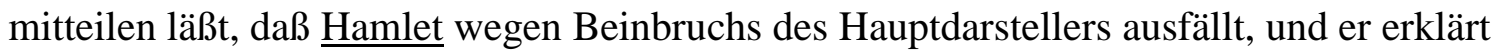
dem Publikum sogar, wie sie für die ausgefallene Vorstellung entschädigt werden:

Die Abonnenten der Reihe B2, D bis F, erhalten ihre Ersatzvorstellung am 24. des kommenden Monats. Danke.

Die Karten aus dem freien Verkauf sollen sich morgen an der Kasse melden. Sie erhalten dort ihr Geld zurück. Danke. (Heute, 2)

Lewandowski will kein lethargisches Publikum, das nur unterhalten werden möchte. In vielen seiner Stücke spricht er das Publikum direkt an. So auch hier: „, Das Publikum, verunsichert durch diese plötzliche Ankündigung, ist einen Augenblick lang aus dem Gleichgewicht gebracht... Ein Publikum, das so angesprochen wird, kann sich nicht passiv zurüklehnen, sondern gerät in gespannte Erwartung” (Schlunk, 6). Diese Verunsicherung des Publikums funktioniert so gut, daß fast jedes Mal, am Anfang von

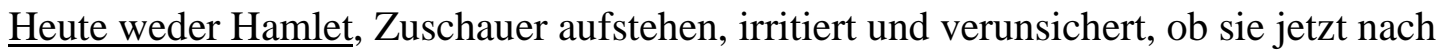
Hause gehen sollen oder nicht.

Sassmann, der für das Öffnen und Schließen des Vorhangs verantwortlich ist, aber heute abend ausnahmsweise auch einmal beim Wegräumen der Requisiten behilflich ist, entdeckt das Publikum und beginnt, es anzusprechen. Daraus entwickelt sich das Einpersonenstück, in dem Sassmann dem Publikum vom Schauspielen, von seiner Bedeutung als Vorhangzieher und von seinem Leben erzählt. Aber während des ganzen Stückes sind die Grenzen zwischen Realität und Schauspielen derart verwischt, daß man nie so recht weiß, ob Sassmann nun von der realen Welt erzählt oder ob er eine Rolle spielt. „Diese dramatische Strategie: der ständige Wechsel zwischen Wirklichkeit und 
theatralischer Illusion, wird während des Spiels, das sich jetzt entwickelt, aufrechterhalten“ (Heute, 6). Zum Beispiel, als Sassmann von seinem Unglück in Bruchsal (sprechender Name!) erzählt, verwischen sich Realität und Theater, er versucht zu erklären, aber die Grenzen werden undeutlich:

...und meine Frau ist im Urlaub, im Stück, Rebecca damals auch, die Kur nach dem Unfall, Rebecca, meine Frau, nicht im Stück, im Leben.

Aber auch im Stück ist meine Frau im Urlaub. Wie das Leben so spielt.

Wie das Theater. (18)

Sassmann stellt seine eigene Rolle vor: er bewegt den Vorhang, für ihn das Wichtigste am Theater, was er sich und dem Publikum glaubhaft zu machen versucht, denn er könnte „das Theater zum Hörspiel machen” (7). Er erwähnt auch, daß er selber Schauspieler war, daß er selbst eine harte Schule des Lebens hinter sich hat und daß er - angetrieben von der Auswegslosigkeit seiner eigenen Lebenslage, nichts von der seiner Meinung nach heute häufig vorherrschenden „Unfähigkeit als Persönlichkeitskult” (8) mancher Anfänger hält. Hier, durch Sassmanns Kritik am Theater, gelangt ein guter Schuß Realität, Sassmanns Realität, in das Stück. Sassmann beklagt sich, daß nur die Schauspieler den Applaus bekommen und niemand an die Techniker denkt. 
„Den Applaus bekommen immer die anderen. Immer die anderen“ (5). Er beschreibt die Hackordung, die im Theater besteht und die Allüren der Schauspieler. Er bringt Beispiele von Mißgunst der Kollegen, von deren Neid und von der angeblichen Unzulänglichkeit der Regisseure. Er spricht sogar das Publikum selbst an:

Heute weder Hamlet noch sonstwas.

Aber da der Vorhang aufging, einfach aufging...

Da bleiben Sie einfach hocken,

Träge,

Voyeuristisch,

Auch, wenn gar nichts weiter geboten wird.

Aber so ist es nun mal: Das Publikum.

Sitzt da,

Glotzt,

Lässt sich unterhalten....

Sie sind doch gar nicht wegen mir gekommen.

Geben Sie es doch zu.

Hamlet wollten Sie sehen....

Hamlet! Immer nur die großen Namen!

Wie dumm ist doch das Publikum.

Wie dumm.

Aber bitte.

Sie sollen auf Ihre Kosten kommen.

Bitte - Sie sollen etwas über Hamlet erfahren. (23 f.) 
Hier wird Kritik am Publikum direkt ans Publikum gerichtet. Aber in Heute weder Hamlet kann das Publikum nicht passiv und träge sein, es wird gezwungen zu reagieren. Sassmann stellt dem Publikum direkte Fragen: Zum Beispiel fragt er, ob es wisse, wo Hamlet spielt. Später geht er ins Publikum hinein und lässt Zuschauer an der Bilsenkrautphiole riechen. Außerdem wechselt das Stück so schnell zwischen Realität und Fiktion, daß dem Publikum wenig Zeit bleibt, nur träge zuzuschauen.

Sassmanns Leben ist eine Mischung aus Komödie und Leiden, aus Realität und Fiktion. Diese Elemente auseinander zu halten, wird die fast unmögliche Aufgabe des Publikums: Sassmann berichtet von seiner Schauspielkarriere, die ein vorschnelles Ende wegen eines Versehens während einer Vorstellung erfahren hat: Sassmann spielte im $\underline{\text { Raub der Sabinerinnen zusammen mit dem Intendanten des Theaters in Bruchsal. Weil }}$ der Intendant sich als Schauspieler mit dem geforderten Dialekt so plagen mußte, fiel ihm sein Gebiß während des Sprechens aus dem Mund. Das Gebiß landete auf Sassmanns Absatz und von dort purzelte es vor das Publikum und landete auch noch vor dem Vorhang, der wegen des peinlichen Vorfalls schnell zugezogen wurde. Sassmann wurde für das Unglück verantwortlich gemacht und fristlos entlassen. Nach dieser Pleite war er als Schauspieler erledigt, bekam nur noch kleine Rollen und ist schließlich nur noch als Vorhangzieher tätig.

Doch das ist nicht das letzte Unglück, das Sassmann widerfährt: seine Frau Rebecca, auch Schauspielerin, stürzt während der Balkonszene in Romeo und Julia mitsamt dem Balkon ab und bricht sich das Bein so kompliziert, daß sie von da an ein verkrüppeltes Bein hat und nicht mehr schauspielen kann. Er fühlt sich verantwortlich, da er sie hätte auffangen können, statt dessen wich er der fallenden Frau und dem Balkon 
aus, um nicht selbst getroffen zu werden. Von nun an werden Sassmanns Leben und Theater miteinander vermischt, indem er zu Hause mit der kranken Rebecca die Rollen durchspielt, die sie hätte spielen können, wenn sie im Beruf hätte bleiben können. Rebecca gerät in eine Identitätskrise, sie spielen Hamlet und Ophelia, Romeo und Julia, und am Schluß ihres Lebens ertränkt sich Rebecca, wie auch Ophelia gestorben ist. Zum Schluß des Stückes trinkt Sassmann das Gift aus einer Phiole, dessen Wirkung er dem Zuschauer vorher, anläßlich des Todes von Hamlets Vater, genau beschrieben hat. Der Zuschauer könnte glauben, Sassmann sei tot, aber dann richtet er sich auf, lächelt und sagt: „Der Rest ist Schweigen. Vorhang” (46).

„Das Ende ist ebenso zweideutig wie der Anfang“ (Schlunk, 8). Wieder weiß man nicht, was von Sassmanns Leben Realität und was Illusion war.

In meinem Interview mit Rainer Lewandowski erklärt er, daß er „,zunächst selbst glaubte, daß es wichtig sei, für die Rolle jemanden auszusuchen, der kein bekannter Schauspieler ist. Das hält die Illusion länger aufrecht. Aber die Illusion ist stark genug, sich auch bei bekannten Darstellern einzustellen. Das spricht für das Stück und dessen Grundanlage. Das ist dann sogar noch viel toller... weil die Zuschauer sich selber plötzlich in Zweifel ziehen, weil sie doch wieder , hereingefallen ' sind und so klettern sie noch intensiver mitten hinein ins Geschehen. Das macht die Sache sehr spannend““ (I, 78).

Dieses Stück hatte großen Erfolg, da es das Publikum direkt anspricht, an dessen Intellekt größere Anforderungen stellt als nur zuzuhören und sich unterhalten zu lassen. Es nimmt das Publikum ernst, indem es es zum Mitdenken auffordert. Es ist ein virtuoses Spiel zwischen Fiktion und Realität, genauer zwischen fiktiver Realität und realer Fiktion, aber auch zwischen fiktiver Fiktion und realer Realität. 


\section{II.4.b) Der Geburtstag oder The same procedure as every year}

Uraufführung dieses Stückes war am 11. Februar 1990 zur Eröffnung des neu gegründeten Studiotheaters des E.T.A. Hoffmann Theaters in Bamberg. Bamberg, so Lewandowski, habe, als er dort anfing, kein Studiotheater gehabt, und dieses Studio ist kurz nach seiner Übernahme der Intendanz von ihm gegründet worden. Bis heute ist es ein wichtiger Teil des E.T.A. Hoffmann Theaters.

Rainer Lewandowski erzählte anläßlich meines Interviews mit ihm über die Entstehung des Stückes: „Es ist ein Stück, Der Geburtstag, das sich mit der Geschichte im Dritten Reich und der Nachkriegszeit befaßt, unter deutscher und ausländischer, englischer Sicht, Sieger und Besiegte, ein Einpersonenstück über das Leben einer Frau. Das haben wir zur Eröffnung unseres Studios aufgeführt” (I, 75).

Rainer Lewandowski schrieb das Stück Der Geburtstag bewußt in lockerer Anlehnung an das Stück Dinner for One, das man in Deutschland zu Silvester regelmäßig mehrmals im Fernsehen sehen kann.

Maria, die Hauptfigur des Stückes, hat Geburtstag und sie will ihre Geburtstagsfeier auf Video aufnehmen. Ihre beste Freundin Judi, die in England lebt, kann nicht kommen, und Maria will ihr das Video von ihrer Geburtstagsfeier mit ihren Freundinnen schicken. Lewandowski erklärt, daß das Videogerät die situative Motivation für Maria ist, überhaupt zu reden, mit Judi zu sprechen. Richard, ihr Sohn, der in großer Eile ist, stellt das Videogerät für sie auf, erklärt ihr kurz dessen Benutzung und verläßt sie. Maria ist an ihrem Geburtstag allein, ohne ihren Sohn. Sie hofft, daß ihre Freundinnen kommen, aber sie hat nur zwei Stück Kuchen, sie scheint also die meisten 
nicht wirklich zu erwarten. Der Zuschauer sieht, das ist das Besondere an der Bühnensituation, wie Maria auf der Bühne agiert und gleichzeitig das, was die Kamera davon aufnimmt. Im Fernseher merkt man, daß der Aufbau der Möbel dem gleicht, wie man ihn aus Dinner for One kennt. Maria spielt für die Kamera, für andere eine Rolle, die sie aber eigentlich selbst nicht glaubt. Alles was geschieht und alles was sie sagt, wird unbarmherzig von der Kamera aufgenommen, zum Teil ,spielt' sie direkt für die Kamera, in beinahe selbstzerstörerisch ehrlicher Weise. Es gibt auch Dinge, über die sie nicht sprechen will, wie z. B. am Anfang, als jemand sie am Telefon über ihre Erlebnisse im Dritten Reich interviewen möchte: „Nein! Ich sage nichts. Ich sage dazu nichts. Ich habe es Ihnen bereits mitgeteilt, junges Fräulein. Ich möchte nicht an Ihrer Arbeit über ,Frauen unter dem Hakenkreuz' mitarbeiten. Nein. Ich möchte darüber nicht sprechen. Ich habe keine Angst vor der Erinnerung! Nein. Ich habe die Zeit miterlebt. Das genügt mir. Ich habe außerdem zu tun..." (Geburtstag, 4).

Maria äußert sich über ihre Freundinnen. Sie bewundert Judi am meisten, da diese unabhängig ist und sich nicht von Männern unterdrücken lässt. Judi bestimmt ihr Leben selbst, wohingegen Maria sich von Adolf, ihrem Mann, (und dem ,Führer' gleichen Namens!) abhängig macht. Einerseits ist sie von ihrem Mann, der einarmig aus dem Krieg zurückgekehrt ist, abhängig. Sie erzählt, wie hungrig sie nach dem Krieg war und wie Adolf ihr Essen verschaffte: „Ich hatte Hunger, verstehst du Hunger! Und jetzt zeigte sich, wie praktisch der Krieg war, denn Adolf wußte sofort, was zu tun ist, wenn's um's Überleben geht.....Adolf hat mich satt gemacht” (14). Adolf hat die Fähigkeit, sie zu versorgen, zumindest um sie, was das Materielle anlagt, zu befriedigen. 
Andererseits betreibt sie auch freiwillige Selbstaufgabe: sie umsorgt ihren Mann und den Sohn und erntet keinen Dank dafür. Der Mann betrügt und verläßt sie, später macht er sie zudem noch verantwortlich für seine eigenen Unzulänglichkeiten. Der Sohn, bereits erwachsen und beruflich erfolgreich, zieht seine Karriere und ein Treffen mit einem Kunden dem Zusammensein mit der Mutter an deren Geburtstag vor. Maria zieht bittere Bilanz, als der Sohn absagt: „Richard! Wie immer! Ich habe es geahnt. Man bringt sie zur Welt, zieht sie groß - dann sind sie weg. Hauen ab, kümmern sich nicht mal....Sein Geschäft geht ihm vor. Sein Geschäft! Und wer hat ihm das Geschäftliche beigebracht?" (15)

Später, als Maria und Adolf sich wieder einmal versöhnen, kaufen sie sich eine Vespa, einen Motorroller, auf Kredit, um in Italien Urlaub zu machen. Maria verkauft sich an ihren Chef, um die Vespa finanzieren zu können. Aber Adolf bricht sich den Arm und so können sie nicht fahren. Selbst an ihrem „Liebes-Verhältnis” hat sie keine Freude. Auch das war für sie ,Dienst“, ,Arbeit‘. Leben heißt für sie: ,sich aufgeben’, Zumutung, es wird ihr angetan, sie ist Opfer der Verhältnisse.

Bis es eines Abends, Silvester, geschieht: Als alle sich auf einer Party betrinken, macht Adolf Maria Vorwürfe: „Die schönsten Jahre meines Lebens im Schützengraben... pleite! Weg! Futsch! Daran bist nur du Schuld! .... Du taugst zu nichts! An mir hätte er, Adolf, nie eine Stütze gehabt, und nur weil ich nicht aufgepaßt hätte... “ (24).

Maria berichtet weiter über diesen Silvesterabend: „Adolf sprach sich weiter aus, erzählte alles über seine Affaire mit Marianne, war stolz auf ihre Schwangerschaft, auf ihre aufgeblähte Pauke. Verglich mich ständig mit ihr. Körper. Leben. Bett. Alles“ (24). 
Damit hat Adolf das Maß für Maria überschritten. Sie beschließt, sich zu befreien und vergiftet ihn. Später hilft Judi ihr, den Mann verschwinden zu lassen: er wird von beiden im Keller, der gerade renoviert wird, ,verfliest', im wahrsten Sinne des Wortes, unter den Kellerfliesen vergraben. Nur der Kopf paßt nicht hinein. Den verbirgt Maria im Schrank. Als Maria während ihrer, Geburtstagsfeier' betrunken ist, sie trinkt, wie in Dinner for One für alle nicht vorhandenen Gäste, holt sie den Schädel aus dem Schrank. Von da an betrinkt sie sich mehr und mehr, denn es kommt ihr immer deutlicher zum Bewußtsein, daß sogar diese Mordtat ihr Leben nicht wirklich befreit hat, denn sie hat weitergemacht sich aufzuopfern, wenn auch diesmal für Richard, ihren Sohn.

Im weiteren Fortgang des Stückes erinnert Maria sich, was sie alle an dem berüchtigten Silvesterabend im Fernsehen gesehen hatten: Dinner for One, und nun fängt Der Geburtstag an, Dinner for One zu ähneln. Maria fängt an, über den Kopf ihres Mannes zu stolpern, den sie, als das Telefon klingelte, beiläufig auf den Boden gelegt hatte. In Dinner for One ist ein Löwenkopf an einem Fell der ständige Stolperstein. Lewandowski erläuterte dazu, daß er wollte, daß man mit dieser Frau Mitleid hat, sehr viel Mitleid und sie sehr bedauert, aber es sollte nicht sentimental werden. Deshalb diese Zitate aus Dinner for One, ein Stück, das unbestrittenermaßen als komisch gilt, zum Lachen zwingt. Das Lachen wird aber ständig gebrochen an Marias aktueller Situation, bleibt also im Halse stecken. Lewandowski erklärt weiter, er habe bewußt das Stück ins Makabre geführt und absichtlich weiter von der Realität entfernt. Der Schädel des Ehemannes macht seinen besonderen Eindruck auf die Zuschauer. Aber einmal sei bei einer Vorstellung das Makabre noch makaberer geworden durch ein Versehen der Schauspielerin. Die Schauspielerin, so erzählte mir Lewandowski „stolperte einmal nicht, 
sondern stieß an den Kopf an, so daß dieser wegrollte und hinter der Bühne verschwand. Weg war er, die Leute fanden das auch toll, denn die Schauspielerin hat mit einem gekonnten Hackentrick den Kopf zufällig wieder an die gleiche Stelle zurückgekickt. Jubel, denn die Besucher wissen ja nicht, was inszeniert war, und was nicht" (I, 76f.). Diese Lacher, so meint Lewandowski, wären ihm zu viel gewesen. Man kann das „Übersteigern” auch übersteigern.

Lewandowski arbeitet hier wieder mit der Nähe zum Publikum, denn die Videokamera, in die Maria hineinspricht, ist ja in Wirklichkeit das Publikum. Das Publikum, wie bereits gesagt, sieht auch in einem Fernsehgerät, was Maria spielt. Lewandowski erklärte das folgendermaßen: „Das Schöne war, und deswegen haben wir das so gemacht, daß man über die Videokamera, die lief, immer auf dem Bildschirm das sah, was auf der Bühne passierte. Alles spielte sich immer auch zugleich auf dem Bildschirm ab und die Perspektive war so gewählt, daß dieser Tisch im Fernsehen, nicht auf der Bühne, so aussah, wie man es aus dem Fernsehen kennt” (I, 75f.). Die Betrachtungsweise wurde noch während des Betrachtens medial gebrochen. Es wurde jedem bewußt, daß das Fernsehen nur einen Ausschnitt aus dem , wirklichen` Leben zeigt. Am Anfang belügt Maria nicht nur sich selbst, sondern auch ihre abwesende Feundin Judi, indem sie so tut, als wäre sie von Freundinnen umgeben. So ist es zu sehen im Fernsehbild, aber das reale Leben der Party zeigt, neben dem Fernsehschirm, wie einsam Maria in ,Wirklichkeit‘ ist. Je mehr sie über ihr Leben und ihre Vergangenheit erzählt, und je betrunkener sie wird, um so mehr läßt sie „die Katze aus dem Sack”. Die Videokamera und das Publikum werden ihr zum Gegenüber, dem sie alles anvertraut: Das Heiratenmüssen, die Misere der Ehe, die Abhängigkeit, die Selbstaufgabe, das 
Fremdgehen des Mannes, der makabere Mord. Und, wie Lewandowski im Programmheft schreibt:

Maria zieht schonungslos Bilanz über ihr bisheriges Dasein, und kommt dabei zu Erkenntnissen, die ihr die Ausweglosigkeit ihrer Situation zwanghaft vor Augen führen, und Maria, die sich, bis auf ein einziges Mal in ihrem Leben, nie gewehrt hat, wehrt sich, aber - wie immer - am falschen Objekt, nämlich an sich selbst. Maria, verstrickt in notwendige Lebenslügen, in ideologisch verbrämte Verklärungen ihrer mütterlichen Selbstaufgabe, Maria, die Unfähigkeit vor Augen, ihr Leben selbst aktiv zu gestalten, Maria verkörpert so das Bild der Frau, der Emanzipation nicht möglich war, weil sie damit das in ihr sozial verankerte Frauenbild hätte zerstören müssen. (Geburtstag-Programmheft, 4)

Der Ausgang dieses Geburtstages ist allerdings anders als der Ausgang ihres bisherigen Lebens, da sie sich all das Versteckte und „Verflieste” vom Herzen reden konnte mit Hilfe der Videokamera. Ob sie allerdings von diesem Prozeß lernt und ihr Leben ändert, bleibt offen. Vielleicht bringt sie sich um? Als ihr Sohn sie doch noch besuchen kommt, antwortet sie nicht auf sein Klingeln und Klopfen an der Tür. 


\section{II.5. Musicals}

\section{II.5.a) Mambo Mortale oder Der Notruf ist leider besetzt}

Mambo Mortale wurde 1989 in Detmold uraufgeführt und später vom Norddeutschen Rundfunk als Fernsehaufzeichnung gesendet. Dieses Stück richtet sich thematisch an Jugendliche. Es ist für ein Rock-Musical, im Gegensatz zu üblichen Produkten für die Altersgruppe, sehr politisch und sozialkritisch. Es handelt zwar von Beziehungsproblemen, aber auch von Drogen, Aids, Partnerwechsel, Arbeitslosigkeit, Problemen mit der Arbeitssuche, Problemen in der Arbeit, Sehnsucht nach Liebe und Dazugehören, Problemen mit den Eltern, von Massenmedien und Outfit-Imagefragen. Im Vordergrund steht deutlich das Problem der Isolation, Vereinsamung der Jugend in der Scheinwelt einer konsumorientierten Gesellschaft. Das Stück ist wie ein Hilfeschrei: Mambo Mortale oder Der Notruf ist leider besetzt. Keiner hört mehr dem anderen zu, keiner kümmert sich um den anderen, gleich wie lebensgefährlich die Lage ist. Alle Figuren in Mambo Mortale haben Schwierigkeiten, sich in der heutigen Gesellschaft anzupassen, ihren Platz in der Gesellschaft zu finden.

Die Jugendlichen des Stückes haben jedoch ein gemeinsames Interesse: sie treffen sich in einer Tanzgruppe, aber die persönlichen Probleme schleichen sich auch dort ein und zerstören die Gruppe schließlich.

George, als der Älteste der Tanzgruppe und auch deren Tanzlehrer, versucht, den Jugendlichen zu helfen, aber er hat die schwelenden Probleme selbst zu lange ignoriert, um noch ernstgenommen zu werden. Seine Versuche, die jungen Leute zu versöhnen, scheitern. George ist selbst eine verkrachte Existenz: er war Balletttänzer, verlor aber dann seine Stelle, wurde arbeitslos und schlägt sich nun mit Tanzstunden durchs Leben. 
Dann ist da Martina. Sie ist 19 und eine Auszubildende. Sie will kaufmännische Angestellte werden und hat Probleme mit ihrem Vorgesetzten, der seine Hände nicht von ihr lassen kann. Sie nimmt Drogen, denn sie fühlt sich ausgeschlossen und innerlich tot. Die Arbeitsstelle ist für sie eine Sackgasse und sie fühlt sich ausgenützt. Sie hat Gefühle für André, ihren Tanzpartner, aber sobald der sie erwidert und ihr bei ihrem Drogenproblem helfen will, stößt sie ihn weg und verläßt ihn für René. René, selbst drogenabhängig, ,,versorgt” sie mit Stoff. Am Ende sieht Martina die Ausweglosigkeit der Drogensucht, geht zurück zu André und versucht von den Drogen loszukommen.

Als nächste kommt Anja, sie ist 18 und ein Lehrling in einer Anwaltskanzlei. Dort ist sie, wie sie sich selbst beschreibt „Telefonistin und Empfangsdame”. Sie sieht brav aus während des Tages, außerhalb des Büros aber ist sie ein Freizeitpunk. Sie fühlt sich ebenfalls ,leer', ein Zustand, den sie kompensieren möchte. Sie stiehlt, um die Leere zu füllen. Sie wechselt ihre Frisur und Haarfarbe ständig, was anzeigt, daß sie nicht recht weiß, wer sie ist und was sie will. Manfred, ein Anwalt aus ihrem Büro, verliebt sich in sie, und sie ist am Ende bereit, dieser Liebe eine Chance zu geben.

André ist 21, hat Abitur und ist Wehrdienstverweigerer. Er sucht eine Arbeitsstelle, will aber mehr als nur einen Job. Er will eine lebenslange Aufgabe und stößt damit auf Unverständnis bei seinen Bewerbungsgesprächen. Er „,möchte einen Beruf als Lebensinhalt, nicht als Job. Ich möchte am Ende meines Lebens etwas wissen und können, das ich weitergeben kann, daß ich eine Aufgabe, einen Sinn in meinem Leben sehe, daß ich durch meine Arbeit etwas leisten kann, Glück empfinden" (Mambo, 51). Aber diese Einstellung hilft ihm nicht, eine Stelle zu bekommen. Seine Kritik am Personalchef, dessen Einstellung zur Arbeit ganz anders als Andrés ist, ist seiner 
Arbeitssuche auch nicht förderlich: „Der Personalchef sah aus wie ein Knabe, feist und glattwangig, faltenlos, ein Babypo, der sich nie in seinem Leben irgendeinen Gedanken gemacht hat, der ihm später hätte hinderlich werden können” (50). André bleibt lieber arbeitslos als sich selbst und andere zu belügen, um eine Stelle zu bekommen, in der er nach seinen Prinzipien nicht glücklich werden kann. André liebt Martina, er macht sich wegen ihrer Drogensucht Sorgen. Erst lehnt sie ihn ab, am Ende aber sieht Martina ein, daß André besser für sie ist als René, und sie beginnt, Andrés Gefühle zu erwidern und seine Hilfe zu akzeptieren.

Martin ist 23 und studiert Informatik. Er nennt sich einen „,strengen Logiker”. Auch er hält nicht viel von der Gesellschaft, die ihn umgibt: „Ich will ins Rechenzentrum dieser Gesellschaft. Aber je tiefer ich vordringe, desto schneller will ich wieder raus. Für mich ist die Gesellschaft wie eine große Berechnungsstelle, bloß, daß die meisten die Regeln, nach denen sie berechnet werden, erst erkennen, wenn sie sich schon verrechnet haben" (5).

Martin singt den Titelsong, „Mambo Mortale“ genannt, und er zieht am Ende die Bilanz über das Leben der Menschen: „Ich schaue hinein, in die Menschen hinein. Ich seh' Trauer und Ohnmacht, Intrigen und Zwietracht, seh Wut, Haß und Kampf - mein Herz kriegt 'nen Krampf” (70).

Martin ist der Einzige in der Gruppe, der Nicole gegenüber unvoreingenommen ist, als diese gesteht, positiv für Aids getestet zu sein. Martin bleibt bei Nicole und hilft ihr durch ihre schwierige Zeit.

René hat alles, was man sich wünschen kann, er ist 20 und versucht das Abitur zum zweiten Mal. Er hat wohlbetuchte Eltern, die ihm alles Materielle ermöglichen. Er 
weiß nicht, was er will, er will dem Konsum, dem er tief verhaftet ist, entfliehen und gerät auf den falschen Weg. Er nimmt Drogen und trinkt, um sich zu betäuben. Um seine und Martinas Drogenabhängigkeit zu finanzieren, begeht er Diebstähle und handelt mit Drogen. Es endet damit, daß René dafür verhaftet und in eine Entziehungsanstalt gesteckt wird, um seine Abhängigkeit zu bekämpfen. Aber seine Einstellung der Entziehung gegenüber ist negativ: „Bin jetzt auf Zwangsentziehung. Pillen auf Staatskosten. Aber die schaffen mich nicht. Ich bin doch keine Schnellreinigung... Martina kommt durch. Sie hat es verdient. Von mir weiß ich das nicht" (71). Der, der alles hat, rutscht in diesem Musical am tiefsten ab. Das Materielle ist nicht alles im Leben.

Nicole ist die Figur, die die Gruppenzusammengehörigkeit bis ins Innerste erschüttert und auf die härteste Bewährungsprobe stellt. Nicole ist sexuell aktiv und kann sich nicht entscheiden, welcher ihrer Freunde der Richtige ist. Sie war für eine Weile von den Tanzstunden abwesend und als sie zurückkommt, konfrontiert sie die Gruppe damit, daß sie positiv auf Aids getestet ist. Sie erwartet Verständis, erhält stattdessen die totale Ablehnung der Gruppe. Die Angst und Unsicherheit der Gruppenmitglieder vor der Ansteckung mit dieser Krankheit, die Nicole in sich trägt, schlägt Nicole ablehnend entgegen: „Sag mal, was willst du überhaupt hier? Hau ab! Ich will mich nicht für mein mickriges Leben abstrampeln, um dann an deinem Aids zu krepieren” (35). Später will die Gruppe das Essen nicht berühren, das Nicole und Martin für alle mitgebracht haben. Die Jugendlichen versagen gegenüber Nicole, indem sie ihr Freundschaft und Vertrauen verweigern, und das sogar dann noch, nachdem Nicoles zweiter und dritter Aidstest negativ ausfielen. Sie haben noch immer Angst vor der Ansteckung. Ein happy end gibt 
es nicht. Die gesellschaftliche Lage ist nicht so, daß sie, außer in der Literatur, ein happy end ermöglichte. Aber in diesem Falle verzichtet auch die Literatur darauf.

Typisch an diesem Stück Lewandowskis ist, daß die Darsteller auch hier das Publikum direkt ansprechen. Das Publikum ist der Zuhörer im wahrsten Sinne des Wortes, ein großer „Jemand”, der da ist, um die Probleme und Fragen erzählt zu bekommen. Es wird nicht um eine Stellungnahme gebeten, sondern nur darum zuzuhören, was ja im Endeffekt genau das ist, was die Jugendlichen wollen: keinen quick fix, sondern jemanden, der an ihnen wirklich interessiert ist und ihnen Gehör schenkt. Die Publikumsnähe ist auch dadurch unterstrichen, daß René versucht, wenn auch vergeblich, durch den Zuschauerraum zu fliehen. Ein Polizist kommt durch eine der Eingangstüren für das Publikum herein, stellt und verhaftet ihn. Dadurch wird die Handlung von der Bühne ins Publikum verlegt, das Publikum nahe ins Geschehen einbezogen, verliert seinen nur außerhalb stehenden, beobachtenden Charakter.

Lewandowski hält sich in diesem Stück nahe an der sozialen Realität, deren Probleme sich seit Entstehen des Stückes, wenn auch verlagert, aber doch noch verschärft haben. Bei den Problemen der Jugendlichen hat Lewandowski nicht übertrieben. Die Wahl der Gattung, dieses Stück zu einem Rockmusical zu machen, ist richtig, da man Jugendliche über Musik noch am ehesten und sicher leichter erreichen kann als durch bloße Worte. Die Musik ist durchweg ansprechend, mal langsam, mal schnell, passend zur gegebenen Situation. Als ich Rainer Lewandowski am 9. Februar 2001 per E-mail fragte, ob er glaube, mit diesem Stück sein Ziel erreicht zu haben, teilte er mir mit:

Das Stück lief vom ,Theater der Jugend“ in Hannover aus auf Tournee in ganz Niedersachsen und darüber hinaus mit etwa 500 Vorstellungen. Die 
CDs und Tonbandkassetten mit den Songs sind ausverkauft. Das Fernsehen hat einen Mitschnitt der Bamberger Aufführung gemacht. Das Stück wurde damals außerdem von den Niedersächsischen Ministerien für Kultur und Soziales finanziell unterstützt, außerdem vom Diakonischen Werk und von der Landesstelle Jugendschutz. Aufführung und Tournee fanden statt im Rahmen einer großen landesweiten Aktion zur Drogenprävention. Außerdem wurde das Projekt mit Workshops und Seminaren begleitet von der Landesstelle Jugendschutz und der Drogenberatungsstelle Niedersachsen.

Die Resonanz auf dieses Musical war von Seiten der Jugendlichen und von Seiten besorgter Eltern, Lehrer, Sozialarbeitern, usw. durchweg positiv. In seinem Vortrag: „Rainer Lewandowski. Eine zeitgemässe Stimme im deutschen Theater“ unterstreicht Schlunk, daß Lewandowski hier ein Thema gewählt habe, das die Jugendlichen, die sich in Deutschland oft ignoriert fühlen, interessiert: „Mambo Mortale bestätigt nicht nur das Ausmaß der Probleme, denen Jugendliche heute ausgesetzt sind, sondern es schafft einen therapeutischen Raum für ein jugendliches Publikum und ermutigt es, nach konstruktiven Antworten zu suchen" (Schlunk, 4). 


\section{II.5.b) Ich, Marlene}

Ich, Marlene wurde am 24. April 1993 am E.T.A. Hoffmann Theater in Bamberg uraufgeführt. Den Text hat Rainer Lewandowski geschrieben, die Neukompositionen und die Orchester-Arrangements der Songs sind von Mathias Christian Kosel, der auch die musikalische Leitung übernahm. 1994 wurde Ich, Marlene vom Bayerischen Rundfunk fürs Fernsehen aufgezeichnet. Ich, Marlene wurde 1995 in München an der Komödie im Bayerischen Hof gespielt und Vorführungen dieser Fernsehaufzeichnung in West Virginia und Florida bildeten 1997 und 1998 Höhepunkte während Lewandowskis ersten Amerikabesuchen im Zusammenhang mit dem Kulturaustausch zwischen dem E.T.A. Hoffmann Theater und der Universität von West Virginia. Die folgenden Städte haben das Musical nachgespielt: Stadttheater Ingolstadt (1994), Gablitz bei Wien (1996), Bühnen der Stadt Bielefeld (1997), Komödie Frankfurt (2000). Ich, Marlene wurde ins Englische, Französische und Russische übersetzt.

Das Musical Ich, Marlene überspannt einen Zeitraum von 70 Jahren und erzählt mit Liedern und Texten Aspekte des Lebens von Marlene Dietrich. Rainer Lewandowski schreibt im Vorwort des Programmheftes:

Die biographischen Stationen der Marlene Dietrich stehen weniger für sich selber oder für die unverbrüchliche Treue des biographischen Chronisten, vielmehr sollen sie ein Beispiel sein, ein Beispiel des Lebens und des Umgangs mit und in der deutschen Geschichte seit dem ersten Weltkrieg bis in die siebziger Jahre ... (Marlene soll) Bezugsperson der deutschen Haltung zur deutschen Geschichte sein, deren Kernstück in 
diesem zu Ende gehenden Jahrhundert zweifellos der Nationalsozialismus und seine Folgen sind (Marlene-Programmheft, 6 f.).

Mit vielen bekannten Liedern, Träumen und Erzählungen verschiedener

Abschnitte aus Marlene Dietrichs Leben wird auch der Geist und die Stimmung der Zeit, in der sie lebte, illustriert. Das Publikum erlebt hier, in Lewandowskis Worten, ein Musical, ,einmal anders, das Musical als Möglichkeit, mit der Musik der Zeiten die Zeiten zu erzählen“ (8). In Ich, Marlene findet sich wieder die für Lewandowski so charakteristische Vermischung von Realität und Illusion, die für das Publikum oft schwer durchschaubar ist. Substanz des Musicals sind Geschichte und Sozialkritik, was dem Musical mehr als bloßen Unterhaltungswert verleiht. Im folgenden sollen diese Punkte: Realität - Illusion, Geschichte und Sozialkritik besprochen werden.

Das Stück beginnt mit einer Rahmenhandlung. Anfang und Ende zeigen die alte Marlene, die völlig vereinsamt in ihrer Pariser Wohnung sitzt und einem Sekretär ihre Lebenserinnerungen diktiert.

In einer der ersten Szenen über Marlenes Kindheit wird auf ein Gedicht von Ferdinand von Freiligrath hingewiesen, das einen persönlichen Bezug zu Marlene hat, da deren Mutter dieses Gedicht, mit prächtigen Buchstaben geschrieben und hinter Glas gerahmt, in ihrem Wohnzimmer hängen hatte:

O lieb, solang du lieben kannst!

O lieb, solang du lieben magst!

Die Stunde kommt, die Stunde kommt, Wo du an Gräbern stehst und klagst! ... (11) 
Einige bedeutende Personen aus Marlenes Leben machen kurze Bemerkungen über sie und vermitteln den Eindruck einer selbstbewußten Frau: „Ich weiß nicht zu wem ich gehöre. Ich glaub, ich gehöre nur mir ganz allein“ (Marlene, 5). Dann wird Marlenes Kindheit vorgestellt, ihre erste Liebe, der Vetter Franz und ihre strenge Erziehung. Es bleibt hier nicht bei oberflächlicher Biographie, sondern Geschichte und Sozialkritik kommen hinzu. Geschichte wird hier geschickt mit bekannten Liedern aus der jeweiligen Zeit untermalt:

Gesang: Untern Linden, untern Linden

Gehn spazieren die Mägdelein.

Wenn du Lust hast anzubinden, Dann spaziere hinterdrein.

Trio: Deutschland verliert: ein Drittel seines Bodens und 6,5 Millionen Einwohner! Ein Drittel seiner Kohlenvorräte und drei Viertel seiner Eisenerzvorkommen! ...(Gesang) Knallt ab den Walther Rathenau, die gottverdammte Judensau! ... 114000 Deutsche wandern aus nach Amerika!

Gesang: Wer wird denn weinen, wenn man auseinandergeht.

Wo an der nächsten Ecke schon die andre steht. (10)

Marlene wächst in dieser unsicheren und turbulenten Zeit auf und wird Schauspielerin. Sie spricht Max Reinhardt vor, lernt Rudolf Sieber vom Film kennen und verliebt sich in ihn. Die beiden heiraten, haben eine Tochter, Maria. Für den Moment sieht es so aus, als habe Marlene ein ganz normales, bürgerliches Leben. Dann kommt die Wende: Marlene stellt sich Josef von Sternberg vor und erhält die Rolle der Lola in dem Film Der blaue 
Engel als Partnerin von Emil Jannings. Dieser Film macht sie von einem Tag zum anderen berühmt und Paramount bietet ihr einen Vertrag für sieben Jahre in Hollywood. Sie geht ohne ihre Familie nach Amerika, ihre Karriere in den Staaten ist ihr wichtiger als das Familienglück.

Sie hat Erfolg in Amerika, aber während ihres USA-Aufenthalts bricht der Krieg in Europa aus. Sie übt öffentlich Kritik am Hitlerregime, vor allem wegen dessen Behandlung der Juden. Als sie in der deutschen Botschaft um eine Paßverlängerung bittet, wird sie vom Grafen Welczeck im Namen Hitlers umworben:

Ihr Paß wird selbstverständlich ohne weiteres verlängert. Nur eine Kleinigkeit wäre da noch vonnöten...

Sie kehren zurück nach Deutschland. Ich verspreche Ihnen einen triumphalen Einzug durch das Brandenburger Tor.... Ein einziges Wort des Führers und alle Ihre Wünsche werden erfüllt. Sie werden die ,Königin` des deutschen Films..., falls Sie bereit sind, zurückzukehren... (33)

Dies ist ein geschichtlich hochinteressanter Moment: Marlene wird von Hitler umworben, sie lehnt jedoch Versprechungen von ewigem Ruhm und Triumph ab und wählt stattdessen die amerikanische Staatsbürgerschaft. Ein Schlag ins Gesicht für die Nazis. Nicht nur lehnte sie den Aufstieg in der deutschen Filmindustrie zu einer „deutschen Königin des Films“ ab, sie trat später obendrein noch für die amerikanischen Soldaten in Shows an der Front auf, um deren Moral zu verstärken. Truppenbetreuung. Sofort reagierte die Propagandamaschinerie der Nazis, und sie wurde als Vaterlandsverräterin 
abgestempelt, eine Sichtweise, die viele Deutsche über Marlenes Verhalten während des Krieges heute noch teilen.

Als Marlene 1960 für ein Konzert nach Deutschland zurückkehrt, wird sie zwar offiziell von den Politikern umworben und geehrt, aber während ihres Konzerts wird sie vom Publikum ausgebuht und als Verräterin beschimpft:

Sie gehören gelyncht! Schämen Sie sich!

Verräterin! Kriegsverbrecherin! Go home! Hau ab!

Marlene raus!

Vaterlandsverräterin!

Und sonst gar nichts!

Verräterin!

Marlene raus! (57)

Auch diese Situation ist in dem Musical auf formal besondere Weise dargestellt. Die Grenzen zwischen Realität und Fiktion werden verwischt. Tatsache ist, daß das deutsche Publikum Marlene ausgebuht hat, Illusionsmittel ist, daß Lewandowski Schauspieler während der Vorführung von Ich, Marlene in Zuschauerreihen hat sitzen lassen, die dann aufstehen, das Konzert unterbrechen und, verstärkt von von außen kommenden Demonstranten, gegen Marlene protestieren. Die Folgen dieser Verwischung von Realität und Fiktion erklärt Lewandowski folgendermaßen: „Es hat durchaus Aufführungen gegeben, in denen Leute diese Demonstration nicht als eine vom Theater inszenierte begriffen haben, sondern mit eingestimmt haben im Chor der Empörer gegen Marlene“"(I, 56). 
In meinem Gespräch in Bamberg verdeutlichte Rainer Lewandowski die sozialkritische Tendenz dieser Demonstrationsszene und ihren Zusammenhang mit Zuständen im heutigen Deutschland, indem er erklärte, daß „der Schoß schon noch fruchtbar ist, aus dem der Nationalsozialismus einmal kroch. Das zu erkennen war eigentlich sehr bedrückend“ (I, 56).

Das Aktuelle dieses Themas ist auch gut dargestellt in der Traumszene, in der die Nazizeit nicht einfach reproduziert, sondern in einem Ballett in visuelle Form gebracht wird. Man habe, erklärt Lewandowski, eine in Ballett künstlerisch umgesetzte Form des Nationalsozialismus gezeigt, um die Nazirituale und -embleme nicht zu reproduzieren. Am Ende des Balletts seien alle tot und dann habe er „eingebaut, daß wenn vorne alle am Boden liegen, hinten ein Skinhead erscheint, der dann als einziger diesen Hitlergruß macht. Im Aktuellen scheinen die Wurzeln des Damals auf“"(I, 57).

Beeindruckend ist im weiteren Verlauf des Stückes auch, wenn Marlene im Gespräch mit der Garderobenfrau erwähnt, daß sie sich schäme, Deutsche zu sein. Damit spricht Marlene eindeutig für viele Deutsche, die in der Nachkriegszeit aufgewachsen sind und sich wegen der grauenerregenden Verbrechen, die im Dritten Reich begangen wurden, schämen Deutsche zu sein:

Die Tränen, die ich um Deutschland geweint habe, sind getrocknet. Immer, seit den grauenhaften Missetaten, die mich veranlaßt hatten, Deutschland den Rücken zu kehren, hatte ich mich schuldig gefühlt für das deutsche Volk. Jetzt mehr denn je. (Marlene, 61) 
Im weiteren Verlauf des Musicals wird das Leben der Dietrich und vor allem der Prozeß des Alterns auf eine Weise dargestellt, die die eigene Aktivität des Beobachtens beim Zuschauer anregt. Das spätere öffentliche Leben der Dietrich wurde nach der Filmphase die Konzertphase. Das Stück verdichtet sich scheinbar immer mehr zu einer Konzertsituation. Aber es ist nicht ein Konzert, es sind verschiedene Auftritte, zwischen denen oft Jahre liegen, Jahre des Alterns. So wird Marlene während einer scheinbar unterhaltenden Liedphase zunehmend älter. Ohne besondere Szenen, nur in Form der Darstellung eines immer gebrechlicher werdenden Körpers, der die immer kürzer werdenden Wege auf der Showbühne immer schwerer bewältigt. Schlunk schreibt in seinem Vortrag über Lewandowski, daß es manchmal schwierig ist für den Zuschauer, im Musical zwischen Fiktion - Marlene auf der Bühne -, und Realität - Marlenes Leben - zu unterscheiden: beides scheint identisch. Doch, so Schlunk, ,diese Ebenen scheinen nur identisch. In den Konzert-Songs liegt fiktive Zeit verborgen. Die persönliche Entwicklung der Dietrich wird durch ihren Altersprozeß während der Abfolge von Songs in verschiedenen Konzerten illustriert - ein Konzert über ein bis zwei Jahrzehnte sozusagen“ (Schlunk, 11).

Das Musical Ich, Marlene endet wieder in der Pariser Wohnung mit der alten Marlene. Wieder zitiert sie aus dem Gedicht von Freiligrath und sie singt, ineinander montiert, Liederzeilen, die ihre Einsamkeit und Trauer unterstreichen:

There will come a day,

Youth will pass away, And what will they say about me?

When the end comes, I know, 
They'll say: Just a gigolo,

And life goes on without me...

Was bleibt, ist die Einsamkeit...(Marlene, 69)

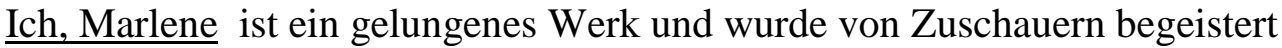
aufgenommen. Es ist kein leeres Unterhaltungsstück, sondern eine anspruchsvolle Darstellung des Lebens einer berühmten deutschen Persönlichkeit und gleichzeitig ein Stück Aufarbeitung deutscher Vergangenheit. Wieder wird das Publikum aufgefordert kritisch zu sein, mit sich selbst und mit der eigenen Einstellung zu einer Person wie Marlene Dietrich, die sich in einer Zeit, in der sich die meisten verführen ließen, gegen den Strom geschwommen ist. 


\section{II.5.c) Nur keine Panik! Ein Jahrhundert geht schnell vorbei...}

Eine - in mehrfacher Hinsicht - Sonderstellung in Lewandowskis Theaterschaffen nimmt die Produktion Nur keine Panik! Ein Jahrhundert geht schnell vorbei... des E.T.A.Hoffmann-Theaters ein. Dieses Musical entstand im Rahmen des kulturellen Austausches zwischen dem E.T.A. Hoffmann Theater und der West Virginia Universität. Obgleich es sich hier nicht um ein Stück von Rainer Lewandowski handelt, sondern um ein Kollektivprojekt des Theaterensembles, gibt es besonderen Einblick in Lewandowskis Arbeitsweise, der das Konzept für das Stück lieferte, Regie führte und für die Erstellung und den Einsatz des umfangreichen Videomaterials zuständig war. Das Musical sollte daher aus dieser Perspektive betrachtet werden. Es wurde am 3. Oktober 1999 in Bamberg uraufgeführt.

Danach, im Oktober 1999 ging das E.T.A. Hoffmann Theater auf eine zweiwöchige Tournee durch West Virginia mit Aufführungen in Morgantown, Charleston und Inwood. Jürgen Schlunk beschreibt Nur keine Panik! als ein multimediales Ensembleprojekt des E.T.A. Hoffmann Theaters, ,eine musikalische Revue über ein Jahrhundert deutscher Geschichte und deren Spiegelung im populären Schlager" (Schlunk, 13). Nach der Amerikatournee reiste das E.T.A. Hoffmann Theater mit dem Stück nach Rodez in Frankreich, im Rahmen der Partnerschaft und eines Kulturaustausches zwischen den Städten Bamberg und Rodez.

Die Entstehung dieser Revue ist insofern interessant, als sie zeigt, wie offen und willig Rainer Lewandowski ist, auf sein Ensemble einzugehen und es in die Entstehung eines Stückes miteinzubeziehen. In meinem Interview beschreibt er die Konzeption der Revue folgendermaßen: 
Die Revue haben wir als Kollektivarbeit gemacht. Das ist es, was ich mit dem kollektiven Gedanken meinte, mit der Gemeinschaft, mit der Freiheit von Menschen, ... jeder konnte sich hier einbringen, entweder als Schauspieler oder als Mitarbeiter oder teilweise sogar in der Regie, wir haben geminsam entschieden, was und wie wir es machen. Das war trotz der knappen Zeit eine sehr schöne kollektive Arbeit, in die wirklich von allen ständig neue Ideen eingebracht wurden. Auch bei dem Entwickeln des Manuskripts saß eine ganze Gruppe zusammen. Wir haben zusammengesessen und ... die Spielvorlage Stück für Stück zusammengestellt, Dramaturgie, Ausstattung, Schauspieler, Regieassistenz. (I, 36f.)

Lewandowski hier als Intendant eines Theaters, der sich nicht als Alleinherrscher sieht, sondern mit seinen Mitarbeitern zusammen Neues erarbeitet, jemand, der Demokratie nicht nur als theoretisches Konzept versteht, sondern auch in die Praxis umsetzt, in der alltäglichen Arbeit, und dort dieses demokratische Prinzip des Zusammenarbeitens auch wirklich einsetzt. Als ich Nur keine Panik! Ein Jahrhundert geht schnell vorbei... in Inwood sah, konnte man erkennen, daß die Schauspieler mit großem Engagement, mit Herz und Seele dabei waren, sie gaben eine ausgezeichnete Vorstellung: es war ihr Stück! Die Revue beginnt mit einer Aufzählung der guten, schlechten, und eher vermeintlichen Fortschritte dieses Jahrhunderts:

Wenn es diese gewaltigen Fortschritte auf allen Gebieten nicht gegeben hätte, würde - stellen Sie sich das bitte einmal vor - würde kein „Frischauf-den-Tisch-Backautomat“, kein „Golden Brown Toaster“ existieren 
...der Mond wäre immer noch nicht von Menschenfuß betreten, es gäbe keine Antibiotika,... keine Döner, keine Pizza,... es gäbe keine süße Schluckimpfung... Es gäbe keine Ölpest vor Alaska, keinen Ölteppich im Wattenmeer. Die Entdeckung der Radioaktivität bis zu deren todbringender kriegerischer wie friedlicher Nutzung wäre uns erspart geblieben. Und das alles entwickelte sich in schlichten 100 Jahren. Die Entwicklung ist nicht nur rasant, sie wird immer rasanter. (Panik, 2)

Die Revue ist voll dieses Wechsels zwischen Amüsantem und ernster Sozialkritik, der Anregung zum Schmunzeln. Was besonders heraussticht, ist die Nutzung der Schlager. Es sind solche Schlager ausgewählt, die entweder in einer spezifischen Weise zum Zeitgeschehen Stellung nehmen, oder es verdrängen wollen. Die Schlager unterhalten nicht nur, sie decken auch Mißstände auf, und seien es die eigenen. Unterhaltung, die auch das Gruseln lehrt.

Der Ursprungsgedanke war zum Beispiel der: Wir wollten zeigen, welche sozialen Probleme in der Gesellschaft vorhanden sind, z. B. die Wiederbewaffnung, die Atomisierung in Bomben und Kraftwerken, Umweltfragen usw., und wir wollten zeigen, wie die Schlagerbranche drauf reagiert: meistens mit Nonsens-Liedern, mit purer Ablenkung. Und wir wollten, daß die Leute erkennen, daß der Nonsens Nonsens ist. Das ist nicht immer gelungen. Es gab auch Aufführungen, wo ungehemmt mitgeklatscht wurde, sich amüsiert wurde und Leute unkritisch begeistert waren, weil sie die Lieder erkannten und mitgeschunkelt haben und in bester Stimmung waren. Es gab aber auch Aufführungen ..., natürlich auch 
Einzelne zwischendurch, die das schon gemerkt haben, denen also das

Klatschen und das Amüsieren sozusagen im Halse steckenblieb. (I, 68) Bestes Beispiel dafür ist die Szene, die die Zeit des Dritten Reiches darstellt, wo die Schauspieler auf der Bühne die Unterhaltungs- und Ablenkungslieder „Das kann doch einen Seemann nicht erschüttern“, „Lili Marlen“ und „Davon geht die Welt nicht unter“ singen und man im Hintergrund auf der Leinwand Bilder der Zerstörungen des Krieges, der Greuel der Konzentrationslager usw. sieht. Es werden hier also bewußt starke Kontraste zwischen der Leichtigkeit und Seichtigkeit der Schlagermusik und der Realität gegeneinander gesetzt. Rainer Lewandowski betonte, daß sie bewußt nicht die Nazizeit illustrierend nachgestellt hätten, wie das in vielen Filmen über das Dritte Reich gemacht werde. Er hielte die Imitation für gefährlich, da die Nazis das tägliche Leben und vor allem die Politik ,,ästhetisiert“ und dem Menschen damit die Verantwortung für das Leben und für die Organisation ihres eigenen Lebens abgenommen hätten: das gäbe den Menschen die Möglichkeit, nicht für sich selbst zu denken, sondern blind den Ritualen zu folgen:

Die Nazis, die in Filmen immer mit den schneidigen Uniformen auftauchen, immer zackig die Hacken zusammenknallen und ihre Arme heben, das hat einen Reiz, das hat einen Sog, das ist etwas, was eben nicht den Schrecken zeigt, sondern es vielen Leuten ermöglicht, sich einer Führung, die sie haben wollen, hinzugeben, mitzumachen, das Leben zu gestalten, auch wenn es zunächst nur durch äußere Formen geschieht. (I, 62) 
Diese Formen sind aber immer auch Ausdruck von Inhalten, geformten Inhalten. Es kam den Autoren darauf an, diese ästhetisierenden Formen der Nazi-Propaganda zu brechen. Anhaltspunkt dazu war ihnen Charlie Chaplin. Konsequenterweise tritt in der Revue dann auch ein Chaplin-Hitler auf, der nur Unsinnsworte sagt, wie in Chaplins Film Der große Diktator. Die Nazirituale werden nicht wiederholt, sondern stattdessen werden ihre Greueltaten auf der Leinwand gezeigt. „Und zwischendrin agiert Chaplin mit seiner Weltkugel, zeigt den Größenwahn, der hinter den Greueln steht“"(Panik, 25).

Nach der Darstellung der immer komplexer werdenden Nationalsozialistischen Durchformung der Gesellschaft - Machtübernahme, Fackelzüge, Bücherverbrennung, Fahnenweihe, Aufmärsche in Nürnberg, Autobahnbau, Konzentrationslager usw. - bis in den Krieg hinein, erfolgt dann das Zitat der gleichzeitig betriebenen Ablenkung von den Greueln der nationalsozialistischen Alltagsrealtät: die Durchhalte-Schlager der UfaWirklichkeit.

Das wiederum hat mit der Entwicklung der Massenmedien zu tun:

Goebbels hat ja den Rundfunk sehr forciert, hat auch sehr auf den Film gesetzt ... Der Unterhaltungswert der Schlager, die in diese Passage aufgenommen sind, „Davon geht die Welt nicht unter”, „Ich weiß, es wird ein Wunder geschehen" beeinflußte die Ideologie der Leute und bewegte sie, vom Realgeschehen wegzuschauen. Es hat ja eine lange Zeit gegeben, da man im Reich nicht unbedingt uneingeschränkt mitbekommen hat, wie es draußen an den Kriegsfronten wirklich aussieht. Dieses Erzeugen einer zweiten Realitätsebene ..., das wollten wir zeigen. (I, 64 f.) 
Nur keine Panik! Ein Jahrhundert geht schnell vorbei... wird nach dem Krieg nicht viel positiver in seinem Blick auf die Entwicklung der Gesellschaft in den neu gegründeten Staaten. Es zeigt knallhart, daß die Menschen nicht viel aus dem Elend der vergangenen Jahre gelernt haben, außer schnell zu vergessen und sich selbst zu betäuben. Deutschland wird als Konsequenz des Zweiten Weltkrieges geteilt. Diese Teilung, besonders in der politischen Anschauung, wird recht amüsant durch einen Vergleich der Rechtschreibung und des Urlaubs in Ost und West verdeutlicht:

Ost:

Pack nicht so viel ein. Noch sind wir vier Tage mit dem Trabi unterwegs. Den Wartburg kriegen wir erst in drei Jahren.

West:

Zuerst mit dem neuen BMW zum Flughafen, dann in den Flieger.

Bustransfer zum Hotel inklusive. Aussteigen - und der Urlaub beginnt. Ost:

Und Faßbrause für die Kinder. Ich freu mich schon auf die Sättigungsbeilage. Hoffentlich gibt's Kartoffeln und frisches Gemüse... West:

Ob's am Buffet wieder Austern Rockefeller gibt? Und die Sangria zur Happy Hour? (Panik, 53 f.)

Das Stück zeigt auch kritisch den Einfluß der neuen westlichen Kultur auf Deutschland, in das die westliche Industrie ungehemmt investiert hat, um im Laufe der Jahre daraus ihren Gewinn zu ziehen. So kamen die Musikbox - und damit die Musik - aus Amerika, der Petticoat, amerikanischer Konsum von Kleidung bis Fast Food. Nicht zuletzt gab es 
auch Wandlungen der Sprache, alles das sollte erfaßt werden. Als Beispiel wurde die Sprache der Liebe gewählt und vorgeführt, wie sie immer direkter wird, von ,Gestatten, gnädiges Fräulein‘ zu , Ich will dich ficken‘, ausgesprochen von der Frau. Gegen Ende der Revue ein kurzer Hoffnungsschimmer, ein neuer Aufbruch: die Wiedervereinigung Deutschlands. Zuerst gibt es große Euphorie, dann wird sich der Westen bewußt, daß er die ganze Wiedervereinigung finanzieren muß, und es ist aus mit der Euphorie:

Ossi:

Ja. Wer hätte das gedacht: Deutschland einig Vaterland. Und so schnell. Wessi:

Und? Geht es uns Wessis dadurch besser?

Ossi:

Ich finde ja.

Wessi:

Ich finde nicht! Solidaritätszuschlag, die Industrie wandert ab zu euch in den Osten, baut drüben neu auf, und bei uns fehlen die Arbeitsplätze. Ich bin seit drei Jahren arbeitslos. Jetzt krieg ich überhaupt nichts mehr... Wenn ich was zu sagen hätte... Man sollte die Mauer vielleicht besser wieder aufbauen... (68)

Nur keine Panik! Ein Jahrhundert geht schnell vorbei... ist sehr gut durchdacht. Die Frage, ob die Menschheit etwas aus der Geschichte gelernt hat, zieht sich indirekt durch das Stück. Die Antwort ist eher ein klares Nein als ein zaghaftes Ja, denn es gibt immer noch Kriege, immer noch Gewalt, immer noch Hunger, die Menschen lassen sich weiterhin an der Nase herumführen von schlauen Politikern und geldhungrigen 
Massenmedien, es geht offenbar immer so weiter. Aber: Nur keine Panik, ein Jahrhundert geht schnell vorbei... - ein kritischer Beitrag des Bamberger E.T.A.-Hoffmann-Theaters zur Jahrtausendwende. 


\section{II.6. Historische Stücke}

\section{II.6.a) Sie sind auch kein Bamberger, wie ich höre?}

Ein Fantasiestück wie in Callots Manier über E.T.A. Hoffmann.

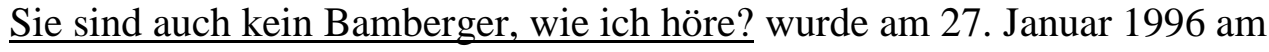

E.T.A. Hoffmann Theater in Bamberg uraufgeführt und erhielt 1996 den Preis für Darstellende Kunst der Bayerischen Akademie der Schönen Künste. Rainer Lewandowski verfaßte das Stück im Hinblick auf Hoffmanns 220. Geburtstag im Jahre 1996, der von der Stadt Bamberg besonders gefeiert wurde. Lewandowski erklärt in dem begleitenden Programmheft zur Uraufführung:

Das Stück hält sich sehr eng an die Ereignisse der Bamberger Jahre Hoffmanns zwischen 1808 und 1813. Es zeichnet gewissermaßen in den Szenen und Bildern den Lebens- und Leidensweg Hoffmanns nach. Die Texte des Stückes halten sich im weitaus überwiegenden Teil des Dialogs an Texte Hoffmanns, an seine Erzählungen, Romane, Aufsätze und Tagebücher. Über aller Phantasie schwebt auch hier das Authentische wie in Callots Manier. ,Sie sind auch kein Bamberger, wie ich höre?‘ sind die ersten Worte, die Hoffmann am 30. März 1809 an seinen späteren Bamberger Freund, Mäzen und ersten Verleger Carl Friedrich Kunz richtete, als sie sich zum ersten Mal in Bug begegneten. (BambergerProgrammheft, 12)

Auch, erläutert Lewandowski, dürfe bei einem Stück über Hoffmann die Musik Hoffmanns nicht fehlen. Aus diesem Grunde ist dieses Theaterstïck voll von Hoffmanns Musik und einiger seiner Zeitgenossen. Eine lohnende Idee, da viele Menschen, selbst 
musikgeschulte Menschen, sich oft nicht bewußt sind, was für schöne und vielseitige Musik Hoffmann komponiert hat, wie z.B. die Oper Undine, Arien, Duettini und Canzonetten, die Hoffmann für Julia Mark komponierte.

Das Stück Sie sind auch kein Bamberger, wie ich höre? umschließt eine Rahmenhandlung: es beginnt mit einem Prolog und endet mit einem Epilog. Im Prolog wird der sterbende Hoffmann dargestellt, der in von Schmerzen - ihm wird gegen die Rückenmarksdarre, die Haut entlang der Wirbelsäule mit glühenden Eisen gebrannt hervorgerufenen Visionen viele seiner von ihm erfundenen literarischen Figuren sieht: den Ritter Gluck, Olympia, Medardus, den Teufel, Coppola, Nathanael, Kreisler, Kater Murr, den Hund Berganza, Anselmus und das Apfelweib. Diese Visionen erscheinen in den Intermezzi erneut, auch im Epilog und sind, wie Kreisler sagt, ein Stück Hoffmanns: „Ich denke mir mein Ich durch ein Vervielfältigungsglas... In diesen Kreisen kreiselt sich der Kreisler... alter ego ... anderes Ich... und alle Gestalten, die sich um mich herum bewegen, sind Ichs...“ (Bamberger, 14). Während er dem Sekretär ein neues Stück diktiert, erinnert sich Hoffmann an seine Zeit in Bamberg und vor allem an seine große, unerfüllte Liebe: Julia.

Die Handlung beginnt in Berlin, wo Hoffmann arbeitslos und alleine weilt. Seine Frau ist schwerkrank in Posen zurückgeblieben und er hat die Nachricht erhalten, daß sein einziges Kind, Cecilia, gestorben ist. Der stellenlose Hoffmann will es mit der Kunst versuchen und bewirbt sich für die Stelle des Musikdirektors in Bamberg. Während Hoffmann seine Bewerbung schreibt, liest von Soden, der Theaterbesitzer, - im Stück geschieht das parallel und dadurch bekommt der Zuschauer ein Gefühl für Hoffmanns verzweifelte Lage und zugleich für die Situation des Bamberger Theaters - die 
Bewerbung Hoffmanns in Bamberg. Diesem ersten Bild folgt ein Intermezzo mit dem Apfelweib, das wie viele der im Stück enthaltenen Intermezzi prophetisch klingt: Apfelweib:

Ja renne - renne nur, du Satanskind! Ins Kristall bald dein Fall - ins Kristall!

Hoffmann:

Nach mir geworfene Steine sausten durch die Luft, bis ich glücklich hier anlangte, wo ich auf seltsame Weise mein Unterkommen bei dem Theater fand...

Apfelweib:

Ins Kristall bald dein Fall - ins Kristall! (20)

Hoffmann aber ist Erfolg in Bamberg nicht gegönnt. Das Bamberger Publikum reagiert mit bösartigem Gerede auf ihn: der neue Musikdirektor käme aus „Posen. Oder Warschau. Oder Glogau... Jedenfalls nicht von hier. Oder Berlin. Berlin, glaub ich. Auf alle Fälle Preuße. Preuße bleibt Preuße. Aber ich glaube gehört zu haben, er sei ein von Minister Stein verjagter Offiziant und in der Musik dilettiere er nur... soll in Berlin ohne jeglichen Erfolg... Pst. - Er kommt“ (26 f.). Nach der Vorstellung, die wegen des Dilettantismus der Musiker und Sänger ein Reinfall ist, wird Hoffmann ausgebuht und ausgezischt. Auch wird er dem bisherigen Musikdirektor Dittmayer „vor die Nase gesetzt" und der schafft es, mit Hilfe des Theaterensembles - beide lehnen Hoffmann wegen seiner neuen Ideen $a b-$, daß Hoffmann schon nach ein paar Wochen gekündigt wird. Von nun an muß sich Hoffmann mit Gelegenheitsarbeiten am Theater und Musikstunden durchschlagen. Hoffmann und Kunz treffen sich, Hoffmann spricht bei 
dieser Gelegenheit den Satz, den Lewandowski als Titel verwendete: „Sie sind auch kein Bamberger, wie ich höre?“ Die beiden finden viele gemeinsame Interessen und werden Zweck-Freunde.

Hoffmann, nun in Bamberg arbeitslos, muß sich mit Musikstunden über Wasser halten. Während dieser Musikstunden lernt Hoffmann Julia Mark kennen und verliebt sich in sie. Diese Liebe Hoffmanns zu Julia Mark zieht sich durch das ganze Stück. Julia, ein Mädchen von 13 Jahren, erwidert Hoffmanns Liebe nicht, sie wird wenige Jahre später von der Mutter mit dem Kaufmann Johann Gerhard Graepel verheiratet und verläßt Bamberg. Damit endet Hoffmanns direkte Beziehung zu ihr. Später jedoch wird Julias Name und Person in vielen literarischen Arbeiten Hoffmanns erscheinen, womit er seine Liebe zu ihr unsterblich gemacht hat.

Julia ist eine der wenigen begabten Musikschülerinnen Hoffmanns, der unter dem Philistertum der Bamberger Abendgesellschaften leidet. Die Bamberger Gesellschaft will die künstlerische Begabung der Töchter zur Schau stellen, und Hoffmann soll mit seinen Musikstunden dabei helfen. Zu diesen Menschen zählt auch die Geheimrätin Röderlein: ... ich bin sicher, Sie werden das schon machen. Sie werden das schon machen. Denken Sie daran, in drei Tagen wird man die jungen Damen fragen, ob sie etwas singen können, etwas Schönes, etwas sehr Schönes, versteht sich. Ich zähle auf Sie, Verehrtester, ich zähle auf Sie ... es wird eine schöne Abendgesellschaft, eine schöne ... wir machen das schon seit Jahren, wissen Sie, schon meine Eltern waren für ihre Abendgesellschaften berühmt... (49) 
Man will also keine Kunst um der Kunst willen, sondern Kunst, um sich selbst zur Schau zu stellen. Hoffmann durchschaut die Philister, muß aber mitmachen, da er ja von den Musikstunden, die diese Herrschaften ihm bezahlen, lebt.

Bald beginnt er zu schreiben und entwickelt seinen individuellen Hoffmannschen Stil. Hoffmann macht das Wechseln zwischen Wahrheit und Illusion in seinen Texten zu seiner literarischen Methode, und das macht ihn als Schriftsteller bis heute so interessant und anspruchsvoll für seine Leserschaft. Lewandowski findet, als er sich mit Hoffmann beschäftigt, aufgrund dieser ähnlichen literarischen Methode eine verwandte Seele in Hoffmann und schätzt ihn von da an um so mehr.

Für eine Weile geht es Hoffmann besser, als Franz von Holbein, ein Bekannter Hoffmanns, das Theater übernimmt. Hoffmann wird nun „Mädchen für alles“: Direktionsgehilfe, Architekt, Bühnenmaler usw. Seine Stelle als Musikdirektor bekommt er jedoch nicht zurück. Das folgende Gespräch erklärt aber, warum sich auch unter Holbein theatermäßig nicht viel ändern wird:

Kunz:

Sie haben nicht nur wieder regelmäßige Einkunft, sondern auch Einfluß. Hoffmann. Nutzen Sie ihn.

Hoffmann:

Sicher. Ich bin Direktionsgehilfe, Architekt, Kompositeur und Bühnenmaler; für lächerliche 50 Florin monatlich ... ja! ... aber kein Musikdirektor! Kunz! Kein Musikdirektor!

Kunz: 
Also, Teuerster, ... etwas Rücksicht auf die mißgünstige Stimmung des Publikums muß auch Holbein nehmen.

Hoffmann:

Nimmt er! Nimmt er! Und wie! Holbein spielt nach wie vor viel zu oft diese Kotzebue, Breitenstein, Ziegler und wie sie alle heißen ...

Kunz:

Wie Goethe in Weimar und wie die Bühnen in Berlin auch! - Etwas Rücksicht auf den Ungeschmack des Publikums muß jeder nehmen. Auch Holbein. (66 f.)

Kunz traktiert im Stück weiterhin das Bamberger Publikum, indem er Hoffmann zu erklären gibt, daß die Bamberger keine Komödien mögen, besonders der „gebildete Bamberger“ möge keine Komödie und vor allem schäme sich der „gebildete“ Bamberger davor, in der Öffentlichkeit zu lachen. Hoffmann und Kunz suchen nach einem neuen Stück. Kunz schlägt eins vor und erwähnt, daß die Presse dieses Stück für gut halte. Hoffmann erwidert darauf, daß er kritische Journale hasse, und er beurteilt die Meinung der Journalisten folgendermaßen: „Ihre Kunsturteile haben das bequeme Schema: ,Zur Zeit, als der wahre Geschmack in vollem Glanze herrschte, stand ich, sozusagen, an dessen Spitze, in mir konzentrierte sich daher der allein richtige Geschmack, ich bin es gewissermaßen selbst, mein Urteil darüber also das allein wahre; was ich daher für gut erkenne, ist wahrhaft gut, so wie das schlecht sein muß, was ich verwerfe"“ (68). Es liegt der Verdacht nahe, daß beides, die Vorurteile des Publikums und der Presse, sich nach Hoffmanns Zeiten vielleicht nur wenig im heutigen Bamberg gewandelt haben. Legt man diese Überlegung zugrunde, muß man feststellen, daß Lewandowski hohe Ansprüche an das Publikum stellt. Er will seine Theatergänger nicht nur unterhalten, sondern auch 
informieren und dadurch zu lebhaften Diskussionen auch über sich selbst anregen. Vor allem sein Theaterstück über Hoffmanns Leben in Bamberg habe einige Meinungsverschiedenheiten hervorgerufen, wie Rainer Lewandowski mir während des Interviews berichtete, da viele Bamberger der festen Überzeugung sind, daß Hoffmanns Aufenthalt in Bamberg ein positiver war und er dort die ganze Zeit über als erfolgreicher Musikdirektor tätig gewesen sei. Diese ,Legende " hat Lewandowski versucht richtig zu stellen. Mit wenig Erfolg. Die Geschichte ist aus Bamberger Sicht so auch bequemer und leichter zu ertragen. Hoffmann ist nun ,Sohn der Stadt`.

Als Hoffmann beschließt, Bamberg zu verlassen, beschreibt er seine Gefühle Bamberg und dem Theater gegenüber: „Meine einzige Zuflucht sind jetzt meine literarischen Arbeiten. Dem ... ganz in die vorige Gemeinheit zurückgesunkenen Theater habe ich mich ganz entschlagen. Keine Freunde, was ich hier in dem an genialen, herzvollen Leuten so armen Bamberg noch immer sehr vermisse“(116).

Bevor er der Theatergruppe des Joseph Sekunda in Dresden beitritt, beschreibt Hoffmann seine Zeit in Bamberg als „Lehr- und Marterjahre“ die er in Bamberg habe „abbüßen“ müssen - kein Kompliment für Bamberg - solche Gefühle von einem begabten Künstler, der kein Verständnis und keine Anerkennung, sondern Ablehnung, Spott und bittere Armut in dieser Stadt gefunden hat.

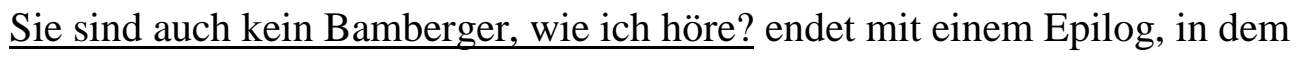
Hoffmann und seine Frau Mischa Bamberg verlassen, weitere Lebensstationen werden angedeutet, Hoffmanns literarische Figuren treten erneut wieder auf, als die Szene zurückblendet zum nun wieder todkrank in Berlin liegenden Hoffmann. Lindhorst (der Archivarius und Geisterfürst aus dem Märchen Der goldene Topf) und Julia erscheinen 
ihm, um ihn zu trösten. Hoffmann klagt, daß er nie in Atlantis gewesen wäre, wie der glückliche Anselmus (auch eine Figur aus Der goldene Topf), aber Lindhorst entgegnet Hoffmann, daß er auch einen „artigen Meierhof als poetisches Besitztum“ seines inneren Seins gehabt habe. Lindhorst beendet das Theaterstück mit seinen Worten aus dem Goldenen Topf: „Ist denn Seligkeit etwas anderes als das Leben in der Poesie?“(132)

Rainer Lewandowski wollte offensichtlich mit diesem Stück zwei Dinge erreichen. Erstens wollte er dem Bamberger Publikum nahelegen, nicht alles hinzunehmen, was allgemeine Auffassung ist und daher oft aus reiner Bequemlichkeit geglaubt wird, zweitens wollte er vielleicht Parallelen ziehen zwischen Hoffmanns Problemen als Theaterdirektor und seiner eigenen Situation als Intendant des Bamberger E.T.A. Hoffmann Theaters. Gibt es in unserer heutigen, modernen Zeit nicht genauso oft Menschen, wie zu Hoffmanns Zeiten, die Neues ablehnen aus dem einfachen Grund, weil sie ihre bisherige Denkweise nicht erschüttert haben wollen, die das Theatererlebnis haben wollen, um unterhalten zu werden und Modernes ablehnen, weil sie dann vielleicht ein bißchen umdenken müßten?

Lewandowski stellt das Publikum wieder vor eine eigene Entscheidung: wollt ihr unterhalten werden oder wollt ihr herausgefordert werden, wollt ihr passiv sein oder wollt ihr mitdenken? 


\section{II.6.b) Königsmord}

Königsmord wurde am 4. Juli 1998 als Teil der Calderón-Festspiele in der Alten Hofhaltung in Bamberg uraufgeführt. Diese Festspiele bestehen laut Lewandowski seit nunmehr 28 Jahren in Bamberg. Sie gehen auf die Tatsache zurück, daß Hoffmann, als man am Bamberger Theater war, zum zweiten Mal Calderón aufführte (nur Goethe in Weimar hatte Calderón davor gespielt). Anfangs waren die Gründer der Festspiele von Calderón so beeindruckt, daß man vor hatte, nur Calderón Stücke aufzuführen (Das wäre in Anbetracht seiner mehr als 200 Stücke auch möglich gewesen). Vor zwölf Jahren beschloß man jedoch in Bamberg, zu den Festspielen auch andere Stücke zu spielen und Calderón wird jetzt hauptsächlich nur noch zu Jubiläen aufgeführt, da das heutige Publikum ein breiteres Angebot vorzieht. ${ }^{2}$

Im Jahre 1998 gab es im Bamberger Historischen Museum eine große Ausstellung über das Geschlecht der Andechs-Meranier, und Rainer Lewandowski beschloß, als seinen Beitrag zu dieser Ausstellung, über den im Jahre 1208 in Bamberg geschehenen Königsmord zu schreiben. Während seiner Arbeit an Königsmord konsultierte Lewandowski den Mediävisten Bernd Ulrich Hucker, einen Spezialisten auf diesem Gebiet, der auch an der Ausstellung des Historischen Museums Bamberg über die Andechs-Meranier mitgearbeitet hatte. Bernd Ulrich Hucker schrieb auch einen Beitrag in Rainer Lewandowskis Buch Königsmord, das nach der Aufführung des Theaterstückes herausgegeben wurde.

Ungefähr ein Jahr verging zwischen der ursprünglichen Idee und dem Schreiben des Stückes, eine Zeit, die Lewandowski zur Forschung benutzte. Seine Nachforschungen

\footnotetext{
${ }^{2}$ Pedro Calderon de la Barca war ein spanischer Schriftsteller und Verfasser vieler Komödien und religiöser Stücke. Er war Hofdichter und Leiter des Hoftheaters unter Phillip IV. (1635-1653).
} 
über den Hintergrund der Geschichte waren sehr genau und er schrieb die Ergebnisse seiner Arbeit in dem Buch Königsmord und auch im Programmheft zur Uraufführung nieder. Damit wollte er sein Publikum informieren und auch dazu anregen, sich selbst noch weiter mit der Materie auseinanderzusetzen. Das Programmheft gibt z.B. dem Zuschauer eine Stammtafel der staufisch-meranischen Verwandtschaft, damit man sich die Zusammenhänge mit Hilfe der Personen besser vor Augen führen kann. Hier gibt es auch erklärende Beiträge von Rainer Lewandowski, Bernd Ulrich Hucker, und Ursula Vorwerk. Es handelt sich um ein umfangreiches und außergewöhnlich interessantes Programmheft. Im Zusammenhang mit der Aufführung wurden in Bamberg Vorträge über das Thema gehalten. Intensive Nachforschungen, Beiträge und Zitate helfen dem Zuschauer und Leser, Schlüsse zu ziehen, wie es damals hätte sein können. Wieder will Rainer Lewandowski das Publikum aktiv dabei haben, es soll nicht nur unterhalten werden, sondern sich selbst durch die Vorträge und das Lesen des Buches aktiv mit der Geschichte befassen. Die Möglichkeit, sich mit dem Königsmord aus dem Jahre 1208 über das Theaterstück hinaus zu beschäftigen, legt Lewandowski in die Hände seines Publikums, diesmal als Aufforderung, sich weiterzubilden und eigene Schlüsse über den Tatbestand zu ziehen.

Bernd Ulrich Hucker gibt in der Einleitung des Buches Königsmord zu bedenken: „Samstag, der 21. Juni 1208, früh nachmittags: Pfalzgraf Otto von Wittelsbach erschlägt König Philipp von Staufen mit dem Schwert. Daß diese Mordtat, eine , bis dahin bei den Deutschen unerhörte Tat', aus Privatrache geschehen sei, ist einer der gängigsten Topoi moderner Geschichtsschreibung“ (Königsmord, 6), aber, wenn man genauer hinsieht, ist das Ganze hochpolitisch verwoben und läßt sogar darauf schließen, daß noch andere als 
nur Otto von Wittelsbach an diesem Mord beteiligt waren. Königsmord gibt Einblick in ein Stück deutscher Geschichte - und geklitterter Geschichtsschreibung.

Rainer Lewandowski:

Wir wissen nicht genau, was wirklich wa(h)r. Deshalb bescheiden wir uns mit dem, was wahrscheinlich oder möglich ist, aber immer, trotz aller durch das Medium Theater notwendigen Konkretisierungen, mit dem Bewußtsein, verantwortungsvoll und verantwortungsbewußt mit dem zur Verfügung stehenden Material als Belege umzugehen.

Darin liegt die schlichte Grundverantwortung von jedermann, der etwas (auf)schreibt. (127)

Das Geschehen des Stücks - das ist ein interessanter Nebenaspekt - spielt in der Alten Hofhaltung, also genau dort, wo der Mord vor ca. 800 Jahren stattfand und wo nun die Aufführung stattfand. Die Zeit ist 1208 und die Menschen sind den Mächtigen untertänig, die jederzeit bereit sind, für ihre Rechte, für Land, den Thron und die Erhaltung ihrer Macht, um jeden Preis zu kämpfen:

In dieser wirren, von Gott vollen Zeit, Sind Könige noch zu kämpfen bereit, Interessen zu wahren, zur Not mit Gewalt.

So nehmen Intrigen politisch Gestalt.

Um eine derselben woll'n wir uns kümmern.

Und sollt es die Sicht unseres Weltbilds verschlimmern.

Das nehmen wir gerne in Kauf, Um zu begreifen der Welten Lauf. (31) 
Eine weithin bekannte Persönlichkeit, Walther von der Vogelweide, tritt im Prolog, Epilog, in Intermezzi und im Stück selbst auf, um als Spielansager dem Publikum wichtige Vorgänge im Stück zu verdeutlichen oder es zum Nachdenken anzuregen. Weniger bekannt ist, daß der historische Walther von der Vogelweide nicht nur Minnesänger war, sondern auch „,eilweise im Auftrage des Landgrafen von Thüringen ... scharfe, analytisch-politische Dichtungen“ (145) schrieb. Daran knüpft Lewandowski mit seiner Figur des Walther von der Vogelweide an. Im Prolog sagt Walther:

Es war einmal eine Zeit, da gab es zwei Könige.

Das waren, was jeder begreift, nicht zu wenige.

Das war einer zuviel.

Und ihres Streites Ziel?

Es ging um Macht und um Geld -

Damals wie heut auf der Welt. (33)

Hier liegt durchaus auch ein Bezug zur modernen Welt, in der sich in dieser Beziehung mancherorts nicht viel geändert hat. Lewandowskis sozialkritischer Fingerzeig auf die moderne Zeit findet sich mit gutem Grund wiederholt in diesem Stück.

Im ersten Akt unterhält sich König Philipp mit seinem Mündel Beatrix von Burgund über deren Hochzeit mit Herzog Otto von Andechs-Meranien. Dabei wird deutlich, daß zu jener Zeit eine Heirat nicht unbedingt ein Akt der Liebe und Zuneigung war, sondern eine politische Verbindung, die Macht, Ländereien und einen möglichen Anspruch auf einen Königsthron mit sich brachte. Marschall Heinrich von Kalden und Bischof Konrad von Speyer unterbrechen die Unterhaltung. Sie scheinen großen Einfluß auf Philipp zu haben, was die Fürsten ärgert, da beide aus niedrigerem Adel stammen. Sie 
sprechen mit Philipp über die politische Situation, vor allem über den Gegenkönig Otto IV. und die Stellung des Papstes beiden gegenüber. Bei dieser Gelegenheit warnt von Kalden den König Philipp vor Gefahr. Von Kalden befürchtet, daß Ekbert von Andechs-Meranien, Bischof von Bamberg, und dessen Bruder Markgraf Heinrich von Istrien Intrigen gegen Philipp planen:

Nun - wir sind in Bamberg, mein König.

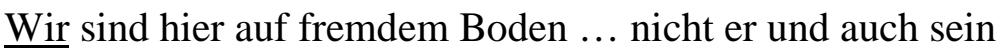

Bruder nicht, dieser durchtriebene Heinrich von Istrien ...

Denkt einmal darüber nach ...

Aus alten Feinden werden selten neue treue Freunde ... (42)

Von Kalden und der Bischof schlagen dem König vor, Ekbert für seine Papsttreue zu bestrafen, doch Philipp will damit nichts zu tun haben. Auch im Hinblick auf den bevorstehenden Kriegszug gegen Otto IV. ist Philipp wankelmütig, er zögert, wohingegen seine Ministerialen zur schnellen Tat raten.

Im anderen Lager treffen sich Bischof Ekbert, Heinrich von Istrien, Otto von Andechs und Hermann von Thüringen. Man freut sich über die bevorstehende Hochzeit und die damit verbundenen Vorteile für die Familie der Andechs-Meranier. Hermann von Thüringen hat jedoch schwere Bedenken, da er befürchtet, daß König Philipp und sein Heer auf ihrem Weg zur Schlacht mit Otto IV. Thüringen zerstören und ihn wegen seiner Abtrünnigkeit bestrafen werden. Er ist derjenige, der den Gedanken des Königsmordes zuerst äußert:

Mich trifft es zuerst! Zwar zieht Philipp gegen Otto, den Welfen, doch zieht sein Troß zuerst durch Thüringen! 
Das ist der Preis! Er braucht Verpflegung, Unterkunft, Frauen und Geld für seine Krieger. ...

Vier Tage sind es noch, und Thüringen wird in Schutt und Asche fallen ... Der blutigen Opfer wird es viele geben. ...

Ich weiß nur eines: Das Ziel muß Philipp heißen. Redet mit ihm. Redet nicht mit ihm. Tut, was ihr wollt... Philipp ist hier. In euren Mauern... es dürfte ein leichtes sein... (52-56)

Von diesem ersten Gedanken ausgehend, beschließt man nun, den König zu beseitigen. Der Mörder ist leicht zu finden: es ist Pfalzgraf Otto von Wittelsbach, der einen persönlichen Haß gegen Philipp im Herzen trägt, da der ihm für Treue in der Schlacht eine seiner Töchter versprochen und dann wieder entzogen hatte. Die Hochzeit findet im Bamberger Dom statt. Während der Feierlichkeiten gibt es recht gemischte Gefühle unter den Hauptfiguren, wie Walther von der Vogelweide zu interpretieren weiß:

12. Juni 1208:

Denkt dabei man an Niedertracht?

Im Dom ward grad das Wort gesprochen,

Das Ja-Wort Ottos und der Beatrix.

Die Liebe hat sich, scheint's verkrochen.

Ist nicht Gefühl dies’ Augenblicks.

Und trotzdem feiern alle froh.

Doch irgendwie und irgendwo, Lauert Zwietracht, lauert Mord: 
Welcher ist zuerst wohl fort? ...

Gute Minen, böses Spiel.

Keiner kennt des andern Ziel - (60)

Während der Hochzeitsfeierlichkeiten spricht Ekbert den König an und schlägt vor, die durch Heirat erworbenen Ländereien wie einen Braten untereinander zu teilen. Philipp lehnt den Vorschlag ärgerlich ab, wird aber von Walther von der Vogelweide vor seinem Geiz und der bevorstehenden Gefahr gewarnt. Der König hat eine ungute Vorahnung und zieht sich zurück. Ekbert und Heinrich von Istrien schüren den Haß des Wittelsbachers immer mehr, bis der die Tat vollbringt. Der Verdacht der Mitwisserschaft fällt sofort auf die beiden Brüder, und sie sehen sich gezwungen zu fliehen. Von Kalden wechselt zu Otto IV. über und bietet diesem Philipps älteste Tochter Beatrix zur Frau an. Damit bekommt Otto IV. alle Ländereien Philipps. Beatrix klagt Ekbert, Heinrich und Otto von Wittelsbach am Hof Ottos des Mordes an. Daraufhin verhängt der König die Reichsacht und Friedloslegung über die drei Männer. Von Kalden findet Otto von Wittelsbach und enthauptet ihn. Ekbert wird vom Papst begnadigt, da er selbst Ekberts Beistand braucht für eine weitere Intrige - diesmal gegen Otto IV. Später wird auch Heinrich von Istrien von Friedrich II. begnadigt. Allerdings wurde deren Unschuld niemals bewiesen, der Papst schob Verfahrensfehler bei der Gerichtsverhandlung vor.

Soweit zu Königsmord, einem großen Erfolg in Bamberg, einem Stück das, wie bereits erwähnt, ein Stück Bamberger Geschichte aufarbeitet. Allerdings haben sich einige Bamberger darüber aufgeregt, daß hier offenbar dem Bischof Ekbert Mitverantwortung an dem politischen Mord gegeben wurde. Das ist ein heikles Thema für die Bischofsstadt, da Ekbert für die Wiederherstellung und den heutigen Zustand des 
Bamberger Doms verantwortlich war. Rainer Lewandowski erklärte mir, daß die gängige Meinung einiger Affrontierten war: selbst wenn es so gewesen wäre, dann sollte man es nicht sagen und schon gar nicht ein Theaterstïck daraus machen.

Lewandowski besteht aber darauf, daß die Freiheit der Kunst darin bestehe, „Motive des Handelns ihrer Figuren, wenn sie quellenmäßig nicht beweisbar sind, zu behaupten, ja - wenn nötig - auch zu konstruieren“ (125). Allerdings sei hier die Quellenlage so interessant, daß er den Schlüssen des Mediävisten Bernd Ulrich Hucker hätte folgen können. Auch meinte er, daß es egal sei, wie er das Thema behandelt hätte: wie er es auch immer gemacht hätte, wäre es falsch gewesen:

Läßt man alles offen, wird das Geschehen des zu schreibenden Stücks unkonkret, vielleicht spannungslos, uninteressant, von einigen wird gar der Vorwurf erhoben werden, er nimmt ja nicht einmal Stellung, ist feige. Nimmt er aber Stellung, gibt es sofort die anderen, die gerade das zum Vorwurf erheben: Behauptet Dinge, die gar nicht beweisbar sind. ... Also wieder einmal: Jedem kann man es nicht recht machen - und deshalb soll man es auch gar nicht erst versuchen. (125)

Auch in diesem Stück muß das Publikum selbst entscheiden, ob es die weit verbreitete Meinung annimmt, daß Otto von Wittelsbach der Mörder im Alleininteresse war, oder ob da vielleicht doch eine Verschwörung im Gange war, wie es Lewandowskis Theaterstück so spannend erzählt. Wieder eine andere Spielart zwischen Realität und Fiktion. 


\section{II.7. Das Neueste}

\section{II.7.a) Ich}

Dieses Stück wurde im Jahr 2000 verfasst und ist so neu, daß es bis jetzt noch nicht aufgeführt wurde. Hier geht es um ein ganz aktuelles Thema: Genversuche und Klonen, verpackt in einer Liebesgeschichte.

Die wissenschaftliche und politische Welt beschäftigt sich mit dem Thema der Gentechnik und die Diskussion darüber ist in vollem Gange: Wissenschaft und Fortschritt stehen im Konflikt mit Religion und Ethik.

Ein zu theoretischer Stoff?

Was aber, wenn dieses Thema mit persönlichen Schicksalen verknüpft wird?

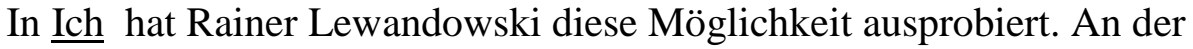
Konzeption dieses Stückes wird wieder einmal deutlich, daß der Autor sich nicht vor aktuellen Themen scheut und daß er, seinem aufklärerischen Anspruch folgend, das Thema Gentechnik und die damit verbundenen ethischen Fragen der Ethik kritisch betrachtet. Auf diese Weise kommt auch in dieses Stück eine aktuelle Sozialkritik, eine Hochrechnung von Wissenschaft, Wissenschaftsvermarktung, Karrieresucht von Wissenschaftlern; die Ansicht, was machbar ist, wird auch gemacht. Dennoch wird kein Urteil von der Bühne herab gefällt. Der Betrachter oder Leser wird sich selbst entscheiden müssen, hat einen eigenen Standpunkt zu wählen.

Zu Beginn des Stückes schaut der Autor in die Zukunft und spekuliert über die mögliche Entwicklung der Gentechnik und teilt dem Leser mit, daß „Großbritannien im Dezember 2000 als erstes Land Europas das Klonen von Embryos zu medizinischen Zwecken per Gesetz erlaubt hat“ (Ich, 2). Eine seiner Fragen: „Was geschieht, wenn die 
ersten geklonten Menschen unter uns weilen werden?“`(2) wird im Stück Thema, die Antwort darauf wird aber zunächst nicht verraten.

Ein junger Doktorand stellt seinem Professor sein Forschungslabor vor und will ihn für sein Steckenpferd in der Forschung begeistern: die Gentechnik. Der Professor ist skeptisch, gibt ihm aber freie Hand, einen Mitarbeiter oder eine Mitarbeiterin anzustellen, welche(r) dem Doktoranden bei erweiterten Forschungen behilflich sein könnte. Der Doktorand gibt die Stelle einer jungen Frau, die selbst großes Interesse an der Gentechnik hat. Die beiden verlieben sich ineinander. Ihre gemeinsame Forschung ist auch erfolgreich, sie klonen eine Maus, diese Klonung und damit auch weitere Experimente in der Genforschung werden aber vom Professor und dessen Assistenten aus ethischen Gründen abgelehnt. Der Professor mag die Idee nicht, daß man mit der Gentechnik Gott spielt und der Assistent hat mehr private Gründe: er ist selbst in die junge Frau verliebt und sieht in dem Doktoranden einen persönlichen und beruflichen Rivalen. Aber momentan hat er keine Chancen. Die junge Frau und der Doktorand sind zusammengezogen und sie bemerkt, daß sie schwanger ist. Doch als sie ihm die freudige Nachricht bringt, kommt er mit einem Geständnis, das die junge Frau völlig aus der Bahn wirft: er selbst sei ein Klon, entstanden, geboren aus einem Versuch, den ihm unbekannte Wissenschaftler (vielleicht seine Eltern?) gemacht haben. So fortschrittlich wie sie sich im Beruflichen und in ihrem Denken gezeigt hat, sobald die Angelegenheit sie persönlich betrifft, nämlich den Vater ihres ungeborenen Kindes und damit ihr Kind, reagiert sie mit Entsetzen und Ablehnung:

Ich glaube: ich spinne!

Wie soll denn das gehen? 
Ist das Kind gesund?

Kann es überhaupt gesund sein?

Was ist das überhaupt für ein Kind...

Ist das Kind auch ein Klon?

Was hast du dir eigentlich dabei gedacht?

Willst du mir einen Klon anhängen?

Ein künstliches Wesen?...

Missbraucht hast du mich! Missbraucht! (53)

Sie verläßt ihn und ist im Zweifel, ob sie das Kind behalten oder abtreiben will. Sie spricht mit dem Professor, um sich Rat zu holen, aber der kann ihr auch nicht helfen, da er mit der ganzen Idee selbst Probleme hat: „Da sitzen wir, gefangen in unserer eigenen Wissenschaft. Zerrissen zwischen ethischen Empfindungen und wissenschaftlicher Neugier. Zwischen Liebe und Verstörung. Zwischen natürlichen biologischen Abläufen und gezielten Eingriffen in dieselbe Natur“ (70).

Der Doktorand und die junge Frau beschließen ihre Beziehung aufzulösen und der Doktorand möchte, daß sie das Kind auch abtreibt, da er denkt, daß sie nie dazu fähig sein werde, ihre Zweifel über ihn und über das Kind positiv aufzuarbeiten. Etwas später erzählt ihm der Assistent, daß die junge Frau nun zu ihm gezogen sei und das neue Paar sogar schon bald ein Kind erwarte. Der Doktorand erfährt nun, daß der Assistent möglicherweise weiß, daß das Kind gar nicht von ihm, sondern von dem Doktoranden sein könnte, und daß der Assistent sich entschließt, aus Gründen der eignen Karriere, Kapital und wissenschaftlichen Ruhm aus der Existenz des Kindes eines Klons zu schlagen. Assistent: „Vielleicht führe ich ja nur zu Ende, was Sie sich beide nicht zu 
trauen wagten... Guten Abend zusammen“ (79). Die Ethik der Wissenschaft wird auch durch Karrieredenken mitbestimmt.

Ein heikles, aktuelles Thema, spannend in ein ansprechendes Stück verpackt, bei dem es sich nicht nur um das Sachthema, sondern auch um mögliche persönliche Folgen des Klonens handelt. Ansatzpunkt ist die Annahme, daß das Klonen nicht erst bevorsteht, sondern schon stattgefunden hat: vor einigen Jahren. Insofern ist das Stück, das in Form und Inhalt zunächst so scheint, als behandle es nur die Gegenwart, bereits ein Stück Science Fiction.

Jeder hat sicher seine eigene Meinung zum Klonen, aber gleich welche Meinung man hat, dieses Stück gibt einem neu zu denken. Es geht nicht nur um das Klonen und dessen ethische Auswirkungen, Lewandowski hat das Stück auch mit Kritik an der Wissenschaft und der Ethik des Wissenschaftlers selbst versehen. Zum Beispiel kritisiert Lewandowski die Wissenschaft als in ihrem Kern unethisch, da sie den Verkauf von Nahrungsmitteln zuläßt, die sie selbst genmanipuliert hat, obwohl man nicht weiß, zu welchen Schäden das führen kann. Er kritisiert die Wissenschaftler selbst, die mehr an ihrem beruflichen Überleben interessiert sind als an dem, was gut ist für die Menschheit: Der Assistent äußert Bedenken gegenüber dem Professor, daß die Gentechnik ihre Forschung bald überflüssig mache. Der Professor antwortet:

Das halte ich für unwahrscheinlich. Wir betreiben Grundlagenforschung und sind darin schon ziemlich weit. Bis die Gentechniker ihr ganzes Genom entschlüsselt haben, werden noch Jahrzehnte vergehen. ${ }^{3}$ Bis dahin

\footnotetext{
${ }^{3}$ Lewandowski schrieb Ich im Jahr 2000. Schon im Jahr darauf wurde das menschliche Gen von Wissenschaftlern aufgeschlüsselt. Das Thema Genforschung ist damit aktueller denn je!
} 
haben auch wir noch eine reelle Chance, die wir nutzen sollten. Und danach, nun ja... nach uns die Sintflut. Zumindest was mich betrifft... Ich möchte jedenfalls nicht die letzten Berufsjahre schwimmen müssen...

Sein Assistent wendet ein, daß man doch den ethisch-moralischen Werten in der Wissenschaft folgen sollte und der wissenschaftlichen Wahrheit. Worauf der Professor ihn zynisch fragt, welcher wissenschaftlichen Wahrheit er denn folge und daran erinnert, daß hinter allem die Macht des Geldes stecke, die im Endeffekt bestimmt, was wissenschaftliche Wahrheit ist und was nicht. Und was das Geld angeht, verheiße die Gentechnik ,die größten Gewinne. Ein einzigartiges Börsenspektakel. Egal, was es kostet und was es nutzt. Ewige Heilung für alle. Nie wieder sterben“ (26). Die Wissenschaft, die eigentlich über allem stehen und im Interesse der Menschheit forschen sollte, ist so käuflich wie alles andere.

Die Auseinandersetzung über die Genforschung spielt sich anfangs zwischen dem Doktoranden und der jungen Frau, später zwischen dem Professor und dessen Assistenten ab. Der Doktorand hat ein persönliches Interesse an der Genforschung, da, wie sich später herausstellt, er ja selbst geklont wurde und er mehr über diese Sache für sich und für die Forschung herausfinden möchte. Sein anfänglicher Partner, die junge Frau, macht eine völlige Kehrtwendung, als ihre Forschungen für sie persönlich von Bedeutung werden, und sie reagiert nicht weniger paranoid als die meisten in der Bevölkerung ebenfalls tun würden. Rainer Lewandowski:

Viele Neuerungen wurden in der Bevölkerung zunächst verteufelt. Wenn wir danach gehen würden oder je gegangen wären, dann gäbe es weder 
Telefon, noch Fernsehen, weder Auto noch Flugzeug ... Aufklärung täte Not, aktive Information, nicht appellieren an gewisse Urängste ...die Menschen hatten und haben ... seit jeher immer Angst vor Neuerungen, vor allem aber vor der Gentechnik und deren unüberschaubaren Folgen.

Warum? (46)

Wieder ein Stück, das Fragen stellt an den Leser und Betrachter, zu denen jeder Einzelne für sich persönlich Stellung beziehen muß. Dieses Stück gibt keine vorformulierte Antwort, sondern einen wohlgezielten Anstoß zum eigenen Denken. Dabei ist es insgesamt noch unterhaltsam geschrieben und enthält formal und inhaltlich sehr komische Situationen, z. B. die, als der Doktorand seiner Freundin die Petri-Schalen im Labor als seine Eltern vorstellt. Hier wird Aufklärung mit Unterhaltung gemischt, U (Unterhaltung) und E (Ernst) gehen, entgegen der landläufigen Verwendung der beiden Ebenen, eine Synthese ein. 


\section{II.7.b) Nichts hält mich mehr in Kisslingen}

Wie im Falle von Der Geburtstag und Heute weder Hamlet handelt es sich auch beim jüngsten Stück des Autors um ein Einpersonenstück: Nichts hält mich mehr in

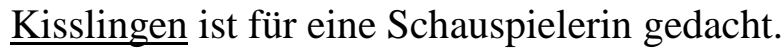

Wieder gibt es für Lewandowski charakteristische Elemente in diesem Stück: es steckt voller Sozialkritik und das Publikum wird durchgehend angesprochen und zum Mitmachen und Mitdenken aufgefordert. Lewandowski erreicht das mit gekonnt eingesetzter Ironie und Situationen, die im Hoffmannschen Stil oft Übersteigerungen sind, gepaart mit Realität, so daß es für das Publikum schwierig ist zu erkennen, was Wirklichkeit und was Illusion ist. Diesmal geht es um die Mißhandlung von Tieren, um zwischenmenschliche Beziehungen und die allumfassende Macht des Fernsehens, worüber das Publikum sich Gedanken machen soll. Das Unterhaltungsmedium Fernsehen und die zunehmende Verdummung der Programme sind Themen, die Rainer Lewandowski besonders am Herzen liegen. In meinem Interview hat er folgendes darüber zu sagen: sein Problem mit dem Fernsehen ist, daß es so viele versteckte Autorenregeln gibt, die zur Verdummung des Publikums beitragen, z.B. „dürfe der Wortschatz der Schauspieler nicht größer als 800 Worte sein, also wirklich nur Grundwörter, die benutzt werden, weil mehr das Publikum angeblich nicht versteht - dann die Auflage, ... alle 15 Minuten muß es einen cliffhanger geben, damit es spannend wird, die Leute bei der Werbeunterbrechung am Apparat bleiben“ (I, 60). Um den Verdummungseffekt des 
Fernsehens bloßzustellen, verwendet Lewandowski auch cliffhanger und Werbung in dem Stück Nichts hält mich mehr in Kisslingen.

Das Stück beginnt mit dem Auftreten einer jungen Frau, die sich ans Publikum wendet und sich als Gerti vorstellt. Sie spricht das Publikum direkt an, da sie glaubt, daß das Publikum auch zum Vorsprechen gekommen sei. Dann wirkt sie aber verunsichert: könnten diese Leute da im Publikum vielleicht eher die Kommission sein, die zu entscheiden hat, ob Gerti einen Auftritt im Fernsehen bekommt? Die Zuschauer werden verunsichert: Ist die Person auf der Bühne nun Gerti oder nicht. Die Schauspielerin wendet sich an das Publikum:

Also: dann stellen Sie sich das bitte einmal so vor:

Ich erzähle Ihnen jetzt zum Anfang erst mal die Geschichte von einer gewissen ... Gerti...

Und Sie hören mal, prüfen mal, oder was auch immer, ob das was für Sie wäre. Beziehungsweise etwas für mich.

Als ob ich... also: ob diese Gerti etwas für Sie wäre.

Oder für was für eine Sendung sie überhaupt in Frage käme. (Kisslingen, 4)

Diese Verunsicherung der Person Gerti und des Publikums wird noch verstärkt, indem ständig Wortspiele und Zweideutigkeiten benutzt werden. Hier wird von einem Schäferstündchen gesprochen, man denkt, es handelt sich um ein intimes Zusammensein, bis Gerti das näher erläutert. Sie erklärt, daß sie dem Schäfer seine Schäferstündchen ermöglicht habe, indem sie aufpaßte, daß niemand sein Schäferstündchen stört: Und so kam es, daß ich, hatte der Schäfer sein 
Schäferstündchen, auf die jungen Lämmer aufpaßte.

Lämmerhirtin....

War ein interessanter Blickwinkel damals....

Ohne mich lief nichts, trotzdem ich war im eigentlichen

Sinn nicht dabei, war außen vor.

Schob Wache. Passte auf,

Wenn der Schäfer sein Stündchen hatte... auf alles! (5)

Als sie dann im Lexikon Hilfe und Erklärungen sucht für das Wort Schäferstündchen, geht es weiter mit der Zweideutigkeit und sie gibt frustriert auf. Die Suche im Lexikon und die angeführten Wortbeispiele zeigen Lewandowskis spielerische Ironie: Als Gerti nach dem Wort sucht, findet sie Schäferdichtung und gelangt von da über Schafe zu Schafhaut und Amnion:

Amnioten!

Eine Mischung aus Amnesie und Idioten.

Wenn das nicht paßte!

Und das was der Schäfer machte in seinem Stündchen, war auch eine Mischung. Das ahnte ich. Ich war schließlich kein Idiot, und hatte auch keine Amnesie.

Eine Mischung der Geschlechter. Dazu passte mit

Sicherheit das Wort: Amnioten.

Wirbeltiere.

Meinen Sie nicht? Alle machten Wirbel? Immer. (8) 
Wortspiele und Ironie dieser Art kommen in Nichts hält mich mehr in Kisslingen häufig vor, sie sind unterhaltsam, weil lustig und doch anspruchsvoll, weil man mitdenken muß, um die Mehrdeutigkeiten zu verstehen.

Übersteigerungen werden hier viel verwendet und, ähnlich wie bei E.T.A. Hoffmann, weiß man oft nicht, wo die Illusion anfängt und die Wirklichkeit aufhört. Gerti bekommt als Lohn für die Schäferstündchen ein Lamm vom Schäfer geschenkt. Der Schäfer mit seiner Schafherde verläßt die Gegend um Kisslingen, ,zog den abgegrasten Hang hinauf und verschwand im Himmel. Nicht wirklich, es sah nur so aus. War aber auch ein Gefühl...“ (6). Gerti behält das Schaf und das Schaf Susie denkt, daß Gerti seine Mutter sei, ähnlich wie die Graugans dachte, der Verhaltensforscher Konrad Lorenz sei ihre Mutter: - ein Realitätsbezug. Auf diese Weise finden sich neben den Übertreibungen mit dem Schaf Susie - z.B. lebt Susie in Gerties Zimmer, Gertie hat Probleme mit Susie im Kaufhaus - durchaus glaubhafte Elemente aus der Wirklichkeit. Weiter wird nun Gertis und Susies Geschichte erzählt und durch diese Geschichte manches Sozialkritische geäußert. Da Gerti sich durch ihre Liebe zu Tieren den Menschen, die ihre Tierliebe für übertrieben halten, entfremdet hat, wird Susie, das Schaf, Gertis einzige ,Bezugsperson'. Kritisiert wird hier auch die Mißhandlung von Tieren, hier am Beispiel der geliebten Susie, die, um den Menschen Nahrung zu geben, auf grausamste Weise im Schlachthof ihr Leben lassen muß (Gertie war auf Zimmersuche für sich und Susie und als sie zum Bauern zurückkam, der Susie einstweilen betreute, war Susie auf dem Viehtransport in den Schlachthof und Gertie kam zu spät, um ihr geliebtes Schaf zu retten). Dieses Thema überrascht nicht, ist doch Vegetariertum in Deutschland weit verbreitet. 
Die Kritik am Fernsehen ist am deutlichsten und stärksten in diesem Stück, in dem über die Leichtgläubigkeit des Publikums gespottet wird. Gerti spricht mit dem Publikum und erklärt, wie eine gestellte Situation als spontane Reaktion ausgegeben wird:

Bilder lügen nicht.

Fragen Sie mal Ihren Nachbarn. Fragen Sie!

Der oder die kann Ihnen das bestätigen.

Bilder lügen nie.

Fernsehen ist Fernsehen. Fernsehen ist wie authentische Wahrheit! Mit eigenen Augen sehen! Und alle gucken hin.

Wie die Schafe. Alle in die gleiche Richtung, alle auf die gleiche Stelle. Tag für Tag! Abend für Abend! (15)

Im Fernsehen ist der Mensch austauschbar und ersetzbar, was zählt, sind Einschaltquoten. Die absolute Übersteigerung zum Thema Fernsehen ist die Wahl des FamilienAktions-Spiels, in dem Gerti mitmacht und in dem die Kandidatin Geld gewinnen kann für sich und den Internationalen Kinderhilfsfond, wenn sie sich in einem elektrischen Stuhl mit steigender Voltspannung elektrisieren lässt. Man stellt sie dem Publikum vor, alles seichtes Gerede, sobald Gerti etwas sagen will, unterbricht die Moderatorin mit: „So genau wollten wir das gar nicht wissen...“ (54). Es wird dem Publikum vorgegaukelt, daß alles für einen guten Zweck sei, die Erfüllung eines großen Traumes:

Amanda: ... Was wollten Sie noch sagen?

Gerti: Wollte gerade heute auch wieder zusehen. Aber aktiv. Habe mir Karten besorgt. Übers Internet der Stadt. Deshalb bin ich hier. 
Und dann gleich so etwas.

Gleich Kandidat.

Todeskandidat.

Amanda: Was Sie da reden, Gerti!

Da kann einem ja Angst und bange werden....

Aber jetzt sind Sie ja erst mal mitten drin. ...

Geht ein Traum in Erfüllung, was? (54)

Obwohl es hier um ein Menschenleben geht, wird trotzdem mit banaler Werbung unterbrochen. Gerti willigt in immer höhere Voltspannungen ein: da Susie tot ist, aus Versehen geschlachtet, scheint auch Gerti nicht mehr leben zu wollen. Ist diese Show ein verschleierter Selbstmord? Die Moderatorin macht mit und spornt Gerti an weiterzumachen. Auch das Publikum muß angestachelt werden: „Prima! Super! Phantastisch! ... Ja diese Sendung hat es in sich: die junge Spielshow für Leute mit den starken Nerven“ (59)! Das Ergebnis: Gerti hat bis zu 500 Volt ausgehalten und nun muß in der nächsten Show dieser Rekord geschlagen werden.

Die Wahl dieses „Spiels“ ist interessant, da es so etwas (noch) nicht im Fernsehen gibt. Vielleicht ist Lewandowskis Übertreibung gar nicht so weit von der Realität entfernt, denn es gibt ja schon Fernsehsendungen, in denen echte Unfälle gefilmt und als Publikumssensation gesendet werden. Menschen werden bis jetzt noch nicht im Fernsehen zur Unterhaltung anderer getötet, es ist noch nicht Circus Maximus, aber was ist als Nächstes dran, um die Einschaltquoten und die Schaulust des Publikums zu befriedigen $?^{4}$

\footnotetext{
${ }^{4}$ Obwohl ja bei manchen extremen Sportarten, die im Fernsehen gezeigt werden, wie das amerikanische Wrestling, das sich gegenseitige Verletzen und Schmerzzufügen zumindest im Ansatz schon gegeben ist.
} 
Am Schluß des Stückes tritt nun die junge Frau vom Anfang auf und bittet das Publikum - die Kommission, wie sie denkt -, per Applaus zu entscheiden, ob sie eine Chance für einen Fernsehauftritt bekommen hat oder nicht. Hier bekommt das Stück zwei mögliche Schlüsse - je nach der Reaktion des Publikums. Wieder wird das Publikum dazu angehalten, sich aktiv in das Geschehen einzumischen und durch seine Wahl den Ausgang des Stückes zu beeinflussen. Aber das Ende gibt keine eindeutige Lösung. Im Gegenteil, der Zuschauer ist verunsichert und sich nicht klar darüber, ob Gertis Geschichte nun wirklich eine Geschichte, also Illusion war oder ob ihre Geschichte beklemmende Realität war.

Dieses Theaterstück - nach dem Theaterbesuch - dürfte Anlaß zu vielen heftigen Diskussionen werden, und das ist offensichtlich das, was Rainer Lewandowski damit bezwecken wollte. 


\section{Schluß}

Das Besondere an Rainer Lewandowski ist, daß er nicht nur erfolgreiche Theaterstücke schreibt und inszeniert, sondern daß er auch über den kreativen Prozeß des Schreibens reflektiert. Er befaßt sich erst einmal mit der Theorie und den Nachforschungen über ein bestimmtes Thema oder den geschichtlichen Hintergrund und dann setzt er sein Wissen in die Praxis um: in ein Theaterstück. Ein gutes Beispiel dafür ist seine Arbeit über E.T.A. Hoffmann. Er hat nicht nur einige Romane und Erzählungen Hoffmanns, anläßlich des Hoffmann-Jubiläums, für die Bühne umgearbeitet, dessen einzige Oper Undine am E.T.A. Hoffmann Theater aufgeführt, ein Theaterstück über Hoffmanns Leben und ein Buch über dessen Aufenthalt in Bamberg geschrieben, sondern er hat die Hauptideen seiner Monographie über Hoffmann auch in einem Aufsatz zusammengefaßt, der Hoffmanns Zeit und dessen Bedeutung als Autor behandelt. Diesen Aufsatz hat Rainer Lewandowski als Vortrag an der West Virginia Universität gehalten, was, wie bereits in der Einführung erwähnt, ein Teil des kulturellen Austausches zwischen dem E.T.A. Hoffmann Theater und der Universität in Morgantown war. Der Aufsatz How Artistic Imagination Came to Console Hoffmann: The Imaginative Realist E.T.A. Hoffmann and the Romantic Movement in Germany erklärt die Zeit der Romantik, deren politische Hintergründe und die verschiedenen Stationen in Hoffmanns Leben. Kernpunkt dieses Aufsatzes ist die Bedeutung der Phantasie, insbesondere die Phantasie von und für Hoffmann selbst: „To compensate for the drudgery of teaching more or less talented girls of wealthy families, Hoffmann created a second, a different 
identity, his alter ego, or, to use a modern word, his ,double', the conductor Johannes Chrysostomus Kreisler" (How Artistic Imagination, 171).

Kreislers, als alter ego Hoffmanns, fehlende Anpassung an die ritualisierten Strukturen der (klein)bürgerlichen Gesellschaft verursachte ihm, Kreisler und Hoffmann, Unannehmlichkeiten, ,but Kreisler compensated by his use of irony. And it is precisely this heart-rending irony that made Hoffmann a modern writer ... At the intersections between reality and fantasy, Hoffmann penetrated areas of modern psychoanalysis, but without being able to define in concrete terms the phenomena he observed and described“ (180). Hoffmann hat unter den Normen der Gesellschaft gelitten und sich durchs Schreiben von deren Fesseln befreit.

Der Aufsatz bietet interessante Einblicke in das Thema Hoffmann und gibt damit dem Leser, Zuhörer und Publikum weiteres, wichtiges Werkzeug an die Hand, um den Autor Hoffmann besser verstehen und schätzen zu lernen und auch um die Theaterstücke über Hoffmann und von Hoffmann besser zu verstehen. Diese, sich mit einem Thema sehr intensiv beschäftigende Arbeitsweise Lewandowskis ist ein Aspekt der Theorie und Praxis dieses Autors.

Rainer Lewandowski setzt sich auch mit dem Theater selbst und dessen Bedeutung innerhalb der Gesellschaft und der Geschichte auseinander. So hat er Beiträge über das Theater mit den Titeln $\underline{\text { Theater und Moderne, }}$ Tugend der Gemeinsamkeit. Das Theater des Nationalsozialismus, Theater und E.T.A. Hoffmann Theater. Konzepte, Pläne und Spielpläne, und Concerning the Current Status of German Theater geschrieben (manche davon speziell für den Kulturaustausch mit Amerika) und sich mit dem Thema 
Theater tiefgehend auseinandergesetzt. Aber auf alle diese hochinteressanten Aufsätze einzugehen, würde den Rahmen einer Schlußbemerkung sprengen.

Was aber hier noch einmal betont werden muß ist, erstens, daß Rainer Lewandowski - neben der Verwendung des well-made-plays und traditioneller Formen des Theaters - auch mit neuen Formen im deutschen Theater experimentiert, indem er z.B. filmtechnische Mittel im Theater einsetzt. Damit bringt er die Attraktion des Kinos auf die Bühne und kommt so dem heutigen Publikum mit seinen von den Medien geprägten Erwartungen entgegen. Diese Anwendung der neuen Medien in seinen Stücken ist jedoch nur die eine Seite.

Eine andere Seite ist, daß Lewandowski versucht, in seinen Stücken das traditionelle bürgerliche Theater der, vierten Wand` zu verändern. In seinem Vortrag „Theater und E.T.A. Hoffmann Theater. Konzepte, Pläne und Spielpläne“ betont Lewandowski, daß er durch den „Versuch der Wiederauflösung der 4.Wand, einer faktisch nicht stimmenden, einer rein mental behaupteten Prämisse des bürgerlichen Theaters, Ansätze [sähe] für eine Weiterentwicklung des Mediums, erste Schritte auf dem Weg in Richtung heutiger ,Moderne““ (Theater, 25). Lewandowski will die unausgesprochene Übereinkunft des bürgerlichen Theaters, des Theaters der Lessingzeit und danach, daß beide Seiten, Publikum wie Schauspieler auf der Bühne so tun, als seien sie nicht gleichzeitig in einem Raum und sich folglich scheinbar gegenseitig nicht beachten, aufheben mit einem Rückgriff auf Traditionen eines vor-bürgerlichen Theaters, das geradezu davon lebt, daß die Schauspieler auf der Bühne und die Menschen im Auditorium wissen, daß sie im gleichen Augenblick lebendig aufeinander wirken. Das Niederreißen dieser imaginären, vierten Wand' der Bühne ist sein dramatisches wie 
dramaturgisches Hauptanliegen. Aus diesem Grund sprechen viele seiner Figuren direkt zu den Zuschauern, heben die Trennung von oben und unten, von Bühne und Auditorium auf. Bei diesen theoretischen, aber auch in die Praxis umgesetzten Bemühungen spielt gerade das Kindertheater eine besondere Rolle, da die Kinder in ihrem Rezeptionsverhalten noch viel spontaner auf diese Herausforderung von Lewandowskis ,offenem“ Theater ohne vierte Wand reagieren. Insofern ist gerade das Kindertheater fester und bedeutender Teil des Schaffens von Rainer Lewandowski. Aber auch Lewandowskis Spielpläne weisen auf diese Änderung im Verhalten zwischen Schauspielern und Zuschauern hin: In Pierre Chesnots Komödie Ein schöner Schlawiner wendet sich der Hauptdarsteller an das Publikum mit der Bitte, die gegen ihn ausgesprochenen Verleumdungen nicht zu glauben und sich eine eigene Meinung zu bilden. Hier wird das Publikum ,,aktiviert, zum Mitdenken aufgerufen: Wer hat Recht? Der Mann oder ,seine“ Frauen“ (30)? In Alan Ayckburns Geschwisterliche Gefühle darf das Publikum wählen, wie die Handlung weiter zu gehen hat. Das Ende des Theaterstückes bleibt also offen und kann von Aufführung zu Aufführung geändert werden.

Eine andere Weise die Zuschauer mehr in die Handlung miteinzubeziehen und das Verstehen des jeweiligen Theaterstückes zu verbessern ist die Verwendung der gut durchdachten Programmhefte, die es zu jedem Stück des E.T.A. Hoffmann Theaters gibt. Darin ist der Hintergrund des jeweiligen Stückes für das Publikum erklärt, mit Beiträgen von verschiedenen Schriftstellern und Historikern.

Theoretisch setzt sich Lewandowski auch mit den neuen Trends im heutigen deutschen Theater auseinander. Einer der Trends ist, daß das Theater sich mehr und mehr 
von dem bekannten bürgerlichen Theater weg zu einem mehr unterhaltungsorientierten Theater entwickeln könnte. Einer der Gründe dafür ist, daß die Gefahr einer Streichung der Subventionen besteht und die einzelnen Theater sich dann zunehmend um Sponsoren kümmern müssten. Das bringt natürlich die Gefahr mit sich, daß ein Theater dann von seinen Sponsoren und deren Wünschen mehr und mehr abhängig wird. All das ist natürlich in der Praxis für Rainer Lewandowski besonders bedeutsam, da er für das Überleben des E.T.A. Hoffmann Theaters als Intendant verantwortlich ist. Daß sich Lewandowski mit diesen möglichen Problemen bereits theoretisch beschäftigt, ist ein weiteres Zeichen für seine umfassende Umsicht und Voraussicht.

Darüber hinaus sind alle seine Texte sozialkritisch, haben also ein gesellschaftsbezogenes Anliegen, haben vielleicht gar ein gesellschaftsveränderndes Potential. Manchmal ist seine Sozialkritik sogar prophetisch, wie bei Mambo Mortale. In diesem 1989 aufgeführten Stück ging es um die große Arbeitslosigkeit in Deutschland als Verursacher vieler Probleme der Jugendlichen. Als das Stück konzipiert wurde, lag die Arbeitslosenzahl bei rund zwei Millionen, als die Fernsehaufzeichnung des Stückes 1998 in Morgantown vorgeführt wurde, lag die Arbeitslosigkeit in Deutschland bei fünf Millionen, wobei ein Großteil der Arbeitslosen die Jugendlichen betraf.

Lewandowski erweist sich hiermit als ein genauer Beobachter der Gesellschaft, der gesellschaftliche Trends erkennt, sie unter soziologischer und psychologischer Perspektive analysiert und dann dramatisch verarbeitet. Die Aktualität seiner Themen, die Zeitbezogenheit seiner Theaterstücke und ihr gesellschaftsveränderndes Potential sind Aspekte, die Rainer Lewandowski als Schriftsteller so bedeutend und sein Werk so lesenswert machen. 


\section{Interview mit Rainer Lewandowski ${ }^{5}$}

Das Gespräch fand im August 2000 in Bamberg statt.

Ulrike Taylor:

Was ist Ihr Interesse an den Staaten? Welche Beziehung haben Sie zu den Staaten?

Weshalb betreiben Sie den Kulturaustausch zwischen dem E.T.A.-Hoffmann-Theater und dem Creative Arts Center der West Virginia University?

\section{Lewandowski:}

Das Ganze ist entstanden über Herrn Schlunk (Deutschprofessor an der West Virginia University). Der Kontakt war zunächst einmal gar nicht als künstlerisches Projekt gedacht, sondern eher privat, für ihn dienstlich. Er begleitete einen Deutschkurs für amerikanische Studenten in Bamberg. Dann haben wir uns vorgenommen, diesen Kulturaustausch zu initiieren und haben eine entsprechende Abmachung vereinbart mit der Universität West Virginia und dem E.T.A.-Hoffmann-Theater. Motiv war ein Kulturaustausch zwischen der westlichen Welt und dem Bamberger Theater, das zu der Zeit schon mehrfach für die Bayerische Staatsregierung auf Gastspielreise gewesen war, und zwar nach Kiew, Ukraine, und Jinan, China, wohin wir mit ganzen Produktionen unterwegs waren. Der amerikanische Austausch begann zunächst mit Vorträgen meinerseits und Videoprojektionen von Aufführungen, die das Bayerische Fernsehen aufgezeichnet hatte, später entstand die Idee, daß man eigentlich auch mit LiveTheaterproduktionen reisen könnte. Ein Problem schien die Sprache zu sein, für

\footnotetext{
${ }^{5}$ Es handelt sich hier um eine gekürzte, aufs Wesentliche reduzierte Fassung des Original-Interviews.
} 
Deutschland nicht so gravierend, weil alle Englisch lernen, obwohl sie dann bei den Aufführungen doch nicht so viel verstehen, wie sie vorher glaubten. Das Problem liegt eher in Amerika mit der deutschen Sprache. Da paßte Ich, Marlene als Videoprojektion ganz gut, weil das - schon im Stückmanuskript - eine Mischung aus beiden Sprachen war und diese Revue bot sich außerdem an, weil englische Lieder vorkamen. Jürgen Schlunk hat eine Übersetzung gemacht und damit haben wir ein Voice over bei der Projektion gemacht, so daß alles in Englisch war bis auf ein paar Songs. Das war, verbunden mit einem Vortrag über das deutsche Theatersystem, der Anfang. Inzwischen war eine Aufführung von Macbeth aus Morgantown bei uns. Eine sehr gute Aufführung.

U.T.: Ja, ich habe sie auch in Morgantown gesehen.

\section{Lewandowski:}

Die Aufführung war einfach gut gemacht, die Mittel gekonnt und sehr sicher gesetzt, es waren gute Schauspieler und eine gute Inzenierung. Die Bühne war auch sehr schön, sehr praktisch, passte gut in unser Haus und von daher war alles ein voller Erfolg. Zuvor hatten wir ein Stück von Frank Gagliano an unserem Theater in der Übersetzung von Jürgen Schlunk aufgeführt, MEIN TSCHECHOW-LICHT. Gagliano war bei uns zur Premiere und hat dann selbst noch eine Lesung anderer seiner Stücke gemacht. Zur Zeit planen wir ein neues Kapitel dieses Austausches, das mit dem Sprachproblem interessant umgeht. Wir werden es so machen, daß Jerry McGonigle, der Regie geführt hat bei Macbeth, zu uns kommen wird von November bis Januar und in dieser Zeit hier mit einem Schauspieler von uns ein Zwei-Personen Stück einstudiert. Das wird Robinson \& 
Crusoe sein, das ist eine Geschichte, in der sich zwei Leute auf einem Hausdach, mitten im Wasser sozusagen, treffen, Überschwemmung, usw. und der eine kann nicht die Landessprache, sondern spricht irgend etwas und so versuchen die beiden sich zu verständigen und entwickeln Kommunikationsformen mit einer eigenen Sprache. Unser Schauspieler spielt den deutschen Part und Jerry die Kunstsprache. Wir wollen dann irgendwann im nächsten Jahr damit nach Amerika fahren und das gleiche Stück dort aufführen. Das ist ein Gemeinschaftsprojekt beider Seiten, eine wichtige Fortsetzung des Kulturaustausches. Das machen wir aus dem Grunde, weil ich meine, daß man Leute besser kennenlernt, um Erfahrungen wirklich kultureller Unterschiede zu machen. Das Spannende dabei ist, daß es im Bereich des Theaters und im Theaterspiel zwar Unterschiede in der Spielweise gibt, im Handwerk, aber nicht so sehr in den zentralen Ausdrucksformen. Obwohl es die andere Seite des Globus ist, sind bestimmte Gesten, Mimiken, ja sogar die Intonation, die Zwischentöne innerhalb von Sätzen, sehr ähnlich, so ähnlich, daß man sie auch verstehen kann, wenn man die Bedeutung der Worte nicht kennt. Das war auch für unsere Schauspieler das Aufregende, als wir mit NUR KEINE PANIK in Amerika gastierten. Wir hatten unser Stück in Deutschland auf deutsch einstudiert. Als wir gebeten wurden es in Amerika auf englisch zu versuchen, wir hatten eine Übersetzung von Jürgen Schlunk, waren einige Schauspieler aus Unsicherheit zunächst dagegen. Natürlich kam der Einwand: ,Wir sind deutsche Schauspieler, wir denken deutsch, wir fühlen deutsch, das können wir nicht in einer anderen Sprache spielen.' Als wir es dann doch versucht haben, ging es. Wir haben gelernt, daß man auch in einer fremden Sprache die gleichen Dinge zum Ausdruck bringen kann, weil die emotionale Grundlage sehr ähnlich ist. Das ist eine Erfahrung, die man nur in der Praxis 
machen kann. Deswegen ist dieser Kulturaustausch, denke ich, auch so wichtig. Einmal war auch eine Praktikantin bei uns, Melody Hallman, die wir in einem Stück an unserem Theater eingesetzt haben.

Unser Theater macht aber auch andere Austausche. Demnächst wird Prag anstehen. Auch machen wir Kulturaustausche mit den Partnerstädten der Stadt Bamberg. In Frankreich Rodez, in Österreich Feldkirchen. Ich denke auch das ist eine Besonderheit von unserem Theater, daß wir in den Kreis derer aufgenommen sind, die die deutsche Kultur auch außerhalb präsentieren und repräsentieren.

U.T.: Wie sehen Sie Ihre Zeit in Bamberg vom Künstlerischen her?

Lewandowski:

Das ist sehr komplex. Es sind zwei Ebenen. Das eine ist, daß das Bamberger Theater ein kleines Theater ist, auch mit einer regional beschränkten Bedeutung, die wir durch diese Auslandsgastspiele z. B. punktuell steigern und aufwerten. Das führt aber nicht dazu, daß wir in den Feuilletons der großen, überregionalen Zeitungen wahrgenommen würden. Das ist nicht der Fall, das schafft kein kleines Theater. Das ist einfach im Hierarchie- und Bedeutungsdenken der deutschen Feuilletons nicht möglich. Das wiederum hat auch zu tun mit ICE Anschlüssen. Man macht sich als Kritiker nicht in die Provinz auf, wo man den ganzen Tag unterwegs ist. Wohin kein ICE hinfährt, dahin kommt auch keiner. Jetzt hat Bamberg allerdings seit Mai einen ICE Anschluß, aber nur für die Strecke von Berlin nach München. Durchfahrt. 
Es gibt zwei Standpunkte. Der eine ist, man sagt, man sollte Karriere machen und kann dann Bamberg als Sprungbrett betrachten auf dem Weg in größere Häuser. Der andere ist, man macht in Bamberg, was für das Bamberger Theater und für die Zukunft dieses Theaters notwendig ist. Das ist meine Grundhaltung. Wir haben über Jahre hinweg in dieses Theater, durch aufreibende Überzeugungsarbeit und mit Hilfe des Stadtrates viel Geld gesteckt. Der Etat wurde, als wir hier anfingen, richtig erhöht: wir haben etwa zwei Millionen Mark mehr gekriegt. Einmal für Bühnenausstattung, für Personal, auch Anschaffungen sind getätigt worden, Geräte, die es vorher hier nicht gab. Ich habe auch von Anfang an von meiner Seite gesagt, daß dieses Theater saniert werden müsse, denn ohne Sanierung könne es nicht so weitergehen. Wir können die Leistungsfähigkeit in einem maroden Haus auf Dauer nicht halten. Wir, das Theater, haben durch unsere Auslandsgastspiele für die Staatsregierung einen guten Kontakt nach München geknüpft. Wir haben durch bestimmte Programmgestaltungen, E.T.A-Hoffmann-Jahr, Fernsehaufzeichnungen unserer Produktionen, die auch in München und überregional wahrgenommen wurden, die Aufmerksamkeit auf Bamberg und sein örtliches Theater gelenkt. Zu der überregionalen Andechs-Meranier-Ausstellung haben wir ein Stück beigetragen über den Königsmord, der hier in Bamberg, interessanterweise sogar der Stelle, an der wir das Stück gespielt haben, geschehen ist, nämlich in der Alten Hofhaltung. Das hat ebenfalls große Beachtung gefunden. Zur Landesausstellung 2002 sollen wir das auf Wunsch des Bayerischen Hauses der Geschichte auch wieder machen. Durch solche Projekte also, die in München sehr interessiert wahrgenommen wurden, es sind viele Münchner gekommen, auch aus dem Ministerium. Diese Gelegenheiten haben wir genutzt, denen unser Theater zu zeigen. Sie haben es sich angeguckt - und dann sind 
sie Geldgeber geworden für unsere Sanierung. Auf diese Weise ist es gelungen, daß, als dieser Kulturfond gegründet wurde, für Bamberg und sein Theater Geld bereit gestellt wurde für das Theater von München aus - natürlich nicht genug, aber ein Teil davon. Das hat die Stadt in Bewegung gesetzt und andere Geldgeber wurden dazugeholt. So ist es gelungen, daß über die Hälfte des Geldes für die Sanierung als Zuschüsse von anderen gekommen sind und die Stadt Bamberg selbst nicht mehr so viel Geld investieren muß. Nur so war es möglich, daß die Sanierung in Gang gesetzt wurde.

Insofern hat sich hier unsere künstlerische und theaterpolitische Arbeit ergänzt. In dieser Phase der geplanten Sanierung, als die Stadt noch überlegt hat, ob sie das Geld wirklich für das Theater investieren will, erhielt ich ein Angebot eines größeren, namhaften Hauses aus einer anderen Stadt. Das war eine schwierige Situation! Dann haben meine Frau, die Familie und ich entschieden, daß man das Angebot aus moralischen Gründen nicht annehmen kann. Wir drängen zehn Jahre auf die Sanierung, es ist kurz davor und dann sagen wir, wir gehen jetzt. Dann haben andere Leute, mit denen wir uns beraten haben, gesagt: ,Wenn du weggehst, dann ist die Sanierung gestorben. ' Dann würde die Stadt das Projekt sofort stoppen und sagen: ,Jetzt müssen wir erst mal abwarten was der Nachfolger will.

An dem Tage, als wir das letzte Gespräch mit dem Aufsichtsrat des anderen Theaters haben sollten, haben wir entschieden, wir bleiben hier und bringen hier diese Arbeit zu Ende.

Das haben viele nicht verstanden, ist vielleicht ein Fehler in der Biographie. 
Es wird sich zeigen, ob nochmal ein Angebot kommt oder ob sich dann das Gerücht festsetzt: der bleibt sowieso in Bamberg. Manche Zeitungen haben das auch gleich behauptet.

Dann hat die Stadt entschieden, daß sie diese Sanierung machen und die haben sie jetzt auch angefangen.

Es gab dann zwischendurch nochmal eine Anfrage, ein Sommer-Festspiel in der Nähe zu übernehmen, auch das haben wir abgesagt, denn beide Seiten haben erkannt, daß man mit einer Sanierung so viel zu tun hat, daß man nebenher kein Festspiel leiten kann. Danken wird einem diese Entscheidungen niemand, aber man hat vor sich selber ein gutes Gefühl. Es kann allerdings durchaus sein, daß man sich mit dieser Entscheidung ins Abseits gebracht hat.

Das Positive ist, daß Bamberg als Kleinstadt ein ganz anderes Bewußtsein und auch Verständnis von Kunst und um Kunst hat als manche Großstädte. Das heißt, man kann hier manchmal mit ganz kleinen Dingen noch richtig viel bewirken, was in der Großstadt total untergeht. In der Großstadt müßte man ganz andere Dinge machen, die mit dem Stoff und dem Stück nichts zu tun haben, nur um mehr aufzufallen. Man kann hier, indem man einfach mal die Wahrheit sagt, die Leute bewegen. Das ist eigentlich ganz schön. Nehmen wir als Beispiel mal den Königsmord, woran der Clou eben war, daß - nach der Beweislage mit Indizien, die von einem namhaften Historiker nachgewiesen wurden - offensichtlich der Bischof selber Teil dieses Mordkomplottes gewesen sein muß. Das konnten einige nicht gut vertragen. Da wurde schon am Premierenabend die Mär verbreitet, das sei alles ganz anders gewesen und ein Vorwurf lautete: „Und wenn es so war, dann sagt man es nicht!” So etwas hätte in einer Großstadt 
niemanden erregt. So etwas macht das Stück dann aber auch interessant für die Leute. Dann kommen sie und schauen es sich an. So kann man wirklich was erreichen. Oder ein anderes Beispiel: Wir hatten eine Komödie, die erotische Untertöne hatte. Da war ein Trick dabei: Ein bewußtes Wort wurde zwar ausgesprochen, aber von Ornithologen, nicht in dem eindeutigen Zusammenhang. Aber alle haben es eindeutig verstanden. Ihre eigene Phantasie ist mit ihnen durchgegangen, und dann haben sie gemeint, das sei eine Ferkelei. Daß das aber nur ihre eigene Phantasie war, das ist eigentlich der spannende Punkt. Das ist nämlich nicht das Problem des Stückes, sondern das Problem des Zuschauers selbst.

\section{U.T.: Welches Stück war das?}

\section{Lewandowski:}

Das heißt Alarm. Das ist eine Komödie, die auch wirklich eine Komödie ist mit allen Schemata, die man für Komödien braucht: mit klemmender Doppeltür, allen möglichen Versatzstücken, die in eine Farce gehören.

Es gab viele, die es verstanden haben, die haben dann sogar Leute aus therapeutischen Gründen in die Aufführung geschickt, damit die ihre Partnerschaftsbeziehungen unter anderem Gesichtspunkt neu durchdiskutieren können.

Die eigentliche Arbeit ist allerdings ursprüngliche Theaterarbeit. Entwicklungen mit Besetzungen, die mit den Schauspielern zu tun haben, die mit immer größeren Rollen betraut werden, daß man auch die Geduld hat, eine Förderung zwei, drei Jahre lang durchzuziehen. 
Außerdem liegen in Bamberg die Stoffe für Stücke eigentlich auf der Straße. Das ist ein historisch zentraler Ort, der vor 1000 Jahren auch mal Hauptstadt des Deutschen Reiches gewesen ist, kurzzeitig. Es gibt so viel Historisches hier, daß man es nur mit Händen greifen muß. Das haben wir auch schon gemacht: wir haben ein Hoffmann-Jahr durchgeführt, eine Biographie über Hoffmann auf die Bühne gebracht.

Da war sehr interessant, daß Hoffmann hier in Bamberg gelitten hat wie ein Hund, aber heute ist es der große Hoffmann und kein Bamberger nimmt das Leiden auch nur irgendwie wahr. Das hat das Stück ihnen vorgeführt, aber ich glaube nicht mit durchschlagender Wirkung, denn es herrscht nach wie vor die touristisch wirksame Meinung, Hoffmann war hier glücklich. Es gibt immer noch die Legende, daß Hoffmann hier die ganze Zeit seines Aufenthalts Musikdirektor gewesen sei. Es waren nur etwa sechs Wochen, in denen er Musikdirektor war.

Ein anderes Thema, was ich gerne einmal bearbeiten würde und irgendwann muß man das mal machen: es gibt hier die Willy-Lessing-Straße. Das war ein Jude, der von Bambergern sozusagen erschlagen wurde, in der Reichskristallnacht. Das wäre ein Stoff für die ganze Aufbereitung des jüdischen Lebens im Dritten Reich in Bamberg, die Annexion von Kaufhäusern, Wohnhäusern und diese ganzen Sachen.

,Das kannst du nicht machen', hieß es, ,die leben ja alle noch. ‘

Ein anderes Beispiel war die Universitätsgeschichte: 350 Jahre Universität Bamberg. Da haben wir auch ein Stück gemacht im Innenhof der Universität. Das war für die Abonnenten gut, die haben etwas über die Zeit und über die Universität erfahren. 
Also wichtig: Theater für die Region, in der Region, auch mit regionalen Themen. Für einen Autor bringt das natürlich ein Problem: wenn man sich so regional bindet, finden überregional wenig Leute Anhaltspunkte, diese Stücke auch bei sich aufzuführen. Das ist eine Schwierigkeit, aber da gibt es ein paar andere Stücke von mir, die überregional funktionieren und die werden auch gespielt. Aber es ist eine zweischneidige Sache. Meine neuen Stücke werden wahrscheinlich ,überregionaler‘.

\section{U. T.: Warum Ihr Interesse an E.T.A. Hoffmann ?}

\section{Lewandowski:}

Da gibt es, ohne eingebildet zu sein, ein paar parallele Entwicklungen, glaube ich. Der Mann war ja auch in Bamberg, hat damals diese ortsspezifische philisterhafte Engstirnigkeit kennengelernt, die es sicher heute in Auswüchsen auch noch gibt. Es gibt viele Strukturen, die sehr ähnlich gelagert sind. Hoffmann hatte auch mit dem hiesigen Theater zu tun. Aber das ist nur äußerlich. Der Umgang mit Phantasie ist, glaube ich, der entscheidende Punkt, der zu Hoffmann gewisse Beziehungen hervorbringt. Es ist der Ansatz, die Phantasie aus der Umgebung zu holen. Er nimmt lebendige Erfahrungen, Wahrnehmungen, die er verändert in Geschichten einbringt, aber man kann den realen Kern, wenn man ihn kennt, wiedererkennen. Wenn man ihn nicht kennt, muß man ihn nicht wissen, weil eine eigenständige Geschichte erstanden ist, aber diese hat eine realistische Basis. Es sind Utopien, es sind Hochrechnungen von realen Verhältnissen. Das ist vielleicht das richtige Wort. Das kann mit Phantasie auch gemacht werden. Man zeigt, es gibt einen bestimmten Grundbestand und wenn man nicht aufpaßt oder wenn 
man das ungebremst weiterlaufen läßt, wie auch immer, dann kann daraus das und das entstehen. Es ist wichtig, daß man Phantasie produktiv begreift, gebunden an die Realität, und sie nicht nur frei flottieren läßt in den unendlichen Weiten des Alls. Hat vielleicht etwas mit Warnliteratur zu tun, was ja mal ein altes Genre war. Es gibt eine sehr frühe Guache von Hoffmann, die heißt: „Die Phantasie kommt Hoffmann zum Trost”. Da ist die ganz entscheidende Sache schon drin, er brauchte seine Phantasieleistung für sich selbst, um bestimmte Dinge ertragen zu können. Das ist der Kern seines Umgangs mit der Phantasie im Leben von Menschen.

Ich denke, Phantasie hat jeder, und man hat sie auch nötig, noch dazu genau in dieser Funktion wie eben beschrieben, hauptsächlich in der Kindheit. Da strömen die vielen Eindrücke auf den jungen Menschen ein, und die müssen verarbeitet werden. Da müssen Strategien entwickelt werden, wie man sich gegen diese übermächtigen Erwachsenen wehrt, gegen die Bewußtseinsindustrie der Medien. Das Kind bewahren heißt, etwas von dieser Fähigkeit seiner Phantasie zu bewahren. Es gibt ein Märchen von Hoffmann: „Das fremde Kind“. Das fremde Kind ist eine Allegorie für die Phantasie, eine Personifizierung, und am Ende sagt der sterbende alte Mann, er hätte als Kind auch dieses fremde Kind, sprich: die Phantasie kennengelernt, aber sie wäre ihm im Laufe des Alterns, er wisse nicht genau wodurch, abhanden gekommen. Dieses im Erwachsenwerden anerzogene rationale Denken, dieses ,Vernünftigwerden, ‘ dieses sich in Ordnungen einfügen, das Sich-passen, nicht mehr ausbrechen aus vorgegebenen Wegen, der als , vernünftig' geltende Verhaltenskodex eben, das ist ja das, was das Kind erlernt. Ich meine aber, es geht auch darum, Ausbuchtungen der Phantasie noch 
lebensfähig zu erhalten, quer zu denken, eigenständig zu denken. Das ist die ganz entscheidende Fähigkeit.

Die nehme ich, hoffe ich, auch für mich in Anspruch. In meiner Schulzeit hat einmal ein Lehrer zu mir gesagt: „Wenn 100 Töpfe vor dir stehen, 99 mit Gold und einer mit Senf, dann trittst du in den mit Senf.” Diese Einschätzung ist in gewisser Weise richtig, weil das teilweise sogar absichtlich geschieht, nicht immer. Dann geschieht eben genau das, was die Leute nicht erwarten. Und das ist gut, das ist unkonventionell.

Für diese Denk- und Arbeitsweise kann auch Theater dienen. Auch andere Situationen, z.B. ein Gespräch im Stadtrat. Mal abrupt das Thema wechseln, die Gedanken aus ihrer sozusagen verbohrten Diskussion herausnehmen, etwas ganz anderes ansprechen, daß die vielleicht lachen, und dann ebenso überraschend wieder zurück in das Thema, dann sind die Gesprächspartner schon wieder ganz anders verfaßt. Auch so etwas hat mit dem Umgang mit Phantasie zu tun. Das ist in gewisser Weise ein praktischer Nutzen der Phantasie. Für manche ist das sicherlich schwierig, weil man für ihre Begriffe nicht im Sinne von Rationalität diskutiert. Regelverletzung.

U.T.: Haben Sie einen inneren Zwiespalt wie Hoffmann zwischen seiner Liebe zur Musik und seinem Schriftstellertum?

\section{Lewandowski:}

Ich glaube nicht, daß das bei Hoffmann ein Zwiespalt war. Er wollte beides, sonst hätte er nicht geschrieben, aber er wollte auch komponieren, was am Schreibtisch auch möglich war, jedoch die Umsetzung erheblich schwieriger und aufwendiger. Literatur mußte nur 
gedruckt werden, das Musikalische mußte aufgeführt werden. Es müssen andere Leute überzeugt werden, ein Orchester muß das Werk umsetzen. Letzteres war für ihn in Bamberg schwierig, nachdem er die Position als Musikdirektor nicht mehr innehatte. Er hat aber noch Kompositionsaufträge vom Theater aus gehabt, nach seiner Entlassung als Musikdirektor. Ballettmusiken, Schauspielmusiken, Arien. Er hat wunderschöne Canzonetten komponiert, die man heute gar nicht mehr kennt. Er hatte für meine Begriffe ein überaus großes Talent, sehr schöne Melodien zu schreiben und die miteinander zu verweben. Nicht umsonst war Undine mal eine Zeitlang d i e romantische Oper überhaupt. Es hatte zwar Jahre gedauert, bis die Oper in Berlin aufgeführt wurde. Sie war ein Riesenerfolg. Dummerweise hat es im Theater am Gendarmenmarkt damals gebrannt. Was übrigens in Bamberg während der Umbauphase ebenfalls passiert ist.

Damals sind alle Undine-Kostüme verbrannt, und die Oper konnte nicht wieder in den Spielplan aufgenommen werden. Unsere Kostüme sind nur verräuchert, die müssen gereinigt werden.

Für einen der kein Geld hat, ist es viel schwieriger im Musikgeschäft voranzukommen als mit dem Schreiben. Das Schreiben kann er nebenher machen, das findet hauptsächlich im Kopf statt, es ist eine Phantasietätigkeit und man braucht Papier und Stift, um etwas aufzuschreiben und Zeit. Die Musik ist ohne ihre instrumentale Umsetzung nicht hörbar, gewissermaßen nur virtuell existent.

U.T.: Hoffmanns Liebe war ja die Musik. 


\section{Lewandowski:}

Ja, seine Liebe war die Musik. Aber ich glaube nicht das ganze Leben lang. Es war wohl am Anfang so, aber er hatte auch eine realistische Wahrnehmung seiner Situation. Er war auch Jurist, er war so eingebunden in diese Arbeit und in sein Schreiben. Da war keine Zeit mehr, etwas zu machen. Ich denke also nicht so sehr, daß das sein lebenslanger Zwiespalt war. Sein Zwiespalt bestand eher mit der bürgerlichen Welt und der Kunstwelt: Phanatsiekunst zu machen - und gleichzeitig eingebunden zu sein in diese bürgerliche Ordnung des - nicht nur - juristischen Alltags. Meine Theorie ist, daß er diesen Zwiespalt sehr wohl fühlte, und im Alkohol ein Mittel gefunden zu haben glaubte, ihn zu überwinden. Ob diese These stimmt, weiß ich nicht, aber ein Indiz ist, daß er ein Wort erfunden hat, nämlich sich ,imprägnieren”. Dieses Wort ist eine Umschreibung für ,sich betrinken', um eben die in ihm befindlichen bürgerlichen Hemmschwellen herabzusetzen, um auf diese Weise der Phantasie ungehemmt freien Lauf lassen zu können.

Diese Methode funktioniert bei mir übrigens nicht, ich werde von Alkohol müde.

U.T.: Wie arbeiten Sie? Was bringt Sie zum Arbeiten?

Lewandowski: Das sind verschiedene Sachen...

U.T.: Das mit dem Regal bauen, vor einer Schreibphase hab' ich schon mitgekriegt.

Lewandowski:

Ja. Das ist das körperliche vorherige Austoben, bevor man lange still sitzen muß. Das Schreiben ist ja Arbeit, das ist vielen vielleicht nicht ganz so klar, es ist auch eine 
anstrengende, ja auch körperliche Arbeit, die erschöpft. Man schwitzt, obwohl man sitzt. Ich schreibe meistens früh, wenn ich aufstehe, wenn ich fit bin. Es ist eine gewisse Unruhe in mir, eine Neugier, denn ich schreibe nicht unbedingt immer so, daß die gesamte Handlung schon im Kopf ist. Es macht mir mehr Spaß, wenn man eine Grundsituation hat, sozusagen einen Anfang, einen Konflikt, der sich dann anscheinend von selbst fortentwickelt. In den Personen, in den Situationen. Ich habe lange Zeit vorher die Idee für einen Stoff. Die wird dann umgesetzt, aber irgendwie ist es nicht das, was es werden sollte. Eine Zeit später kommt ein ganz anderer Gedanke, der zunächst gar nichts mit dem anderen zu tun hat, bis dann der Augenblick kommt, wo man erkennt: „Mensch, eigentlich gehören die beiden Stoffe zusammen“, und es ergibt sich plötzlich ein Ganzes. Wenn man dann noch das Eigenleben der Figuren verfolgt, die man erfunden, die auch auf der Basis von Beobachtungen - und das ist Hoffmanns Arbeitsweise ähnlich -, auf einer realistischen Basis beruhen, dann wird die Arbeit not-wendig. Früher habe ich alles mit der Hand geschrieben, und nach der Korrektur in der Handschrift in die Schreibmaschine getippt. Heute schreibe ich mit dem Computer, lasse aber sofort ausdrucken und mache die Korrekturen auf dem Papier. Das erneute Eingeben ist dann eine weniger erquickliche Arbeit, aber auch dann verändert sich meistens noch etwas am Compuscript. Sofort wieder ausdrucken, korrigieren, eingeben, ausdrucken. Das passiert so 4 bis 5 mal, solange wie man es halt machen will. Das kostet viel Papier. Zum Glück sind wir ja heute nicht mehr auf Pergament angewiesen.

U.T.: Wie lange streckt sich das hin? Jürgen Schlunk hat erwähnt, daß Sie ein sehr genauer Mensch sind, wenn es um das Nachforschen geht. Stimmt das? 
Lewandowski:

Ja. Aber dennoch ist der Vorgang sehr unterschiedlich. Es gibt Dinge, die sich sehr schnell ergeben, andere dauern länger. Schreiben bei mir ist ein ganz komplexer Prozeß, der schwer zu beschreiben ist. Es gibt mehrere Ebenen, die auch im Hirn nebeneinander her arbeiten. Das ist es, was es so anstrengend macht. Es gibt die Figuren, die sozusagen ein Eigenleben entwickeln, da steckt natürlich ein Antrieb dahinter, der Autor, aber dennoch sind sie eigenständig. Sie wehren sich auch gegen bestimmte Ideen. Das ist schon spannend. Man ist sozusagen nicht nur der Initiator, sondern auch eine Art Kontrolleur, der die Figuren in Korrespondenz mit den Figuren, beobachtet und leitet. Dann gibt es aber noch eine dritte Ebene, die das rein Praktische bewerkstelligt, also das Aufschreiben, die Rechtschreibung, das Formatieren etc.. Das eigentlich Spannende ist immer wieder: welche Eigendynamik gewinnt die Geschichte? Und je nach Kurvenlage der Entwicklung fängt der Kontrolleur wieder an auszugleichen. Man ist beim Schreiben, glaube ich, in einem Zustand der aufgespaltenen Persönlichkeit. Da arbeiten mehrere Facetten in einem selber, Logik, Unlogik, Unmöglichkeiten, und das neben den handwerklichen Dingen, die man sich im Laufe der Zeit angeeignet hat: Sprachführung, Rhythmus, Begrifflichkeiten, Vokabeln, auch Reime.

Alltagsprobleme nehmen in einem solchen inneren Zustand keinen großen Stellenwert ein, alles ist wie in einem nebulösen Dasein. Ich habe das mal beobachtet. Wenn man sitzt und schreibt, dann ist das Schreiben selbst ein Nebenvorgang, ich gucke weder auf die Tasten, noch auf den Schirm, noch vor mich hin. Ich sehe eigentlich gar nichts. Ich bin immer wieder überrascht, daß man trotzdem richtig schreibt. Die 
Rechtschreibkontrolle ist offensichtlich tatsächlich da, nicht nur im Computer, sondern im Hirn. Deswegen mache ich auch die neue Rechtschreibung nicht mit. Ich habe sie im Computer zwar eingeschaltet, aber nur für die Schlußkorrektur. Beim Schreiben kümmert sie mich nicht.

U.T.: Sie sind ja Schriftsteller und Intendant - gibt es da Probleme ?

\section{Lewandowski:}

Ja, die gibt's immer. Es sind verschiedene Probleme. Es ist beides zeitintensiv und das beißt sich dann. Man kann vieles durch die Intendanz gar nicht machen, was man sonst machen würde.

Schreiben ist eine Art Grundbedürfnis. Ich habe ja schon vorher geschrieben, bevor ich zum Theater kam, und dann immer nebenher weiter. Meistens für den Rundfunk, aber manchmal auch fürs Leben. Die sogenannte ,Real-Reportage', auch eine Form von Literatur. Viele der damaligen Mit-Kommilitonen hatten Probleme mit ihrem 2. Staatsexamen, weil sie dafür eine Arbeit schreiben mußten: Unterrichtsprotokolle, Stundenverläufe, wie die Schüler reagieren auf das, was sie in den Unterricht einbrachten. Das mußte alles unter pädagogischen Gesichtspunkten aufgearbeitet werden. Da habe ich dann Stundenverläufe geschrieben für ihre Arbeiten, also Stunden beschrieben, die es gar nicht gegeben hat. Das war reine Literatur. Sie haben alle Einser gekriegt, war wunderbar.

Ich habe sehr früh als Autor viele Rundfunksendungen gemacht, Hörspiele, Serien, die für den Unterhaltungsrundfunk damals absolut ungewöhnlich waren. Das 
würde es heute gar nicht mehr geben. Das war eine Erzählung, die ein paar Hörspielelemente hatte, das hieß „Streife Anton 8“. Ungefähr 80 oder 86 Folgen. Es wurde jeden Tag gesendet, jeder Tag hatte eine Folge, aber die wirklich vergehende Zeit innerhalb dieser ganzen erzählten Zeit war nicht länger als eine halbe Stunde. Das ist unglaublich irre, weil die Hörer das natürlich miterleben, wie die zunächst identische erzählte Zeit immer weiter zurücklag. Monate. Das Ganze war aufgelöst in verschiedene Schauplätze und Handlungsstränge, die nebeneinanderliefen und war durch genaue Detailbeschreibungen gekennzeichnet. Alles war sehr präzise beschrieben: was in dem Moment an der Stelle passiert und was der und der denkt, und was gleichzeitig der denkt. Manchmal blieb die Zeit geradezu stehen, über Tage hinweg. Ein Spiel mit der erzählten und zu erzählenden Zeit. Unglaublich spannend. Ich bin allerdings nicht sicher, ob das viele der Hörer unter all den geschehenden Turbulenzen überhaupt gemerkt haben. Damals gab es noch diese Redakteursmentalität, auch in den Sendern, die von der 68er Generation mitgeprägt war. Leute in unserem Alter, die den Weg in die Medien gefunden hatten und noch den Anspruch hatten, nicht nur Unterhaltung oder Beiprogramm für die Werbung zu produzieren. Ein Schuss Realsatire war häufig dabei.

Wir haben eine Serie gemacht, angelehnt an die Hobbythek Sendung, wo Basteltips gegeben wurden über den Rundfunk, immerhin 15 Folgen, die eine halbe Stunde lang waren, mit Musikeinspielung unterbrochen. Darin wurden auch Alltagserscheinungen kritisch hochgerechnet. Das waren Nonsense-Bastelanleitungen, aber sie funktionierten, und die Leute haben's auch nachgebaut. Das war ja das Irre dabei: ,Wie gieße ich mir einen Zahnersatz?`,Wie töpfere ich eine Urne?‘,Wir erschwimmen uns ein Seemannsgrab "und solche Themen. Das war mit dem Hessischen 
und dem Norddeutschen Rundfunk. Beim damaligen Südwestfunk gab es den Redakteur und Regisseur Thomas Köhler. Mit dem habe ich sehr schöne Sachen gemacht. Wir haben einmal eine Wahlsendung simuliert, einen Wahlabend, und zwar haben wir simuliert, es gäbe heute ein neues Wahlverfahren, daß man mit Hilfe der Computertechnik immer genau weiß, wer in welchem Wahlkreis wieviele Stimmen abgegeben hat und man deshalb sofort weiß, wieviele Stimmen noch fehlen. Das hätte den Vorteil, daß man noch vor 18 Uhr Leute mobilisieren kann. Wenn noch 10 Stimmen fehlen, holt man das Altersheim heran, sozusagen Sternfahrt mit dem Bus aus dem Seniorenheim, oder eine Pfadfindergruppe für die andere Partei. Das ganze als LiveReportage von vor Ort. Dann haben wir einmal eine Telefonnummer angegeben, die es wirklich gab. Wir wollten wissen, was wirklich passiert. Es war eine simulierte Fahndungssendung. Die Hörer haben tatsächlich mitgeholfen. Die Leute haben alles gesehen, auch Personen, obwohl alles völlig frei erfunden war! Aber die Hörer haben die Person gesehen, haben angerufen und mitgeteilt, wo sich die Person aufhält. Man könnte also beliebig irgendjemanden verdächtigen und das würde sozial funktionieren. Die meisten Sachen von damals hatten einen klaren gesellschaftskritischen Anspruch, trotz aller Unterhaltung.

Später gab es dann über einen Schauspieler, Dieter Hufschmidt, einen Kontakt zum Theater. Dieser Schauspieler hat auch Regie geführt in Hannover am Niedersächsischen Staatstheater. So fing es an: über Hospitanzen, dann eine erste Assistenz, zunächst ohne Bezahlung, dann Dramaturgie und andere Tätigkeiten. Später gab es die erste offizielle Regieassistenz, also mit Vertrag, zunächst für ein Stück, dann den zweiten Vertrag, einen dritten und so hat sich dann das andere ergeben. 
Nach zwei Jahren war ich dann in einer ganz merkwürdigen Position, nämlich Regieassistenz und Dramaturg, auf der einen Seite gehörte man zur Theaterleitung, mußte also Entscheidungen treffen, die den Kurs des Hauses mitbestimmten, auf der anderen Seite war man als Regieassistent mit der Ensemble-Basis direkt verquickt. Das ist eine sehr prägende Zeit gewesen, wo man das Meckern, das ja immer stattfindet, in Relation setzen konnte zu dem, was wirklich vor sich ging. Das war eine gute Schulung. Dann habe ich auch angefangen Regie zu führen. Da wurde mir klar, das hat mit Schreiben zu tun, das ist eine ähnliche Form der Kreation von Figuren, auch wenn die Texte vorgegeben sind, sie leben ja noch nicht in der Form. Daraus entstand für mich die Frage: ist das Theaterstück die Kunst oder ist es die Inszenierung? Daß die Regie mit einem Schraubvorgang sehr ähnlich ist, daß man die Figur erzeugt und sozusagen die Frage wie beim Film ist: ist das Drehbuch die Kunst oder der Film, und das gleiche kann man übertragen: ist Theaterstück die Kunst oder erst die Aufführung? Damit hatte sich die Regie praktisch verbunden mit dem Schreiben und sie ist bei mir aus dem Schreiben hervorgegangen.

U. T.: Ich habe gelesen, daß sie mit Lehrern und Schulen zusammenarbeiten, mit den Kindern - Was ist das genau ?

\section{Lewandowski:}

Es gibt verschiedene Sachen, die wir am E.T.A.-Hoffmann-Theater anbieten. Da ist einmal das Programm ,Theater und Schule‘. Hierbei können Lehrer Schauspieler in die Schule bestellen, die tragen ihnen dann dort einen Text vor, Gedichte, Erzählungen, 
Auszüge aus Romanen, spielen auch Szenen. Wir gehen auch mit kleinen mobilen Produktionen direkt in die Schulen, also ins Klassenzimmer. Z.B. ,Junges Gemüse` oder auch Stücke für Jugendliche.

Das zweite ist, daß die Lehrer uns auch Texte schicken können, die wir dann vortragen, also daß sie sie direkt in ihren Unterricht einbauen können. Das kommt der Ausrede zuvor, das passe nicht in den Lehrplan. Außerdem gibt es noch als praktische Form eine Theatergruppe, die mit Schülern und Schülerinnen veranstaltet wird - meistens übrigens Mädchen, wenig Jungs, weil die viel früher in diese vernünftige Welt hineingezogen werden, bei denen wird die Phantasie viel früher domestiziert oder ausgetrieben. Die Gruppe betreibt eine ausgebildete Theaterpädagogin. Das sind so die drei Gebiete. Es gibt darüber hinaus noch ein Seminar von uns an der Uni. Diese Teilnehmer spielen mittlerweile auch selbst.

U.T.: Mal ganz was anderes. Sie haben einige Bücher geschrieben über Filmemacher. Warum Filmemacher?

Lewandowski:

Weil ich im Studium mit Film angefangen hatte. Mein Werdegang hat durchaus mit Film zu tun. Es gab gute Filmseminare an der Uni Hannover über Wirkungsweise, Funktion von Filmen, auch deren Analyse: Was bedeutet ein Schnitt, was bedeuten Schnittfolgen etc.. Das haben wir gemacht mit Elmar Buck, heute Leiter des Theaterwissenschaftlichen Instituts in Köln. Später haben wir mit dem Apollo-Kino zusammengearbeitet für die Examensarbeit über Alexander Kluge. Das war das erste Programmkino in Hannover. Da 
hat Joachim Flebbe damals das Programm zusammengestellt, dem jetzt die ganze Cinemax Reihe mit den Großkinos gehört. Der war wirklich toll, der hat uns sein Kino zur Verfügung gestellt, hat die Filme bestellt, hat sogar die Leihgebühr für die Filme entrichtet, und wir mußten nur den Vorführer bezahlen. Es ist schon was Interessantes, wenn man so ganz allein im Kino sitzt und es läuft ein Riesenbild vor einem ab, das ist wie Theater, wenn kein Publikum da ist. Dann kommt noch etwas Geheimnisvolles hinzu. Wir haben übrigens die Filme mit Video abgenommen von der Leinwand, so daß wir sie hinterher noch einmal analysieren konnten. Das hat auch gleich die Videoerziehung mit sich gebracht. Und daher ist vielleicht auch das Interesse an Film und Video verstärkt worden, die Experimentierfreude, so etwas - viel später - auch im Theater einzusetzen, zum Beispiel in ,Nur keine Panik', wobei ich den gesamten Videoschnitt übernommen habe. Kleine Videofilme mache ich noch immer, zur Zeit einen großen Film über die Sanierung des E.T.A.-Hoffmann-Theaters.

U. T.: Warum jetzt gerade Kluge und Schlöndorff?

Lewandowski:

Ja, Kluge wegen seiner Methodik. Wir haben Seminare gemacht über Bauformen des Erzählens. Das ist eine ganz entscheidende Sache, das ist das Handwerkszeug. Der Punkt bei Kluge war dessen literarische Ausdrucksform. Er nannte es: „Fiktion in der Ausdrucksform des Dokumentarischen“. Das ist eine ganz wesentliche Formulierung. Diese Methode hat mit andern Mitteln übrigens auch Hoffmann schon angewandt. Er hat aus dem Dokumentarischen, also aus der Realität, aus dem Realen heraus, die Fiktion 
geschaffen. Und Kluge hat das auch gemacht, wie ich später für den Rundfunk, , OriginalTon-Reportagen', ,Realdokumentation`. Wirken wie fiktionale Geschichten, gibt es aber alles. ,Ferien im Flöz‘ zum Beispiel. Damals wurden im Ruhrgebiet gerade die meisten Gruben stillgelegt und diese Flöze, das sind die abgebauten Schächte, sind ja leer und das wäre der wunderbarste Ort für Abenteuerurlaub. Heute gibt es das. Amerika fährt nach Vietnam, um in den Stollen von den Vietkong herumzukriechen. Das ist genau der Punkt, genau diese Hochrechnung der gesellschaftlichen Entwicklung, wobei man immer wieder sagen muß, man kann gar nicht so phantasievoll sein wie die Wirtschaft selbst, um Geld zu verdienen.

Schlöndorff ist ein Gegenstück zu Kluge, der kaum Filmstoffe selber geschrieben hat, kein Autorenfilmer in dem Sinne ist. Er hat sich auf Romane gestützt. Das merkwürdige Phänomen ist, daß, sobald Literatur verfilmt wird, sie nicht einmal die Geschichte beibehalten, die der Roman hat, es wird alles verändert. Es kommen neue Personen dazu, andere werden weggelassen, und es gibt eigentlich keinen ersichtlichen medialen Grund dafür, außer das sich Berufen auf sogenannte Marktgesetze. Schlöndorff ist in diesem Gewerbe so eine Mittelposition, der immer am Markt orientiert ist, aber auch noch den Künstler in sich hat.

U.T.: Hätten Sie Interesse daran, einen eigenen Film zu machen und wenn, welche Art? 


\section{Lewandowski:}

Nein, würde ich, glaube ich, nicht machen. Ich filme zwar, aber eher Dokumente. Ich zeichne auch manchmal unsere Theateraufführungen auf und mache Schnittfassungen aus verschiedenen Aufführungen.

U.T.: Haben Sie schon mal etwas fürs Fernsehen gemacht?

\section{Lewandowski:}

Eine Folge für eine Serie habe ich einmal fürs Fernsehen gemacht. Beim Hessischen Rundfunk. Die Folge wurde auch produziert und gesendet. Die Folge hatte aber mit dem, was ich geschrieben hatte, wenig zu tun, weil der Regisseur alles geändert hatte. Dann hatte ich noch mal Kontakt durch eine Schauspielerin zur ,Lindenstraße‘, eine Serie, die schon über zehn Jahre läuft, jede Woche einmal.

\section{U.T.: Also wie ein „Soap“ bei uns?}

\section{Lewandowski :}

Nein, schon anders. Sie hat schon einen politischen Anspruch. Das ist ein Mietshaus in einer ganz normalen Münchner Straße, wird allerdings in Köln gedreht. Dort sind in einem Studio sämtliche Räume, Hausflur, die Wohnungen, die Zimmer der Wohnungen, aufgebaut, aber eben wie Ladendekorationen, also wie frisch aus dem Möbelgeschäft. Man merkt sofort, daß diese Räume nicht bewohnt sind, da lebt keiner. Der Anspruch der Sendung ist gut gemeint. Ein bißchen alt-68ig. Das Problem ist, sie machen in jeder 
Woche eine Folge, mit Drehen, mit Schnitt, mit allem. Sie sind ungefähr drei Folgen voraus, falls mal was schiefgeht, aber sie sind dadurch in der Lage, ziemlich aktuell zu sein. Herr Geißendörfer, der auch mal mit Schlöndorff zusammengearbeitet hat und zu den Autorenfilmern gehörte, hat durchaus einen Anspruch.

Für diese Serie habe ich drei Folgen geschrieben, Probefolgen. Habe eine Woche lang die Serie studiert, Storyline, alle 15 Minuten ein cliffhanger geben, damit es spannend wird und man Werbung einblenden kann, der Wortschatz der Leute nicht größer als 800 Worte, damit das Publikum alles versteht.

Ich hätte das natürlich imitieren können, aber das wäre nichts von mir, und so habe ich mir gesagt, ich mach's mal so, wie ich mir das vorstellen könnte. Das war ein Fehler, in deren Sinne. Geißendörfer sagte dann, das sei sehr gut, das seien die besten Drehbücher, die er hatte, aber - meine Figuren sind zu intellektuell. Damit war die Episode für mich zu Ende.

U.T.: Sie haben das vorhin am Rande erwähnt, daß Sie Interesse hätten, eine Geschichte zu schreiben über das Dritte Reich, mit diesem Willy Lessing. Wie stehen Sie denn zur Geschichte des Dritten Reiches?

\section{Lewandowski:}

Das Problem ist: Die ,Abbildungen` des Dritten Reiches haben eine Schwierigkeit, und die ist grundlegend. Das ist aber nicht von mir, sondern das hat Theodor Adorno schon festgestellt. Ich habe darüber mal einen Aufsatz geschrieben und eine Radiosendung. Das Dritte Reich hat in seiner Selbstidentifikation sehr stark mit theatralischen Mitteln 
gearbeitet, die haben viele Sachen, übrigens auch aus der linken Bewegung übernommen, viele Aufmarschformen, Embleme usw. sind sogar angelehnt an kommunistische Traditionen. Die Nazis haben den Alltag sozusagen ästhetisiert. Haben also schöne Formen gefunden für alltägliche Begebenheiten. Und die Klippe, auf die man sich begibt, wenn man das nachgestaltet auf dem Theater, im Film oder auch sonst wie ist, daß man diese ästhetischen Formen wiederholt. Und das heißt, eigentlich reproduziert man sie damit, stellt sie wieder her, macht sie wieder lebendig, wiederholt sie. Das ist ein Riesenproblem, das ist der wirklich geniale Trick bei Chaplin, der eben diese Parodiefigur erfunden hat, diesen Redner mit der Sprache, der nur noch den Gestus zeigt, aber nicht den Inhalt sagt. Denn wenn sich einer hinstellen und wieder über Rassengesetze sprechen würde, hätte er diese Ideologie wieder reproduziert. Dadurch, daß Chaplin das nicht gemacht hat, sondern nur zeigt, wie Hitler sich erregte, wie er Emotionen herstellte, das ist wirklich gut in diesem Film. Und dann macht es obendrein noch lächerlich, das ist eigentlich wirklich der Punkt, Der goße Diktator‘.

Das war auch der Grund, weshalb wir das Dritte Reich in dem ,Panik-Projekt‘ nur im Film hatten, davor ein stummer Aufmarsch aller Bevölkerungsschichten. Also Dokumentbilder aus den Konzentrationslagern, aus dem Krieg auf der Leinwand und ,Chaplin` mit eben dieser Hitlerparodie.

U.T.: Während dieser Zeit spielt ja auch Ich, Marlene.

Lewandowski: Teilweise.

U.T.: Ja. Warum Marlene Dietrich, was ist da Ihr Interesse an ihr? 


\section{Lewandowski:}

Für Deutsche ist interessant an der Figur Marlene, und das ist auch genau der Reizpunkt, daß sie bewußt nicht Gefolgschaft leistete, sondern amerikanische Staatsbürgerin wurde. Als sie 1960 zurückgekommen ist für ein Konzert nach Deutschland, wurde sie noch immer als ,Verräterin` ausgebuht. Das haben wir in unserem Stück auch erzählt, sogar mit einer ,Real-Fiktion“. Die Vorstellung wird scheinbar unterbrochen, Tumult vor den Saaltüren, die Türen werden aufgerissen, es geht Licht im Saal an, eine Demo erscheint und verschwindet wieder: sozusagen Dokumentation als Fiktion, dieser berühmte Anknüpfungspunkt. Es hat durchaus Aufführungen gegeben, nicht alle, da sollte man auch nicht übertreiben, aber es hat Vorstellungen gegeben, daß Leute diese Demonstration nicht als eine vom Theater inszenierte begriffen haben, sondern mit eingestimmt sind im Chor der Empörer gegen Marlene. Das zeigt, daß dieser Schoß noch fruchtbar ist, aus dem das kroch. Und das war sehr bedrückend.

U.T.: Für den Hörfunk arbeiten Sie jetzt nicht mehr?

Lewandowski :

Wenig. Mal eine lange Sendung über Hoffmann.

Der Rundfunk hat sich auch verändert. Zuviel seichte Unterhaltung. Außerdem: seit ich in Bamberg bin, ist einfach keine Zeit mehr dazu.

Ich habe dann eine Zeitlang für das Bamberger Theater geschrieben. Z.B. ,Der Geburtstag', das ist auch eine Geschichte mit dem Dritten Reich und der Nachkriegszeit. Ein Einpersonenstück mit einer Frau, damit haben wir das neue Studiotheater eröffnet. 
Das Stück hat übrigens auch mit den Medien zu tun, denn die Motivationslage für diese Frau überhaupt zu sprechen, war ein Videogerät, um mit ihrer Freundin, die nicht kommen konnte, zu sprechen.

Das Stück knüpft an einer bekannten Fiktion an, ,Dinner for One‘, wendet diese Komödie aber ins Tragische. Zwei widerstreitende Gefühle werden erzeugt. Das ist spannend.

Das geht bis ins Makabere. Sie hat den Schädel ihres Mannes, den sie nach einem Giftmord im Keller , verfliest` hat, das heißt unter den Kellerfliesen eingegraben hat, behalten, den hat sie im Schrank.

Das ist übrigens ein Anknüpfungspunkt zu ,Heute weder Hamlet‘, zu Yoricks Schädel in Hamlets, oder Sassmanns Hand. ,Heute weder Hamlet' ist ja eine Totalfiktion. Es wird die Fiktion aufgebaut, daß eine Vorstellung ausfällt. Es ist interessant, als es Leute gibt, die nach ungefähr einer Stunde, wenn der Schauspieler gut ist, sagen, das ist ja schon das Stück. Also es gibt Leute, die nicht theatergeschult sind, die nicht bemerken, daß das eine Fiktion ist. Und das finde ich gut. Das macht die Sache sehr spannend. Das ist, denke ich auch, ein Grundprinzip vieler meiner Arbeiten. Dadurch nehmen die Zuschauer aktiver teil an der Geschichte, das Publikum ist viel realer anwesend, als wenn es hinter der vierten Wand versteckt bleibt. Das funktioniert, das passierte auch in Afrika,

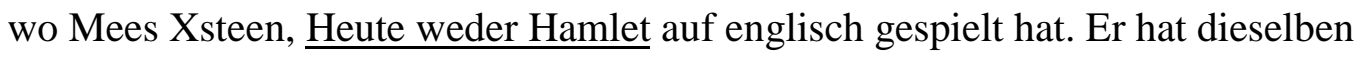
Erfahrungen gemacht, wie wir hier auch: die Leute antworten, wenn er mit ihnen spricht. Er hat die tollsten Geschichten erzählt über Leute vom Okawanda Delta, wo er das Stück in einem Zelt spielte und draußen hat einer sein Auto repariert, was man drinnen immer hörte, wenn er draußen gegen die Kotflügel donnerte. Dann kam der plötzlich rein und 
wollte von irgendeinem was, der mit im Publikum saß. Er kriegte nicht mit, daß der da oben, der ja einen Arbeitskittel anhatte, daß der Theater spielt, weil er gar nicht weiß, was Theater ist. Und da der da oben das Publikum, also ihn ansprach, fing er an zu antworten. Realität und Fiktion liefen so eine Weile nebeneinander her.

Ich stelle in meinen Stücken gern einen Anknüpfungspunkt der Kontinuität her, etwas über das einzelne Moment Hinausgehendes. Quasi eine Verbindung zwischen den Stücken. Das haben wenige bisher bemerkt. Am ausgeprägtesten ist das in den Kinderstücken. Da ist immer eine Verbindung: da taucht mal ein Name auf, mal ein Kostüm, mal geht eine Figur aus dem alten Stück über die Bühne, mal auch ein Liedteil, der zitiert wird. Kinderstïcke sind deshalb so wichtig, weil man Kinder ernst nehmen muß, man darf Kinder nicht veräppeln, daß sie einfach nur da sind um ja oder nein zu brüllen oder „Seid ihr alle da”. Kinder müssen inhaltlich mit einbezogen werden. Wir versuchen das immer, daß die Kinder angesprochen werden. Am weitesten in den ,Bambolo ‘-Stücken. Darin müssen sie relativ komplizierte Rätsel lösen, sonst geht das Stück nicht weiter. Das hat auch funktioniert. Die Kinder sind ja sozusagen die Theatergänger von später. Und ich denke, wenn sie positive Erlebnisse im Theater hatten, gehen sie zumindest mit ihren Kindern wieder hin oder vielleicht auch selber. Und das ist eine wichtige Sache der Vorbereitung für Theaterlernen, denn Theater ist ja schwer zu sehen. Theatersehen ist Arbeit. Der Zuschauer muß ja erarbeiten: was tun die da vorne, wie stehen sie zueinander, also im wahrsten Sinne des Wortes, Arrangement, welche Untertöne sind in ihren Texten, was sagen die Personen überhaupt, meinen sie das, meinen sie das nicht, wie ist das Licht, stehen die im Hellen oder Dunklen, was haben sie an? Das sind alles Dinge, die man natürlich nicht so auspricht am Abend, aber man muß 
sie der Bühne entnehmen, es ist wirklich Arbeit, es ist nicht so einfach und leicht.

Deswegen ist auch das Kindertheater so wichtig, daß die Menschen auch auf solche

Dinge früh hingewiesen werden innerhalb der Vorstellungen, daß sie die

Ausdrucksformen des Theaters verstehen lernen.

U.T.: Ich danke Ihnen für das Gespräch. 
„da wird die Sau geschlacht‘. Von Rainer Lewandowski. Südwestfunk. 1987

“Driving Blind." Time, 26 February 2001.

Ensemble des E.T.A. Hoffmann Theaters. Nur keine Panik! Ein Jahrhundert geht schnell vorbei... Köln: Hartmann und Stauffacher, 1999.

Ferien im Flöz, oder Städteurlaub einmal anders. Von Rainer Lewandowski.

Südwestfunk. 1985.

Hier spricht der automatische Anrufbeantworter. Von Rainer Lewandowski. Hessischer Rundfunk. 1985.

Kincade, Jackson. “The Death Dealer.” Maxim, Sept. 1998: 81-84.

Lewandowski, Rainer. Bambolo. Köln: Hartmann und Stauffacher, 1996.

- - - Das fremde Kind. Hannover: Castor Schallplatten, 1995.

- - - Der Geburtstag oder The Same Procedure As Every Year. Köln: Hartmann und Stauffacher, 1990.

- - - . Der Geburtstag... Programmheft. Bamberg: Fränkischer Tag, 1990.

- - - Der gestiefelte Kater. Unveröffentlicht.

- - - Die Filme von Alexander Kluge. Hildesheim: Olms, 1980.

- - - Fiktion und Realität. E.T.A. Hoffmann und Bamberg. Bamberg: Fränk. Tag, 1980.

- - - . Heute weder Hamlet. Projekt, Theater und Medien, 1986.

- - - Ich. Köln: Hartmann und Stauffacher, 2000. 
- - - . Ich, Marlene. Köln: Hartmann und Stauffacher, 1993.

- - - . Ich, Marlene. Programmheft. Bamberg: Fränkischer Tag, 1993.

- - - . Junges Gemüse. Köln: Hartmann und Stauffacher, 1992.

- - - . Königsmord. Bamberg: Collibri Verlag, 1998.

- - - . Mambo Mortale, oder der Notruf ist leider besetzt. Köln: Hartmann und Stauffacher, 1989.

- - . Nichts hält mich mehr in Kisslingen. Köln: Hartmann und Stauffacher, 2000.

- - - . Sie sind auch kein Bamberger, wie ich höre? Bamberg: Fränkischer Tag, 1995.

- - - . Sie sind auch kein Bamberger... Programmheft. Bamberg: Fränkischer Tag, 1995.

- - . .,How Artistic Imagination Came To Console Hoffmann: The Imaginative Realist and the Romantic Movement in Germany.” West Virginia University Philological Papers 44 (1998): 167-182.

Lewandowski, Rainer. Personal Interview. August 2000. (Ungekürztes Transkript)

Lewandowski, Rainer. Personal Interview. Gekürzte Fassung.

Ohne Motiv. Von Rainer Lewandowski. Radio Bremen. 4. April 1987.

Schlunk, Jürgen. "Rainer Lewandowski. Eine zeitgemäße Stimme im deutschen Theater." Unpublished manuscript.

Stoll, Dieter. "Rainer Lewandowski." Ars Vivendi (1999): 114-117.

"Sub Probe Sheds Light on Vip Tours." AP 12 March 2001. <http://dailynews.yahoo.com/h/ap/20010312/us/submarinecollision_73.html.> 